Argonne

ANL-ART-98

\title{
Water NSTF Design, Instrumentation, and Test Planning
}

Nuclear Engineering Division 


\begin{abstract}
About Argonne National Laboratory
Argonne is a U.S. Department of Energy laboratory managed by UChicago Argonne, LLC

under contract DE-AC02-06CH11357. The Laboratory's main facility is outside Chicago, at 9700 South Cass Avenue, Argonne, Illinois 60439. For information about Argonne

and its pioneering science and technology programs, see www.anl.gov.
\end{abstract}

\title{
DOCUMENT AVAILABILITY
}

Online Access: U.S. Department of Energy (DOE) reports produced after 1991 and a growing number of pre-1991 documents are available free via DOE's SciTech Connect (http://www.osti.gov/scitech/)

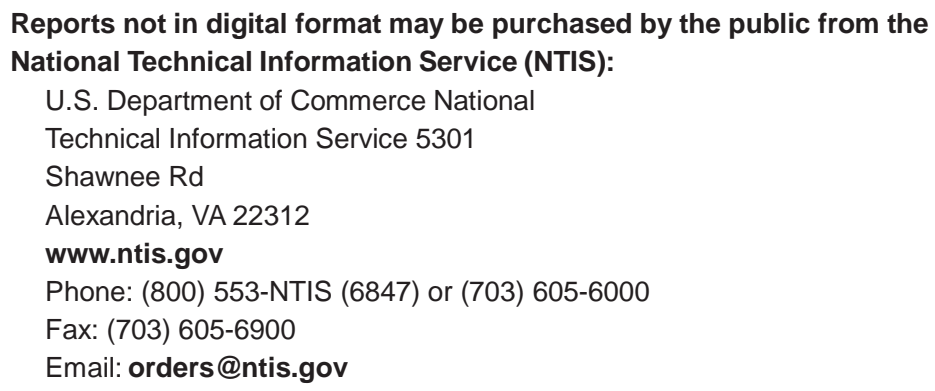

Reports not in digital format are available to DOE and DOE contractors from the Office of Scientific and Technical Information (OSTI):

U.S. Department of Energy

Office of Scientific and Technical Information

P.O. Box 62

Oak Ridge, TN 37831-0062

www.osti.gov

Phone: (865) 576-8401

Fax: (865) 576-5728

Email: reports@osti.gov

\section{Disclaimer}

This report was prepared as an account of work sponsored by an agency of the United States Government. Neither the United States Government nor any agency thereof, nor UChicago Argonne, LLC, nor any of their employees or officers, makes any warranty, express or implied, or assumes any legal liability or responsibility for the accuracy, completeness, or usefulness of any information, apparatus, product, or process disclosed, or represents that its use would not infringe privately owned rights. Reference herein to any specific commercial product, process, or service by trade name, trademark, manufacturer, or otherwise, does not necessarily constitute or imply its endorsement, recommendation, or favoring by the United States Government or any agency thereof. The views and opinions of document authors expressed herein do not necessarily state or reflect those of the United States Government or any agency thereof, Argonne National Laboratory, or UChicago Argonne, LLC. 
ANL-ART-98

\section{Water NSTF Design, Instrumentation, and Test Planning}

prepared by:

Darius D. Lisowski, Craig D. Gerardi, Rui Hu, Dennis J. Kilsdonk, Nathan C. Bremer, Stephen W. Lomperski, Adam R. Kraus, Matthew D. Bucknor, Qiuping Lv, and Mitchell. T. Farmer

Nuclear Engineering Division, Argonne National Laboratory

August 2017 
This page was intentionally left blank. 


\section{Executive Summary}

The following report serves as a formal introduction to the water-based Natural convection Shutdown heat removal Test Facility (NSTF) program at Argonne. Since 2005, this US Department of Energy (DOE) sponsored program has conducted large scale experimental testing to generate high-quality and traceable validation data for guiding design decisions of the Reactor Cavity Cooling System (RCCS) concept for advanced reactor designs.

The most recent facility iteration, and focus of this report, is the operation of a $1 / 2$ scale model of a water-RCCS concept. Several features of the NSTF prototype align with the conceptual design that has been publicly released for the AREVA $625 \mathrm{MW}_{t}$ SC-HTGR. The design of the NSTF also retains all aspects common to a fundamental boiling water thermosiphon, and thus is well poised to provide necessary experimental data to advance basic understanding of natural circulation phenomena and contribute to computer code validation. Overall, the NSTF program operates to support the DOE vision of aiding US vendors in design choices of future reactor concepts, advancing the maturity of codes for licensing, and ultimately developing safe and reliable reactor technologies.

In this report, the top-level program objectives, testing requirements, and unique considerations for the water cooled test assembly are discussed, and presented in sufficient depth to support defining the program's overall scope and purpose. A discussion of the proposed 6-year testing program is then introduced, which outlines the specific strategy and testing plan for facility operations. The proposed testing plan has been developed to meet the toplevel objective of conducting high-quality test operations that span across a broad range of single- and two-phase operating conditions. Details of characterization, baseline test cases, accident scenario, and parametric variations are provided, including discussions of later-stage test cases that examine the influence of geometric variations and off-normal configurations.

The facility design follows, including as-built dimensions and specifications of the various mechanical and liquid systems, design choices for the test section, water storage tank, and network piping. Specifications of the instrumentation suite are then presented, along with specific information on performance windows, measurement uncertainties, and installation locations. Finally, descriptions of the control systems and heat removal networks are provided, which have been engineered to support precise quantification of energy balances and facilitate well-controlled test operations. 
This page was intentionally left blank. 


\section{Contents}

Executive Summary

$\begin{array}{lc}\text { Foreword } & \text { ix }\end{array}$

1 Program Objectives $\quad 1$

1.1 Program Purpose . . . . . . . . . . . . . . . . . . 2

1.2 Primary Interest Areas . . . . . . . . . . . . . . . . . . . 3

1.3 Unique Considerations . . . . . . . . . . . . . . . . . . . . 3

1.4 Measurement Objectives . . . . . . . . . . . . . . . . . . 4

1.5 Areas for Discovery . . . . . . . . . . . . . . . . . . . 5

1.6 Anticipated Testing Process . . . . . . . . . . . . . . . . . . 5

1.7 Quality Assurance . . . . . . . . . . . . . . . . . . . 5

$\begin{array}{lll}2 & \text { Test Planning } & 7\end{array}$

2.1 Checkout Activities . . . . . . . . . . . . . . . . . . . . 11

2.2 Facility Characterization . . . . . . . . . . . . . . . . . 12

2.3 Baseline Test Cases . . . . . . . . . . . . . . . . . . . . . . . 13

2.4 Parametric Studies . . . . . . . . . . . . . . . . . . . . . . 14

2.5 Accident Scenario Testing . . . . . . . . . . . . . . . . . 15

2.6 Geometric Variations . . . . . . . . . . . . . . . . . . . . 16

3 Test Assembly Description $\quad 19$

3.1 Mechanical Systems . . . . . . . . . . . . . . . . . . . . . . . 21

3.1 .1 Insulation . . . . . . . . . . . . . . . . . . . . 24

3.2 Liquid Systems . . . . . . . . . . . . . . . . . . . . . 25

3.2.1 Cooling Panel Test Section . . . . . . . . . . . . . . . . 25

3.2 .2 Network Piping . . . . . . . . . . . . . . . . . 36

3.2 .3 Water Storage Tank . . . . . . . . . . . . . . . . . . . . 43

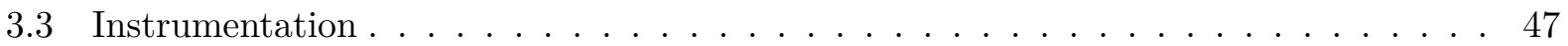

3.3.1 Flow Meters . . . . . . . . . . . . . . . . . . . . . 49

3.3 .2 Pressure Transducers . . . . . . . . . . . . . . . . . . . 50

3.3.3 Temperature Measurements . . . . . . . . . . . . . . . . . 51

3.3 .4 Void Fraction . . . . . . . . . . . . . . . . . 56

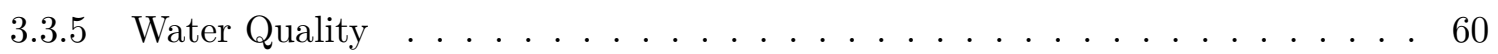

3.4 Control Systems _ . . . . . . . . . . . . . . . . . . . . . . . . . 61

3.4 .1 Throttle and Shutoff Valves . . . . . . . . . . . . . . . . . 61 
3.4.2 Heat Rejection Network . . . . . . . . . . . . . . . . . 63

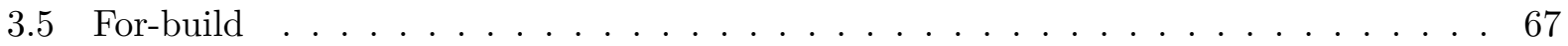

$\begin{array}{ll}\text { Acknowledgments } & 71\end{array}$

$\begin{array}{ll}\text { References } & 73\end{array}$ 


\section{List of Figures}

1 Planned Schedule for Water NSTF Experimental Testing Program . . . . . . . . 8

2 Solid model render of complete water NSTF in laboratory high-bay . . . . . . . . . 20

3 Radiation shield on bottom surface of riser support plate, No. 8 mirror-like finish . . 22

4 Personnel access to top of heated cavity . . . . . . . . . . . . . . . 22

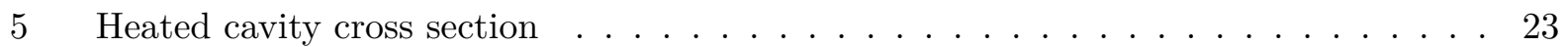

6 Cross section of single subassembly cooling panel unit . . . . . . . . . . . . . 25

7 Inlet region of cooling panel, computational drawing . . . . . . . . . . . . . 27

8 Inlet region of cooling panel, as-assembled . . . . . . . . . . . . . . 27

$9 \quad$ Machined grove along riser \#6, heat transfer epoxy and DTS capillary visible . . . . 28

10 Bead blasted surface of cooling panel, high contrast to original _ . . . . . . . . . 28

11 Vertical cooling panel prior to installation . . . . . . . . . . . . . . . 29

12 Isometric model of assembled cooling panel test section . . . . . . . . . . . . . 30

13 Cross-sectional plan view of two connected cooling panel subassemblies . . . . . . . . 31

14 Hot and cold lines of primary network piping . . . . . . . . . . . . . 37

15 Solid model rendering of inlet piping segment . . . . . . . . . . . . . 38

16 Access ports on dome head (top) and dish pan (bottom) . . . . . . . . . . . . 44

17 Dome and dish of tank . . . . . . . . . . . . . . . . . . . . . 45

18 Side wall of tank . . . . . . . . . . . . . . . . . . . . 45

19 Overview of instrumentation locations on water NSTF . . . . . . . . . . . 48

20 Riser inlet flow meters; stub entrance length sections visible . . . . . . . . . . . . . 49

21 Accuracy of TC and RTD sensors over expected process range . . . . . . . . . . . 52

22 Sensor placement and insulation along 4.0" piping, inserted to $10 \%$ depth of piping ID 53

23 Riser liquid TC . . . . . . . . . . . . . . . . . . . . . . . 54

24 Riser and fin wall TC . . . . . . . . . . . . . . . . . . . 54

25 Riser fluid DTS . . . . . . . . . . . . . . . . . . . . . 55

26 Riser wall DTS . . . . . . . . . . . . . . . . . . . 55

27 Void fraction sensor installation locations, dimensions in inches . . . . . . . . . 58

28 DensityPRO . . . . . . . . . . . . . . . . . . . . . . . . . 59

$294.0 "$ sightglass . . . . . . . . . . . . . . . . . . . . 59

30 Twin-tip RBI probe, $3-\mathrm{mm}$ OD sheath . . . . . . . . . . . . . . . . 59

31 HXG throttle valve (Badger Globe) mated to Krohne EM flow meter . . . . . . . . . 62

32 Single-phase heat removal network . . . . . . . . . . . . . . . . 64

33 Two-phase and steam condensation network . . . . . . . . . . . . . . . . 64

34 Sentry DTC-8 tube-in-tube exchanger, two will be used for heat removal . . . . . . . 65 
35 Return sparger within dome of tank . . . . . . . . . . . . . . . . 66

36 Condensing unit for 20.8 RT chiller . . . . . . . . . . . . . . . . . . 66

37 As-built dimensions of water NSTF, front (East facing) view . . . . . . . . . 68

38 As-built dimensions of water NSTF, side (South facing) view . . . . . . . . . . 69 


\section{List of Tables}

1 Testing Phases with description of involved activities and anticipated duration $\ldots$. . 7

2 Overview of insulation and thermal properties . . . . . . . . . . . . . 24

3 Overview of Water NSTF Instrumentation Suite . . . . . . . . . . . . . . 47

4 EM Flow Meter Specifications . . . . . . . . . . . . . . . . . . . 49

$5 \quad$ Rosemount Static and Differential Pressure Transducer Specifications . . . . . . . . . 50

6 Temperature Sensor Specifications ．.. . . . . . . . . . . . . . . . . . 51

7 Void Fraction Sensor Specifications . . . . . . . . . . . . . . . . 56

8 Water Quality Sensor Specifications _. . . . . . . . . . . . . . 60

9 Control and Throttle Valve Specifications . . . . . . . . . . . . . . . . . . 62

10 Water NSTF Primary Operating Parameters . . . . . . . . . . . . . . 67 
This page was intentionally left blank. 


\section{Foreword}

During a five year period spanning 2005 until 2010, efforts on the modern NSTF were focused on early stage work including scaling studies and preparations for a proposed scale model of an Reactor Cavity Cooling System (RCCS) test assembly [1] [2]. This included disassembly of the legacy NSTF; a facility that resided in Bldg. 310 at Argonne and sucessfully operated in the 1980's to support the General Electric's (GE) PRISM RVACS [3]. From 2010 until 2013, activities shifted to construction of a new facility in Bldg. 308 [4] [5]. This new design was focused on air-based cooling, using a design concept for the RCCS by General Atomics (GA) for their Modular High Temperature Gas Reactor (MHTGR).

The resulting test facility stood nearly $26-\mathrm{m}$ in total height and was designed to represent a $1 / 2$ scale model of the primary features of the GA air-cooled RCCS concept. Shakedown efforts were completed by 2014, and after which the program embarked on an extended formal testing series, ultimately completing over 2,250 hours of active test operations and 16 successful test runs, before finally concluding in July 2016. The result of this work produced a comprehensive project report detailing the thermal hydraulic behavior and performance of a scaled air-based RCCS concept [6] [7]. A quantitative description of the multitude of scenarios and conditions studied has been published in-depth, and may be suitable to guide decisions on the viability of the air-based RCCS concept for the passive safety needs of advanced reactors.

With successful conclusion of the air-based portion, the NSTF program has commenced on a conversion to water-based cooling. Scaling, design framework, and preparation activities were completed in recent years, and published in previously released reports [8] [9]. 
This page was intentionally left blank. 


\section{Chapter 1}

\section{Program Objectives}

At the forefront of this program is an objective to provide data that is suitable for supporting the development and validation of passively safety decay heat removal systems for advanced nuclear power plants. For a Reactor Cavity Cooling System (RCCS) concept to be considered a viable solution for advanced nuclear reactors, it must successfully meet a minimum number of operational requirements:

1. Maintain the vessel wall at safe temperature limits during normal operation and accident conditions, which in turn must ultimately ensure safe peak core fuel temperatures (i.e. retain a solid form) across all design basis scenarios.

2. Maintain the reactor cavity concrete and support structures at safe temperature limits during normal operation and accident conditions to prevent concrete materials degradation and possible failure.

The effort at Argonne is focused on an experimental test facility for data generation, coined the Natural convection Shutdown heat removal Test Facility (NSTF). Since 2005 this program has supported the DOE vision to provide US vendors with data suitable for characterizing the RCCS concept for passive decay heat removal. With previous iterations of the facility design focusing on variants of an air-based RCCS concept, this latest iteration is focused on a water-based design of the RCCS concept.

Given the complexity inherent to natural circulation system, an integral feature of several advanced safety concepts, this program also aims to advance the basic understanding of this phenomenon. By coupling large scale, integral-level observations with local, high-resolution measurements, the NSTF intends to create a shift from uncertainty to predictability, allowing 
industry realization of a successful decay heat removal solution.

The current design of the NSTF at Argonne, and the focus of this testing and design report, is based on an RCCS prototype design for the AREVA Steam Cycle HTGR (SCHTGR) reactor. Scaling studies and preparation tasks with computational modeling were carried out to guide the design decisions, minimize distortions, and ensure relevant data among scales, and can be found in earlier reports [8] [9]. The resulting test facility design will serve as a representative yet bounding configuration of the RCCS concept onto a full scale reactor design.

\section{$1.1 \quad$ Program Purpose}

The purpose of the generated data is centered on two industry needs: validation of codes that can be used in licensing, and optimization of the advanced conceptual designs. These demand a diverse set of requirements for the experimental capabilities and operating conditions, and furthermore, create a need for applicability to full scale systems if the data is to be relevant. Thus, a rigorous scaling methodology and validation process is required to support the provided data. The scaling basis and similarity relationships have been carefully derived to ensure preservation of key thermal hydraulic behavior [1] [5], and are primary driving factors in providing a technical basis for extrapolation of testing results to real conditions.

To successfully generate data that is relevant to nuclear codes and industry designers, the data must be produced within a controlled, traceable, and NQA-1 compliant program. Furthermore, the data must encompass the complete range of thermal hydraulic phenomena. Measurements of integral behavior such as system flow rate and heated section temperature rise become highly valuable only if they can be coupled with high fidelity measurements of local parameters. Integrated system codes such as RELAP5 and MELCOR are currently the standard for licensing, however computational fluid dynamics (CFD) codes continue to mature and are now playing major roles in advancing model development and phenomenological understanding. These advanced codes demand higher resolution data and must be 
considered when determining the overall instrumentation suite. Within the NSTF specifically, computational efforts have been active since the program's inception and will remain an area of continued development as experimental data becomes available. Efforts to-date on modeling of the water-based facility can be found in published reports [10].

Finally, the ability to study design optimization hinges on successful engineering and review processes of facility design. The foresight to include flexibility in facility operation and configuration is a crucial aspect in determining an experimental program's long term sustainability and relevance. The ability to easily adapt to new discoveries, changes in industry requirements, or currently-unforeseen scenarios directly supports this design optimization objective and have been given a high priority in early design stages.

\subsection{Primary Interest Areas}

The behavior of boiling water natural circulation loops such as the water NSTF will be influenced not only by the specific initial and boundary conditions, but also strongly a function of the loop's network geometry [11]. Thus, attention will first be given to the characterization of key design features, form and heat losses, nominal behavior, repeatability, and data uncertainty. Tests performed in the single-phase flow regime will evaluate the steady-state behavior and heat removal performance. Of primary interest are areas of scaling verification, heat flux variation (integral levels and profiling), geometry, orificing, and investigations into the role of the inventory storage tank. Following the transition to saturation with inventory loss due to boil-off will provide insight into design basis accident conditions, complex two-phase flow behavior, and expected levels of heat removal performance.

\subsection{Unique Considerations}

Due to the boiling flow that is anticipated to occur in this scaled water-based test facility design, the system will exhibit complex and uncertain thermal hydraulic behavior commonly associated with two-phase phenomena. Flashing, system-wide flow oscillations, and geysering 
are a few of the instabilities that are likely to be observed and demand unique requirements

for both instrumentation and structural considerations [12]. Collaboration with modeling and simulation teams have been vital in the design of the test facility, as they have aided in identifying nominal system behavior and mapping relevant piping sections for instrumentation placement. This collaboration will be maintained as the program progress and data becomes available.

Finally, specific considerations must be made to characterize the anticipated instability modes. By obtaining knowledge of their behavior and magnitude over a broad range of conditions, the project can reduce the uncertainties associated with water-based RCCS modeling.

\subsection{Measurement Objectives}

The inherent sensitivity of natural circulation systems can invoke a wide range of thermal hydraulic phenomena with minimal variations in operating conditions. Local measurements such as void fraction, pressure drop, system pressure, etc. can be expected to span a wide range of conditions and will guide loop behavioral mechanisms. However, integral performance can be normalized across designs and most readily quantified by three primary system parameters:

1. Heat load from RPV, $\dot{Q}$

2. System flow rate, $\dot{m}$

3. Temperature rise across heated test section, $\Delta \mathrm{T}$

Locally, small fluctuations in temperature, void fraction, and pressure are expected and are of high interest to capture. These local variations will introduce a discrete perturbation into the system, and under certain conditions, can trigger the onset of system wide instabilities. Thus, it is important to include a suite of sensors that provide the ability to capture pertinent thermal hydraulic behavior across both integral, and local, spatial scales. 


\subsection{Areas for Discovery}

During a NSTF project meeting held at Argonne in February of 2015, US vendors provided the team with suggestions of several areas of interest for discover [13] [14] [15]. Results from these areas within the water-based program will be beneficial to future water-cooled RCCS designers in refining their water-based design. These should be considered in extended testing program, and include but not limited to:

1. System behavior with varying riser tube dimensions

2. Material selection effect on temperatures, performance, and water chemistry

3. Influence of system behavior and performance due to inlet and/or riser orificing

4. Ability to capture discontinuities in hot leg piping especially bends and elbows

5. Structural dynamics caused by boiling vibrations

\subsection{Anticipated Testing Process}

Data quality testing, defined as tests conducted with full verification of procedures and calibrated instrumentation by NQA-1 standards, with the water-based NSTF is anticipated to begin by early FY2018 and extend through FY2023. Each test is expected to require 4 weeks of effort, which is largely due to the massive thermal inertia of the test facility, significant water inventory, and quality assurance procedures to be performed at the start and conclusion of each test. Physical testing in single phase can be expected to span a period of 72 - 96 hours, while two-phase testing will likely extend over 168 hours (1 week).

\subsection{Quality Assurance}

The research and development activities of this experimental program are under the control of an NQA-1 compliant quality assurance program plan (QAPP). Based on the requirements set forth in the American Society of Mechanical Engineers (ASME) NQA-1-2008 (with 1a 2009 addenda) Quality Assurance (QA) requirements for nuclear facility applications [16]. It 
is consistent with QA plans adopted by Argonne [17] and the Argonne Nuclear Engineering (NE) division [18], and the QAPP for the Next Generation Nuclear Plant Project (NGNP) at the Idaho National Laboratory (INL) including INL PLN-2690 [19] and 10 CFR Part 50, App. B [20]. These guidelines have been established to provide reliable, reproducible, and timely data on the effects of the reactor cavity cooling system on the heat removal from the reactor vessel wall. Assessments, both internal and formal external audits, will be conducted on a regular basis through the entirety of the water-based testing program. 


\section{Chapter 2}

\section{Test Planning}

To establish confidence in the program's ability to conduct high quality tests within a controlled environment across a wide range of single- and two-phase conditions, six testing phases have been established, Table 1. Similar to the general outline of the air-based campaign, these incremental phases will serve to guide the experimental activities in a manner that is systematic, true to the scientific method, and adheres to the DOE mission for developing reliable and safe reactor technologies. The proposed tests will also be conducted in accordance with the NQA-1 guidelines and requirements set forth in the programs governing quality assurance plan. Ultimately, the testing will generate high quality data that may be well poised to guide decisions on ascertaining the feasibility of the water cooled RCCS concept. A high level summary is discussed, followed by detailed descriptions on subsequent pages. Finally, as observations of the system behavior and performance are learned, specific test plans may be modified or new objectives added.

Table 1: Testing Phases with description of involved activities and anticipated duration

\begin{tabular}{clc}
\hline Phase & \multicolumn{1}{c}{ Activities Conducted } & Duration \\
\hline I & Power, electrical, data acquisition checkout, hydrostatic leak testing & $6 \mathrm{mo}$. \\
II & Gross system mass and energy balance, isothermal testing & $9 \mathrm{mo}$. \\
III & Single- and two-phase baseline test cases & $6 \mathrm{mo}$. \\
IV & Single parameter variations of power, inventory, pressure & $24 \mathrm{mo}$. \\
V & Accident scenarios (design-basis) & $6 \mathrm{mo}$. \\
VI & Geometric variations, off-normal scenarios & $12 \mathrm{mo}$. \\
\hline
\end{tabular}




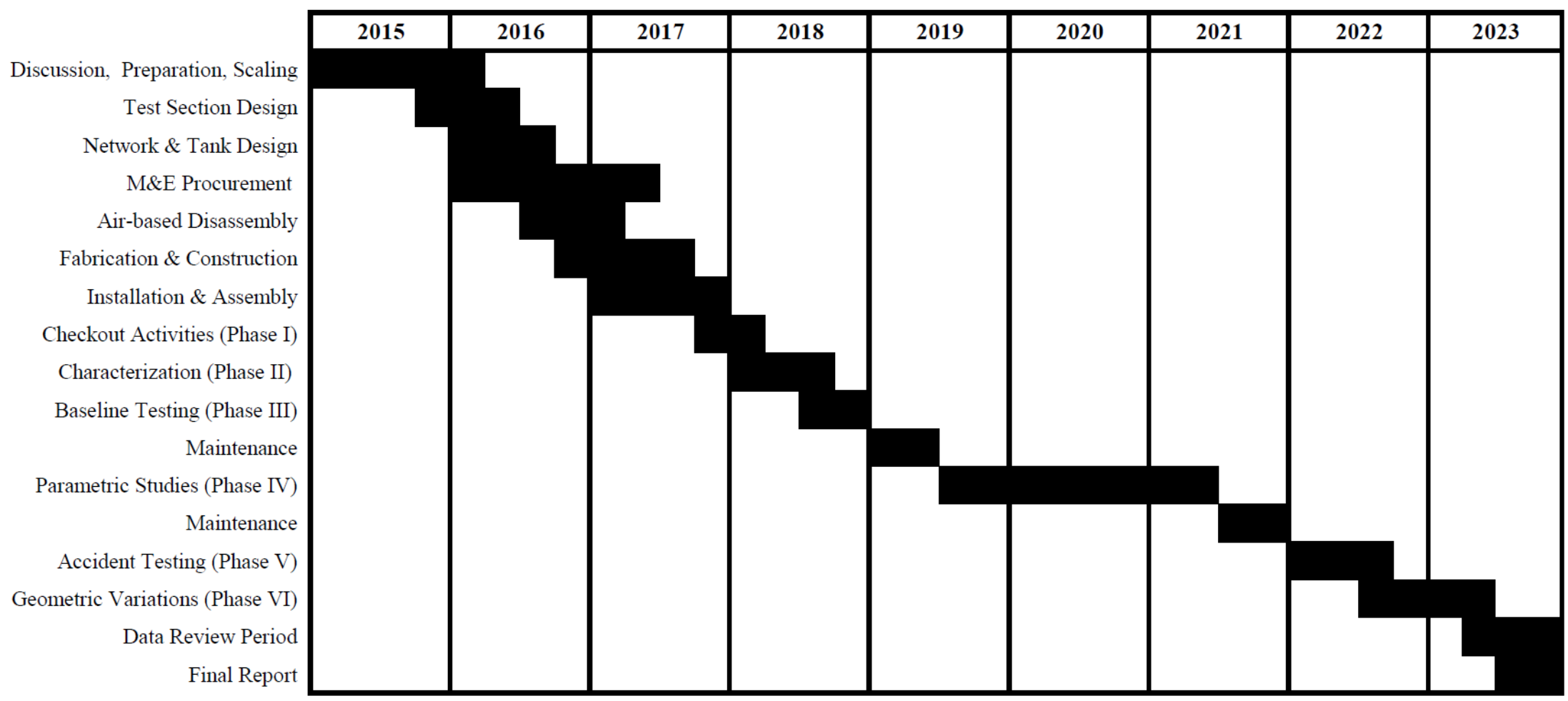

Figure 1: Planned Schedule for Water NSTF Experimental Testing Program 
1. Checkout Activities (6 months, Phase I)

(a) Conduct electrical, power, and instrumentation system shakedown test

(b) Carry out insulation and ceramic heater bake-out procedure

(c) Conduct leak check and hydrostatic pressure test

2. Facility Characterization (9 months, Phase II)

(a) Isothermal Testing

i. Verify gross system mass flow rate measurement

ii. Characterize frictional losses (pressure drop) under isothermal forced flow

iii. Characterize throttle valves to identify K-factors

(b) Shakedown Verification

i. Verify heat removal network for both single- and two-phase operation

ii. System energy balance verification tests and characterization of facility heat loss

3. Baseline Test Cases (6 months, Phase III)

(a) Single-phase baseline testing

i. Flat power profile at $1.4 \mathrm{MW}_{t}$ scaled SC-HTGR power, and $80 \%$ initial storage tank inventory. Achieve steady-state conditions for 2 hours at a constant riser inlet temperature of $30^{\circ} \mathrm{C}$

ii. Repeat above but adjust inlet valve to obtain $15^{\circ} \mathrm{C} \Delta \mathrm{T}$ across heated section

(b) Two-phase baseline testing

i. Flat power profile at $2.1 \mathrm{MW}_{t}$ scaled SC-HTGR power and $80 \%$ initial storage tank inventory. Allow system to reach saturation and boil-off quasi-steady state for 4 hours.

4. Parametric Studies (24 months, Phase IV)

(a) Integral Power testing (repeat baseline with varying powers)

i. Reduced - $700 \mathrm{~kW}_{t}$

ii. Normal - 1.4 $\mathrm{MW}_{t}$

iii. Accident - $2.1 \mathrm{MW}_{t}$

iv. Elevated - $2.8 \mathrm{MW}_{t}$

(b) Storage tank inventory (repeat baseline with varying initial inventories)

i. Varying initial tank volumes $(100 \%, 60 \%, 40 \%$, and $20 \%$ fill $)$

ii. Accelerated tank inventory loss

(c) System pressure (repeat baseline with varying pressures)

i. 1 bar elevated system pressure

ii. 2 bar elevated system pressure 
5. Accident Scenario Testing (6 months, Phase V)

(a) Accident Scenario testing

i. Full time history of design basis power profile incorporated into test procedure, beginning from 'normal' single-phase steady-state at 1.4 $\mathrm{MW}_{t}$ until 'transient accident condition' with two-phase flow and boil-off at $2.1 \mathrm{MW}_{t}$.

(b) Storage tank inventory

i. Full tank depletion and dry-out

6. Geometric Variations (12 months, Phase VI)

(a) Network Blockages

i. Riser tube throttling and full blockage

ii. Inlet throttling

(b) Geometric Alterations (repeat baseline with varying geometry)

i. Lower tank inlet port

ii. Alternate chimney routing (include u-shaped dip in upper chimney)

iii. Network short-circuit 


\subsection{Checkout Activities}

Upon completion of the major fabrication and assembly activities, defined by installation and interconnection of the three primary components: riser tube test section, network piping, and water storage tank, efforts will begin on the first series of the testing program, Phase I. These tests will be split into checkout, verification, and hydrostatic leak testing.

Checkout activities will begin with inspection of the electrical systems, including power control, instrumentation, signal wiring, and data acquisition systems (DAS). The power system is built on 240 and 480 VAC circuits feeding forty TRIode for Alternating Current (TRIAC) controllers, one for each of the zones along the heated wall. Activities will include continuity and resistance checks of the ceramic heaters, communication lines with the controllers and DAS, working operation of each individual zone, and control-room driven operation. Then, a heater-bake procedure will be followed, a necessary step to condition the ceramic potting compounds in the two hundred and twenty ceramic flat plate heaters. Since bake-out procedure will be conducted without water in the network piping, active air cooling will be used to maintain safe temperatures of the test section materials.

Activities will then proceed with end-to-end verification of instrumentation and signal wires. For each individual sensor, their operation will be verified with local stimuli, e.g. hot air gun on thermocouples. Their signal lead wires will be traced by hand to the DAS modules, a route that may include panel terminations, extension leads, etc. with end termination locations visually verified and checked against documented channel listings. Finally, their signals will be confirmed in the LabVIEW control and logging software.

Efforts will then transition to leak checking and hydrostatic pressure testing. Due to the inherent risks of pressure systems, this procedure will undergo an extensive review process, and ultimately require approval from qualified safety personnel. Additionally, an Illinois state representative will come on-site and oversee the actual hydrostatic pressure test. Preparations for this test include inspection of all pressure boundary bolted assemblies, e.g. 
ANSI flanges, Swagelok fittings, NPT, etc., approval of written procedure, verification of calibration on testing equipment, sourcing 1,200 gallons of liquid inventory, etc.

\subsection{Facility Characterization}

The second stage of the testing program, Phase II, will be conducted on a fully assembled and leak-tested facility for the purposes of verifying testing and operation specific parameters. First will be a verification of the gross system mass and energy balances. Provisions will allow the loop to operate in a forced flow mode of operation to confirm the mass transfer balances across the nine flow meter installation on the test loop.

Furthermore, differential pressure transmitters will be used to characterize the frictional losses across individual segments of the full loop. Physical variations in assembly and manufacturing will be identified by comparisons to analytical values for pipe losses, and used to confirm as-intended design, constructed, and behavior. Then, throttle valves, located at the inlet of the primary header, along with at each of the riser inlet tubes, will be actuated at varying amounts to generate loss coefficients or K-factors, a critical input parameter in computer models and simulations.

Verification of system performance will then be conducted by performing energy balances across various portions of the test facility. For example, comparisons will be made against the power supplied to the electric heaters, power deposited in the working fluid, and power removed by the heat exchanger (HXG) heat removal loop. These tests will be repeated at varying power levels, in both single- and two-phase modes of operation, allowing the program to accurately quantify facility heat losses and thermal efficiencies. 


\subsection{Baseline Test Cases}

To establish a common reference basis for nominal behavior, nominal system parameters, and to monitor system repeatability, two baseline cases will be conducted in Phase III. The target operating conditions for both cases have been derived from openly available literature on the full scale reactor design, the AREVA $625 \mathrm{MW}_{t}$ steam cycle high temperature gas reactor (HTGR) [14] [15].

The first baseline case will be conducted in a steady-state and single-phase mode of operation. A flat power profile at 1.4 $\mathrm{MW}_{t}$ scaled SC-HTGR power will be supplied to the electric heaters, which will be applied via a gradual ramp and then kept constant until the test conclusion. When scaled using similarity parameters derived in earlier works, the resulting heat load on the NSTF will be $34.4 \mathrm{~kW}_{t}$. The network geometry will be routed to the midheight tank inlet port, and the water storage tank will be filled to $80 \%$ volume inventory. Using the single-phase heat removal system, steady-state conditions will be reached with a constant riser inlet temperature of $30^{\circ} \mathrm{C}$. Power levels will be verified against the true thermal power of the system inventory, with steady-state conditions maintained for a minimum period of 2 hours. This case will then be repeated with adjustments to the inlet throttle valve to obtain a heated section temperature rise of $15^{\circ} \mathrm{C}$.

The second baseline case will extend operation into saturation and subsequent boiling flow regime. A flat power profile at 2.1 $\mathrm{MW}_{t}$ scaled power will be supplied to the electric heaters, a power level that matches vendor specific values for transient, design basis accident conditions. When scaled using similarity parameters derived in earlier works, the resulting heat load on the NSTF will be $51.6 \mathrm{~kW}_{t}$. Similar to the single-phase case, the network geometry will be routed to the mid-height tank inlet port and the water storage tank will be filled to $80 \%$ volume inventory. The heat removal system will be reconfigured to act as a steam condensation network, with boil-off condensate removed from the system after passing through the heat exchanger. The network inventory will see a gradual reduction in 
time, and thus only a quasi-steady state operation will be achieved. Power levels will be verified against the true thermal power of the system inventory, with quasi-state conditions maintained for a minimum period of 4 hours.

\subsection{Parametric Studies}

Parametric studies will follow after completion of baseline test cases. This portion of the testing program, Phase IV, is expected to be the most extensive and subsequently extend the longest duration, an estimated 24 months. At the conditions identified for Phase III, Baseline Cases, a single parameter will be adjusted and both single- and two-phase test cases repeated.

Integral power will be the first variable studied. Retaining a flat power profile, four levels of system power will be supplied and tests conducted. The powers for normal and accident will be reused for repeatability purposes, with two new tests introduced: one below normal, and one above accident, power levels.

Following, tests will be performed that examine the influence of static (initial) and dynamic (transient) system liquid inventory. Static cases will vary only the starting system inventory, with four volumes identified that will study inventories ranging from overfilled, to reduced, to near-depletion. As with the baseline test cases, each static case will be performed in both single- and two-phase modes of operation. Then, a new case will be introduced that begins to examine the transient behavior of the test facility. Beginning at baseline inventory volumes, inventory will be artificially (with respect to natural boil-off) removed from the system at a rate that simulates accelerated tank depletion. Drain rates will be selected to minimize influence onto the natural behavior of the test loop, i.e. low enough to not create local or system wide perturbations. As with previous studies, this test will be conducted for both single- and two-phase modes of operation, however both will be concluded prior to reaching full inventory depletion.

Lastly, parametric studies will be conducted examining the role of system pressure on 
the behavior of the test facility. The full test facility will be capable of operating at elevated pressures of 2 bars above atmospheric, thus testing will be performed at 1 bar and 2 bar pressures. The mechanisms for introducing the pressures will be based on the mode of operation. For single phase (non-boiling), the gas space above the water level will be pressurized with inert cover gas to achieve the desired system pressure. For two-phase (steam generating), the system will be allowed to self-pressurize by adjusting the steam outlet valve off the tank head.

\subsection{Accident Scenario Testing}

Accident scenario testing, Phase $\mathrm{V}$, are a series of tests aimed to best represent actual operating conditions of a full scale reactor plant. Incorporating the full time history of design basis events, the test procedure will begin with a rise to 'normal' single-phase steadystate operating conditions. Defined by a full scale decay heat load of $1.4 \mathrm{MW}_{t}$, time scales and power profiles (e.g. axial cosine) will reflect prototypic values. The test facility will be allowed to reach steady-state operating conditions with a constant $30^{\circ} \mathrm{C}$ inlet temperature, and maintained for a full 24 hour period.

Following, the accident transient will be initiated by applying a transient power curve that mimics the full scale decay heat load. The exact shape of this decay heat curve will vary based on specific reactor designs, and will exhibit a unique lag from the actual decay heat generated by the fuel within the core. First tests will incorporate specific values based on AREVA's $625 \mathrm{MW}_{t}$ SC-HTGR, which see a peak heat load of $2.1 \mathrm{MW}_{t}$, however literature reviews will be performed and other reactor designs studied. The gradual rise of system inventory temperature from $30^{\circ} \mathrm{C}$ to saturation and subsequent boiling is expected to take on the order of 2 - 3 days. At this point, the 72-hr NRC criterion will be checked to verify that the design allows for sufficient inventory to maintain adequate cooling performance. Measurements of boil-off rate will be used to extrapolate expected performance windows for alternative case loads and design concepts. 
Tests will be allowed to extend past the 72-hour operating window and studied for any changes in performance or behavior. Depending on operator availability and total duration, some tests will extend into tank depletion and subsequent dry-out of network piping. This condition simulates a worst-case scenario of depletion of system inventory and will be closely monitoring by operational staff. The loop behavior is anticipated to exhibit total stagnation of flow rates and rise in material temperatures. The heat removal performance of the RCCS is a big question during these scenarios, with the temperature change of the heated surface or mock RPV providing a likely representation of fuel temperatures within the core. Testing will continue until safety-specific criteria necessitate the shutdown of active heating and will likely require injection of forced cooling to maintain structural integrity. Based on analytical modeling of the as-built welded cooling panel assembly of the current NSTF [21], yield stresses will be exceeded when the maximum temperature difference between the carbon steel fins and stainless steel riser tubes reaches $220^{\circ} \mathrm{C}$. This criteria will be given a safety factor, and used as the basis for determining safe operating limits.

\subsection{Geometric Variations}

The final round of testing, Phase VI, introduces physical modifications to the test facility. Early stages of this testing phase will utilize pre-installed valves along the network piping, e.g. shut-off and throttle valves located near the inlet region of the heated test section. Later stages will create more significant changes, requiring the loop to be fully drained, network piping physically re-configured, leak tested, and re-filled, prior to being able to conduct the tests. The tests will be performed with baseline testing conditions, which will maintain a controlled environment to isolate and identify specific changes to the behavior and performance of the test loop.

The first subset of geometric testing entails studying the impact of network blockages. Testing will first be performed to examine the impact of throttling in the primary network piping. Utilizing a pneumatically actuated full port ball valve along the 4.0" primary piping, 
immediately prior to the inlet header, the system performance will be studied as this throttle valve is gradually adjusted from fully open to nearly-closed. Periods of steady-state operation will be granted at each stage of closure, and will continue until deemed unsafe to the test assembly by the lead operator.

Following, flow blockages will be applied to the riser tubes. Physically accomplished by actuating full port ball valves at the inlet of each riser, a series of tests will be conducted with partial blockage of all risers (e.g. 25, 50, and 80\%), along with full blockage of selected risers. Full blockages will first be conducted where alternating tubes are shut-off, a scenario which mimics the loss of one full loop in the full scale RCCS concept. Then, this condition will be extended to incrementally shut off additional tubes, with the final count to be determined based on the facility response and maintaining safe operating limits of the structural components.

More significant changes to the network geometry will be introduced in later portions of this testing phase, beginning with configuring the chimney piping to discharge into the lower port along the bulk water storage tank. This port location was originally suggested by the full scale designers, placed at a height that leaves only $5 \%$ of the total inventory in the tank remaining. Considerations have been made in advance for the test facility to accomplish this change with relatively minimal effort; a 45-inch section of vertical piping can simply be unbolted and removed, allowing the piping above to be lowered and aligned to the lower inlet port.

To study the impact of real-world factors, e.g. obstructions in the reactor building and discontinuities in the piping, an additional testing series will be performed that introduces a U-shaped dip in the network piping. While the specific details have not yet been determined, likely a new section of U-shaped piping will be fabricated that replaces a previously strictly horizontal segment. Such designs are probable in a real installation and will likely be a source of major instabilities during two-phase operation. Steam pockets may be trapped, leading to a cyclic release of high intensity steam/water flow. 
Lastly, the effect of a network short-circuit will be studied. In this condition, a portion of the cold supply inventory from the water storage tank will by-pass the heated test section and "short-circuit" back into the heated return sections along the chimney network. A proportional throttle valve will join the two regions, allowing the operations to examine varying degrees of by-pass. 


\section{Chapter 3}

\section{Test Assembly Description}

The following sections detail the engineering specifications, design features, and dimensions of the water-based test facility at Argonne. A high level summary will be presented first, followed by details of mechanical, liquid, instrumentation, and control systems. The facility retains some components from the previous air-based facility, specifically infrastructure comprising the heated cavity, electric heaters, heated plate, I-beam support base, etc. Design details of these components are only discussed in-brief, with remaining details found in previous publications [6]. Finally, the chimney stacks have been left in-place on the support mezzanine, however are disconnected from service and do not serve any purpose for the water-based facility. A computational rendering of the completed test facility is shown in Figure 2 . 


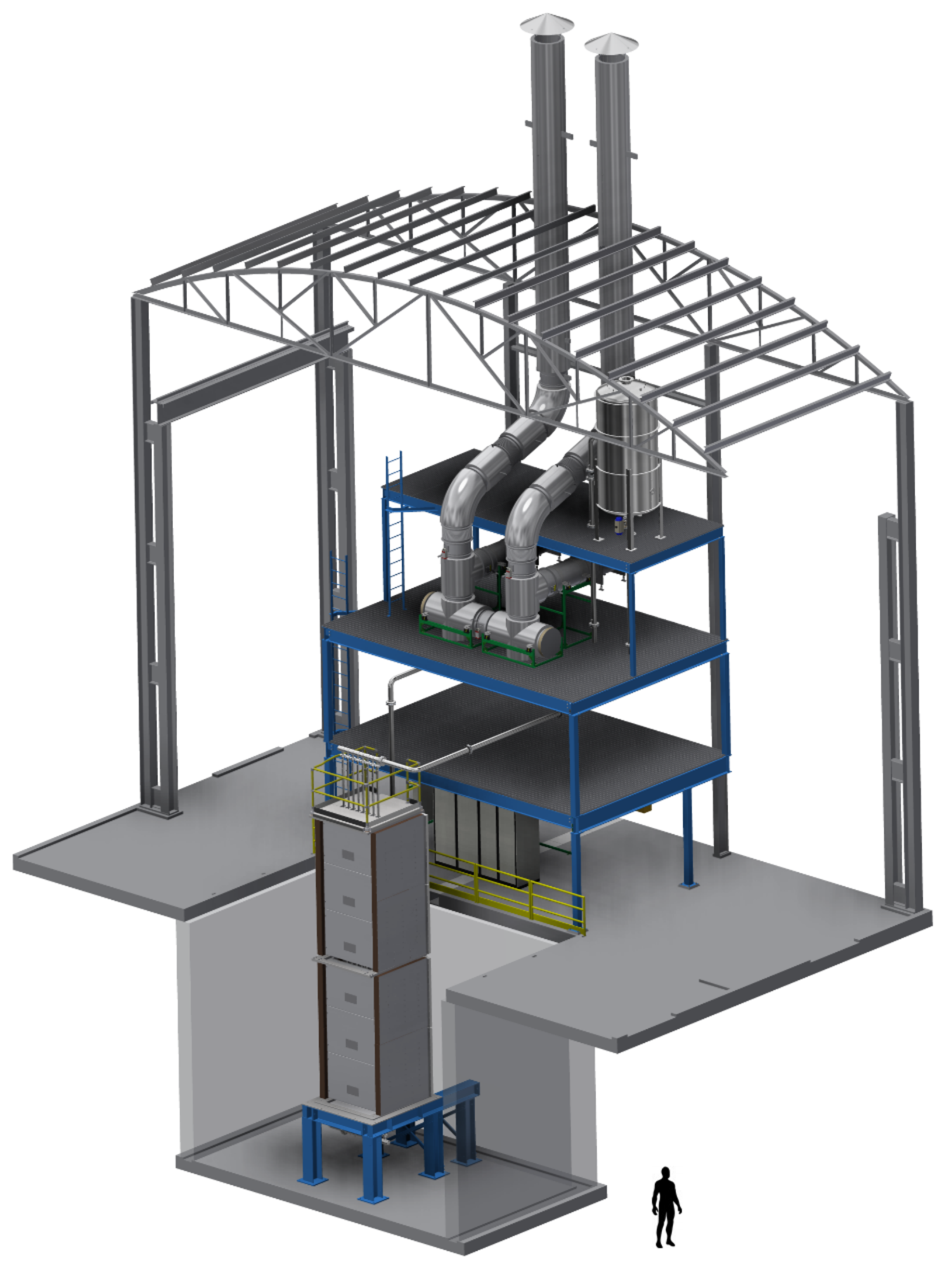

Figure 2: Solid model render of complete water NSTF in laboratory high-bay 


\subsection{Mechanical Systems}

One aspect of the conversion from air- to water-based cooling of the modern NSTF is the preservation of key infrastructure. Specifically, the entire heated cavity representing the reactor pressure vessel (RPV) surface and concrete containment have been retained. A select number of changes were required for the water conversion, however the bulk of design and as-built dimensions can be found in earlier reports [22].

Minor modifications were required to reflect the liquid based test section, including fabrication of a new test section support plate to account for the change from rectangular ducts to circular tubes. Similar to the air-based support plate, a 1.0-inch thick steel plate resides on top of the skeleton frame-work with notches cut out to allow protrusion of the riser tubes outside the cavity. Based on lessons learned during air-based disassembly activities, improvements were made to include low-emissivity surfaces on the side facing inside the heated cavity, Figure 3. Additionally, since a sealed outlet plenum was no longer required, the top plate was fitted with a deck plate and hand-rails to allow personnel access, Figure 4. A walk-bridge will be placed from the 2nd floor of the mezzanine and facilitate inspection of outlet header bolted-flange connections, installation of instrumentation, etc..

In design of the new support plate, considerations were made to maintain the horizontal spacing from the center of the test section to front face of the heated wall. This reflects a motivation to retain the concept reactor building layout (RPV and concrete positions), and

only substituting the air ducts for water tubes. An cross-sectional view of the water-based heated cavity, with material locations and dimensional spacing, is provided in Figure 5. 


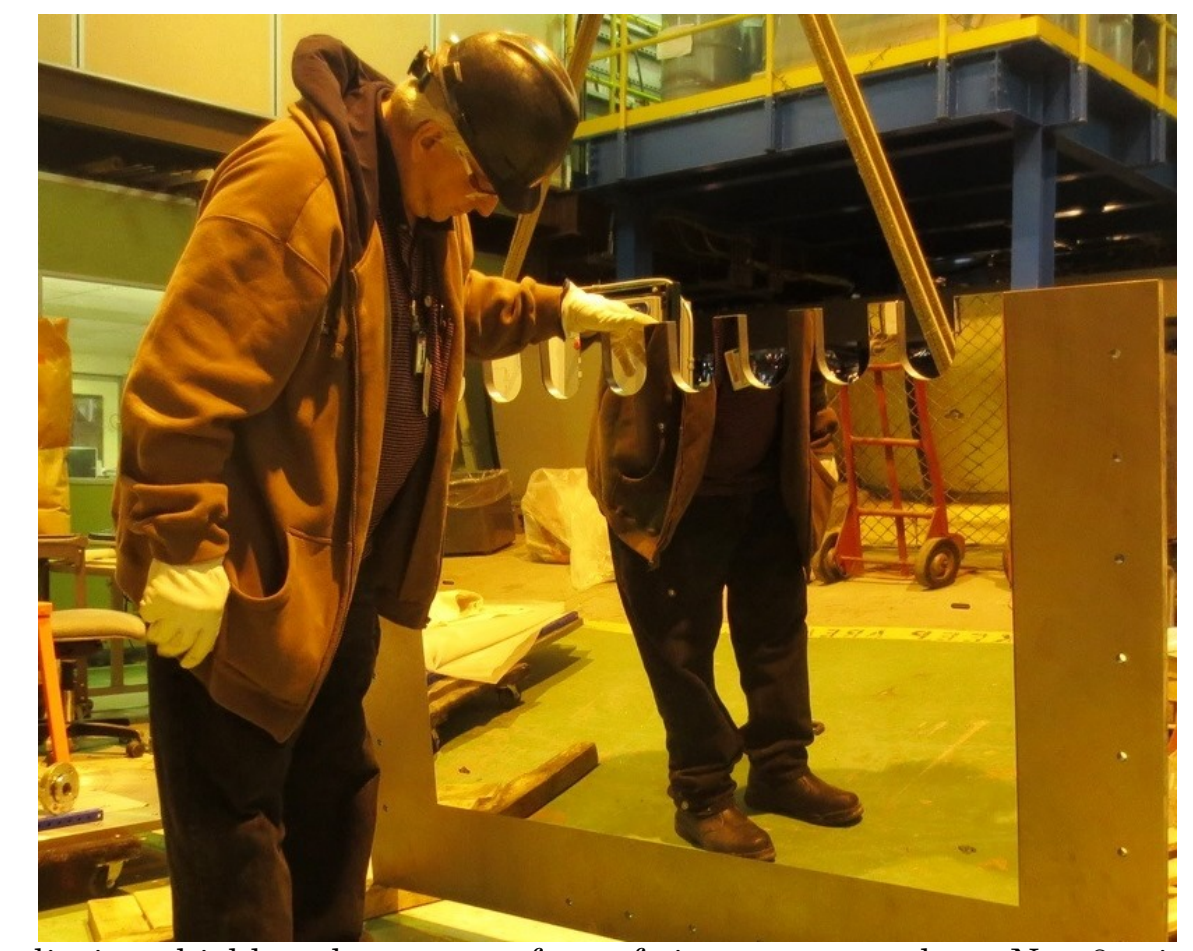

Figure 3: Radiation shield on bottom surface of riser support plate, No. 8 mirror-like finish

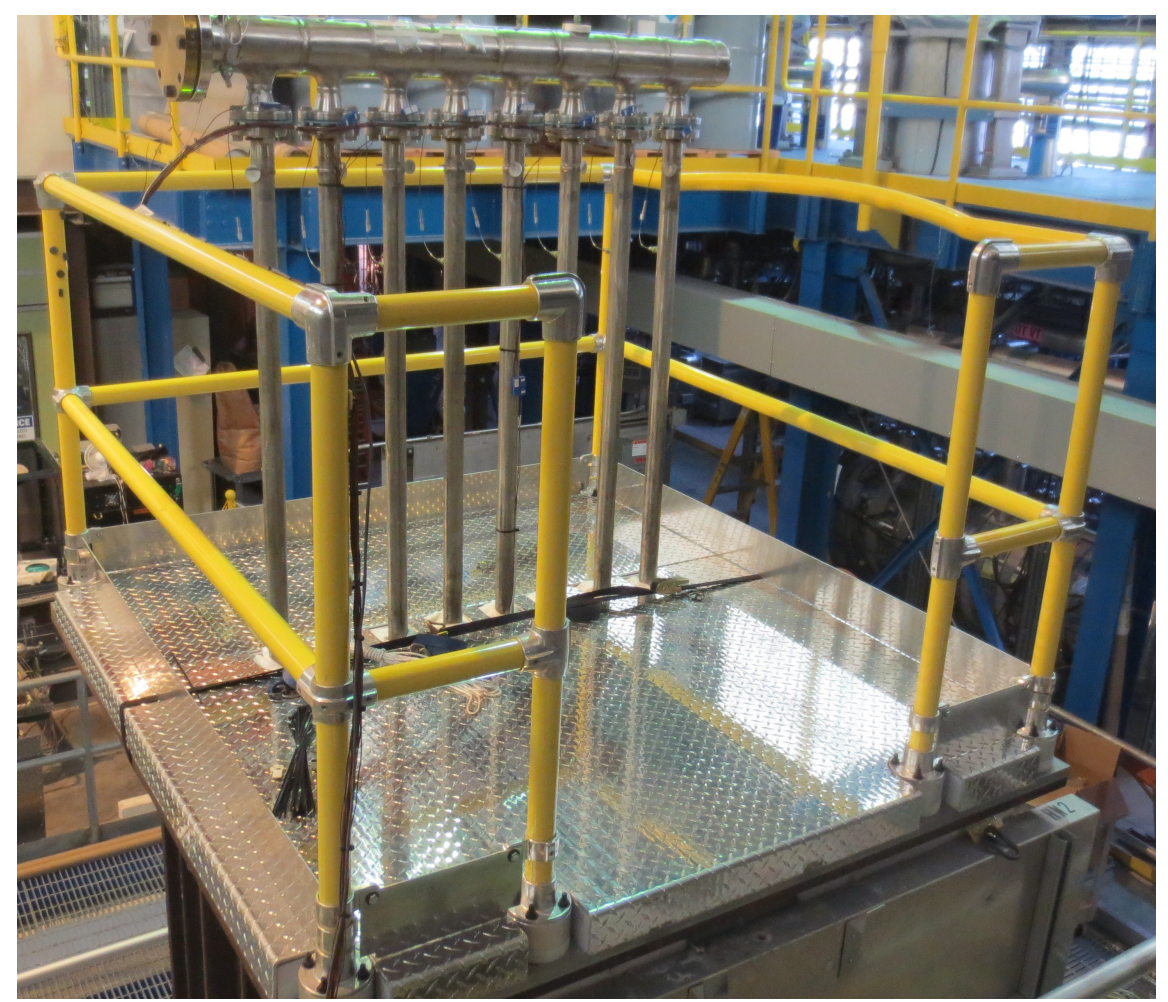

Figure 4: Personnel access to top of heated cavity 


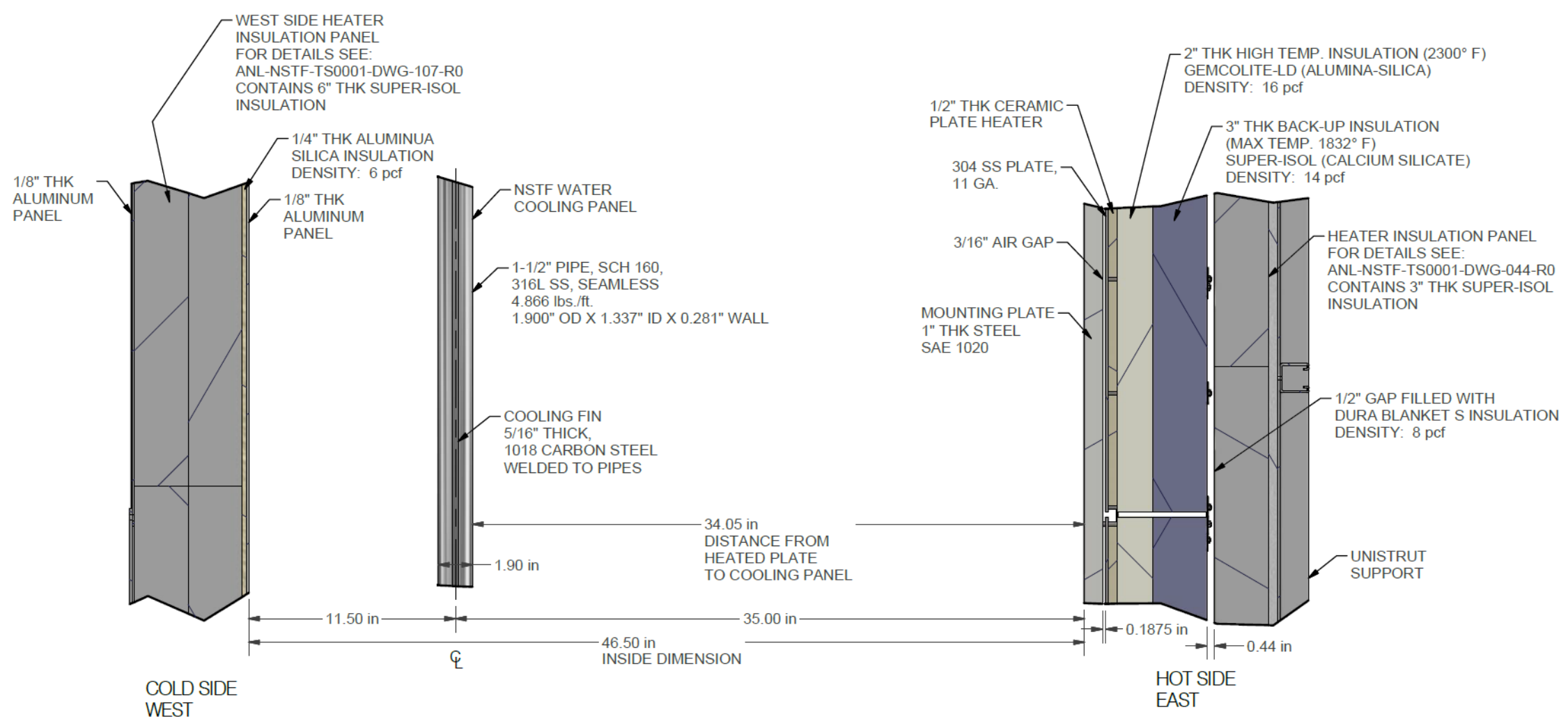

Figure 5: Heated cavity cross section 


\subsubsection{Insulation}

Within the heated cavity, the various insulation composites were maintained during the air to water conversion. Some portions, however, were refreshed to provide optimal thermal efficiencies. Refreshed insulation includes the high temperature Gemcolite ${ }^{\circledR}$ that is placed against the flat plate ceramic heaters, and the medium temperature SuperIsol that is built into the hinged exterior panels. For the liquid piping systems, a new type of insulation, KFLEX $^{\circledR}$ Insul-Sheet ${ }^{\circledR}$, was added to the overall suite. Commonly used for HVAC applications, this elastomeric, nitrile butadiena rubber based close-cell foam is optimally suited for the temperature ranges of the network piping. Outside surfaces of the risers, network piping, and water storage tank will be covered with a 2.0-in wrap of K-FLEX ${ }^{\circledR}$. A summary of the insulation types and thermal properties is provided in Table 2.

Table 2: Overview of insulation and thermal properties

\begin{tabular}{|c|c|c|c|c|}
\hline & K-FLEX ${ }^{\circledR}$ & SuperIsol & Gemcolite $^{\circledR}$ & Cerablanket $^{\circledR}$ \\
\hline Series & Insul-Sheet ${ }^{\circledR}$ & - & LD-2300 & - \\
\hline Thickness & 2 -in & 3-in & 2-in & 1 -in \\
\hline Density & $64 \mathrm{~kg} / \mathrm{m}^{3}$ & $225 \mathrm{~kg} / \mathrm{m}^{3}$ & $256 \mathrm{~kg} / \mathrm{m}^{3}$ & $128 \mathrm{~kg} / \mathrm{m}^{3}$ \\
\hline \multirow[t]{2}{*}{ Max Temp. } & $104^{\circ} \mathrm{C}$ & $1,000^{\circ} \mathrm{C}$ & $1,260^{\circ} \mathrm{C}$ & $2,150^{\circ} \mathrm{C}$ \\
\hline & \multicolumn{4}{|c|}{ Thermal Conductivity, W/m-K } \\
\hline $24^{\circ} \mathrm{C}$ & 0.035 & - & - & - \\
\hline $200^{\circ} \mathrm{C}$ & - & 0.060 & 0.052 & 0.053 \\
\hline $400^{\circ} \mathrm{C}$ & - & 0.080 & 0.078 & 0.089 \\
\hline $600^{\circ} \mathrm{C}$ & - & 0.100 & 0.134 & 0.150 \\
\hline $800^{\circ} \mathrm{C}$ & - & 0.120 & 0.178 & 0.225 \\
\hline $1,090^{\circ} \mathrm{C}$ & - & - & 0.288 & 0.340 \\
\hline
\end{tabular}




\subsection{Liquid Systems}

\subsubsection{Cooling Panel Test Section}

The test section of the water NSTF is a 30-ft assembly of eight water tubes joined at their centerline by cooling fins, and serves as the sole means of heat removal from the heated cavity. This design shares similarities to legacy 'water-wall' panels, a heat exchanger technology commonly employed in coal-fired power plants. For ease of handling and installation, the cooling panel was divided into four subassemblies, with each unit consisting of two water tubes and three cooling fins. Steel joining plates are bolted to the back faces to mechanically and thermally connect the four units into a single assembly.

The water tubes extend 27.75-ft in length, and are constructed from 316L stainless steel pipe, 1.5" nominal diameter, and Schedule 160 wall thickness. Spaced apart by a pitch of 5.91-inch, 1018 carbon steel fins, 5/16" in thickness, are welded to the tube centerline for a final pitch-to-diameter ratio of 3.1, as shown in Figure 6. However, the fins extend only along a $6.75-\mathrm{m}$ length, which reflects the portion located within bounds of the heated cavity.

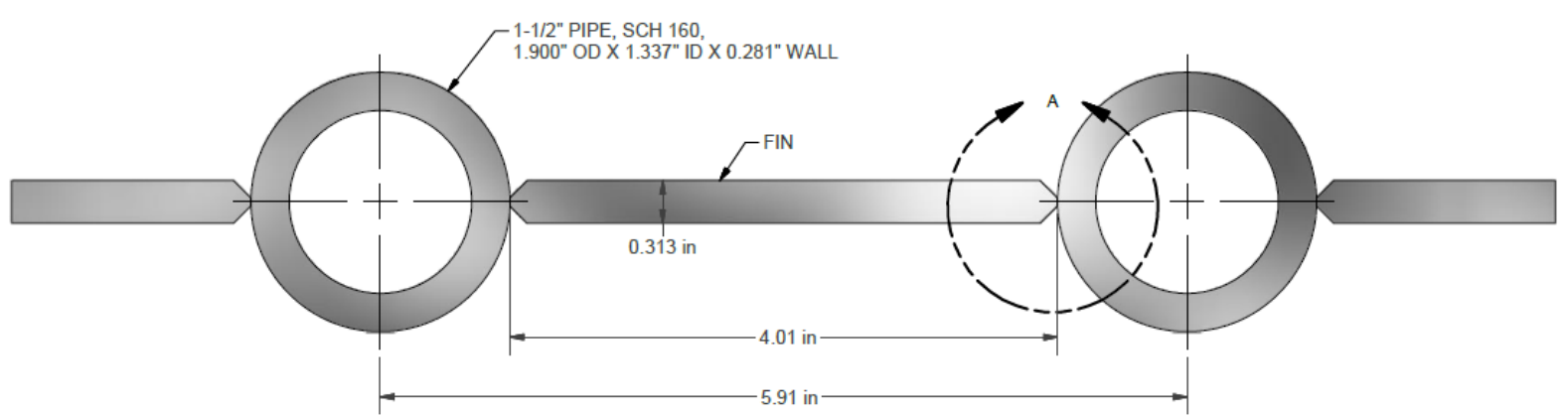

Figure 6: Cross section of single subassembly cooling panel unit 
The inlet region, or tube-only sections prior to the start of the cooling fins within the heated cavity, consists of a 13.25-inch stub length, full-port shut-off valve, EM flow meter, 8-inch stub length for flow development, and finally inlet header. A model representation, and image of the as-installed layout, is provided in Figure 7 and 8.

Riser tubes \#5 \& \#6 features added instrumentation and has been coined "SuperDuct". These tubes were pre-machined with 0.047-in diameter grooved channels prior to fabrication, Figure 9, and allow the installation of wall capillaries for distributed temperature sensing (DTS) measurements. These risers also includes a single DTS capillary installed along the axis centerline and span the full vertical length of the tubes. Finally, a higher number of wall thermocouples, along both hot and cold faces of the riser tube and cooling fin wall, have been added to these risers.

To maintain acceptable production of these water-wall panels (e.g. minimize warping), specialized welding processes were established, including the method of Helium Laser Arc Welding (HLAW). The process is able to achieve full penetration with significantly less heat than conventional processes such as submerged arc welding (SAW) or shielded metal arc welding (SMAW). A US based company was contracted to fabricate these panels for the water NSTF program. The delivered product met Argonne specifications and stamped as a pressure vessel under ASME BPVC Section VIII, Div. 1.

Prior to installation into the heated cavity, the hot face of the cooling panel was bead blasted to achieve a uniform starting surface condition and emissivity. Three passes at 90 psig with Spherglass beads, $212 \mu \mathrm{m}$ sieve size, Grade 2024, were used in the process. Great care was taken to minimize exposure to the elements and contamination from human oils, and allowed the team to install a clean test section with a uniform surface emissivity of 0.43 , Figure 10 - 11. 


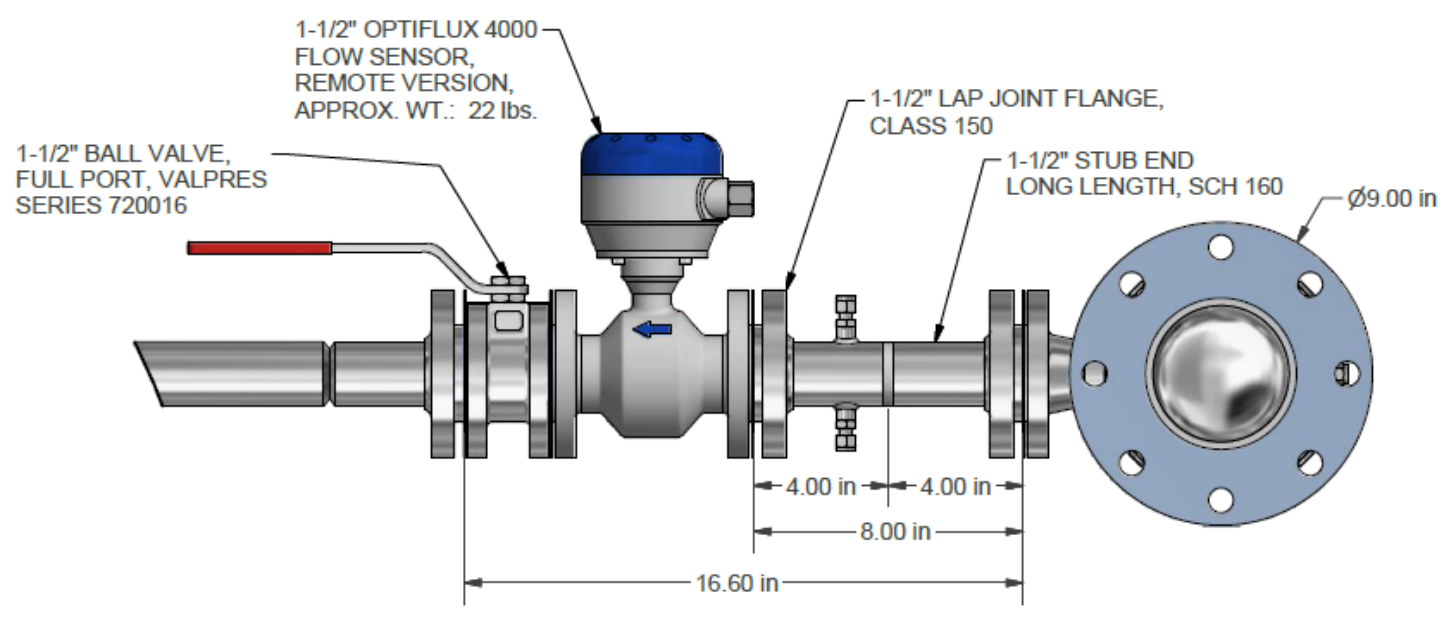

Figure 7: Inlet region of cooling panel, computational drawing

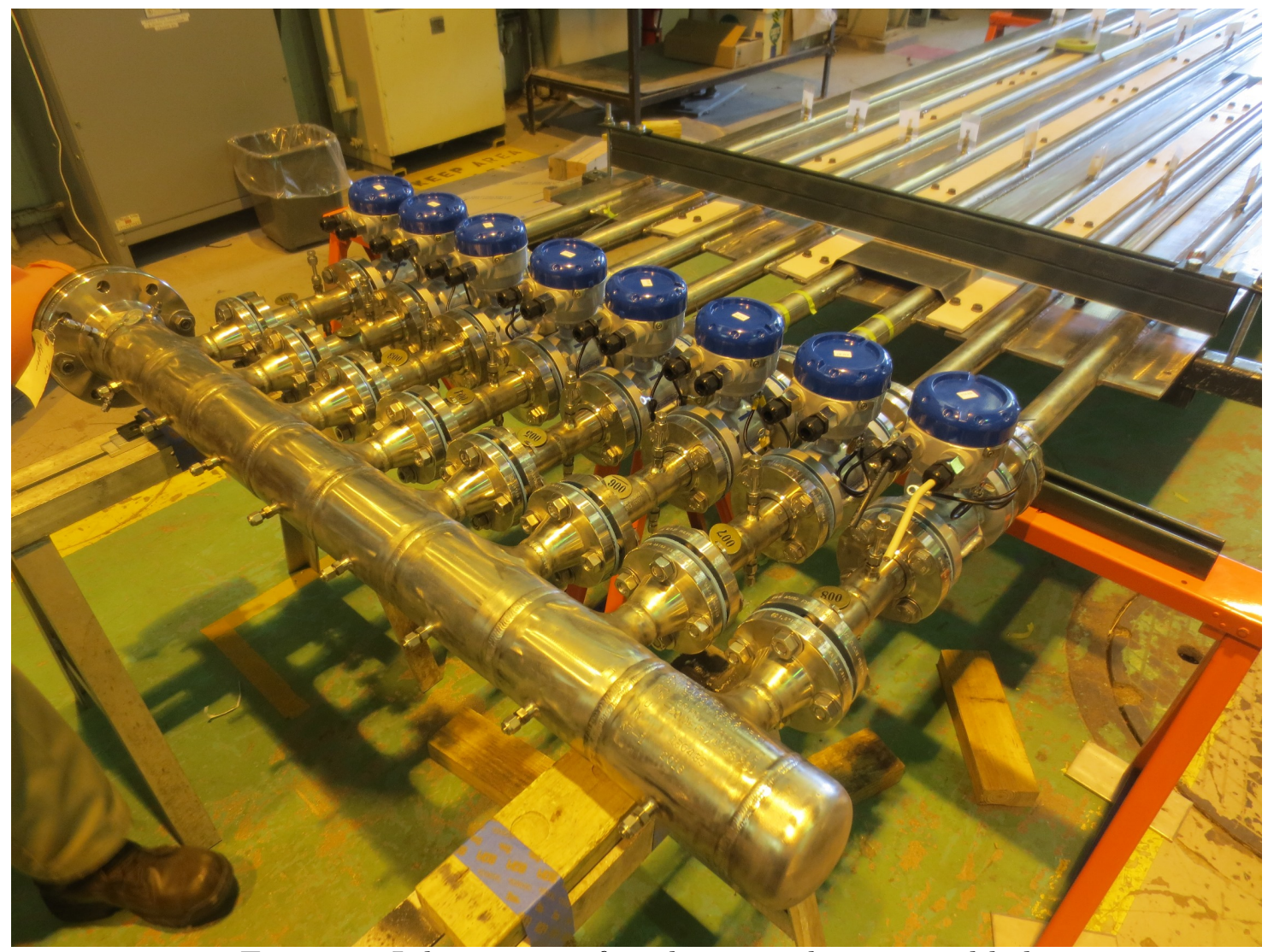

Figure 8: Inlet region of cooling panel, as-assembled 


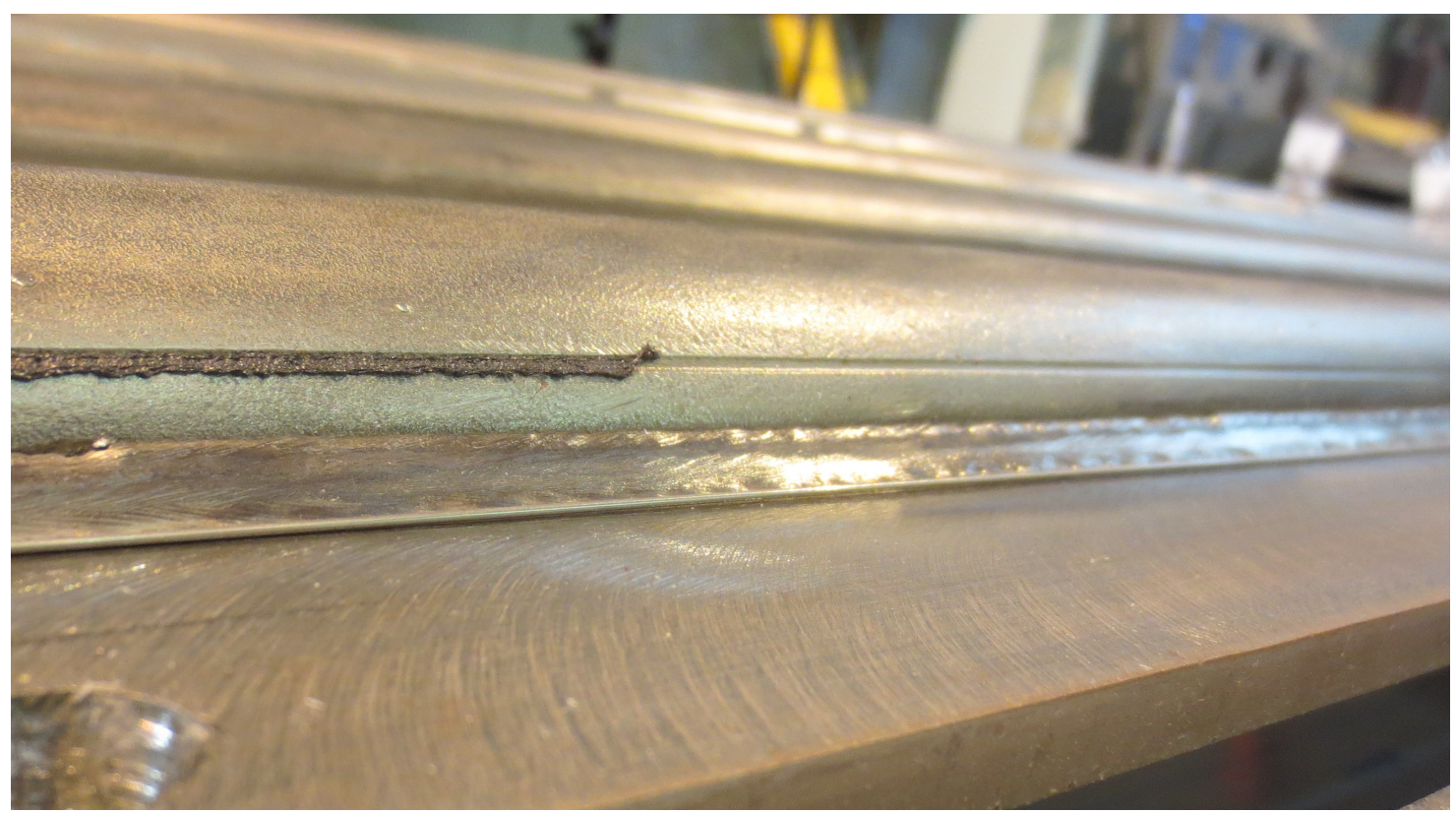

Figure 9: Machined grove along riser \#6, heat transfer epoxy and DTS capillary visible

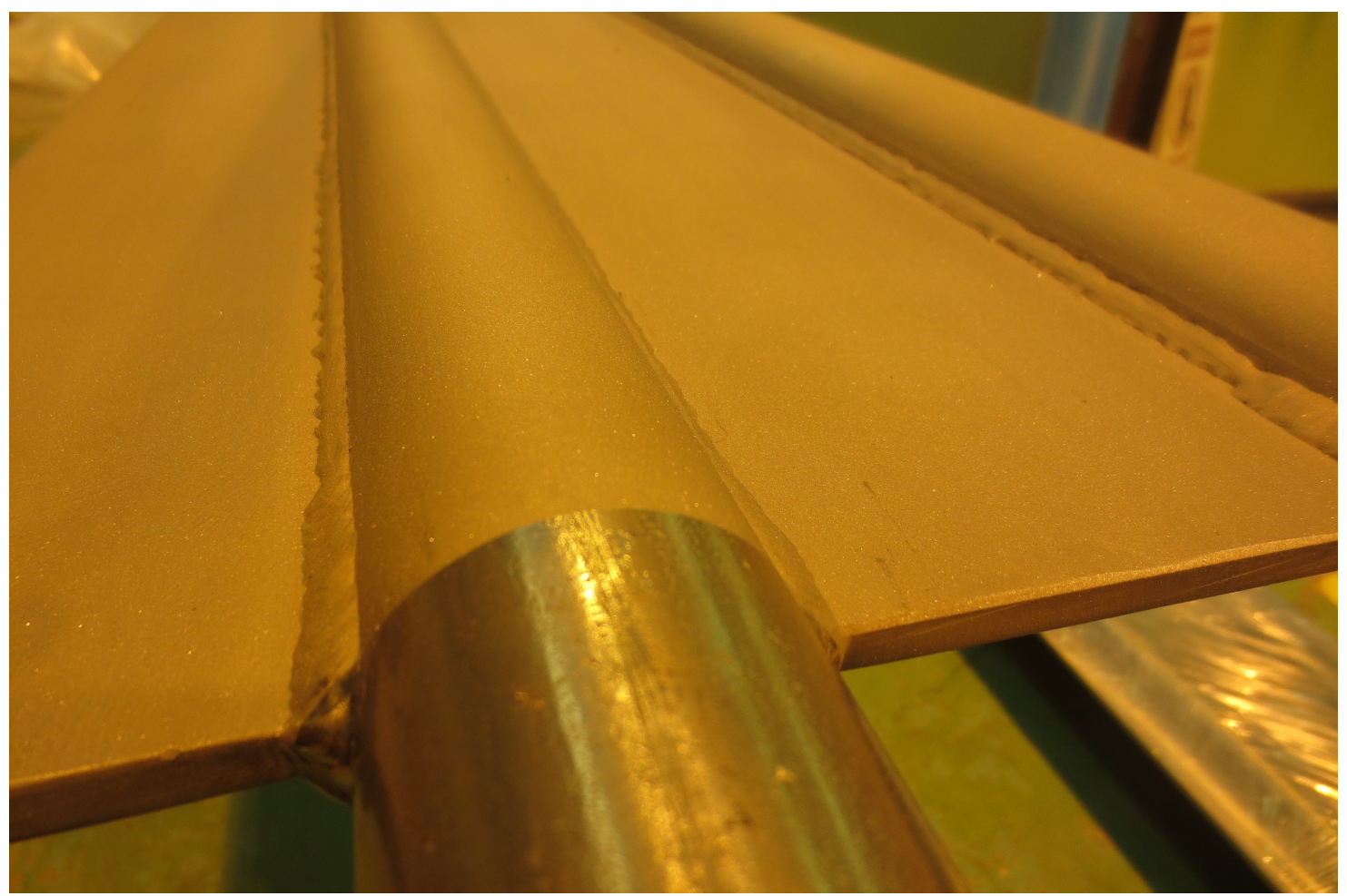

Figure 10: Bead blasted surface of cooling panel, high contrast to original 
Water NSTF Design Report, Instrumentation, and Test Planning

August 2017

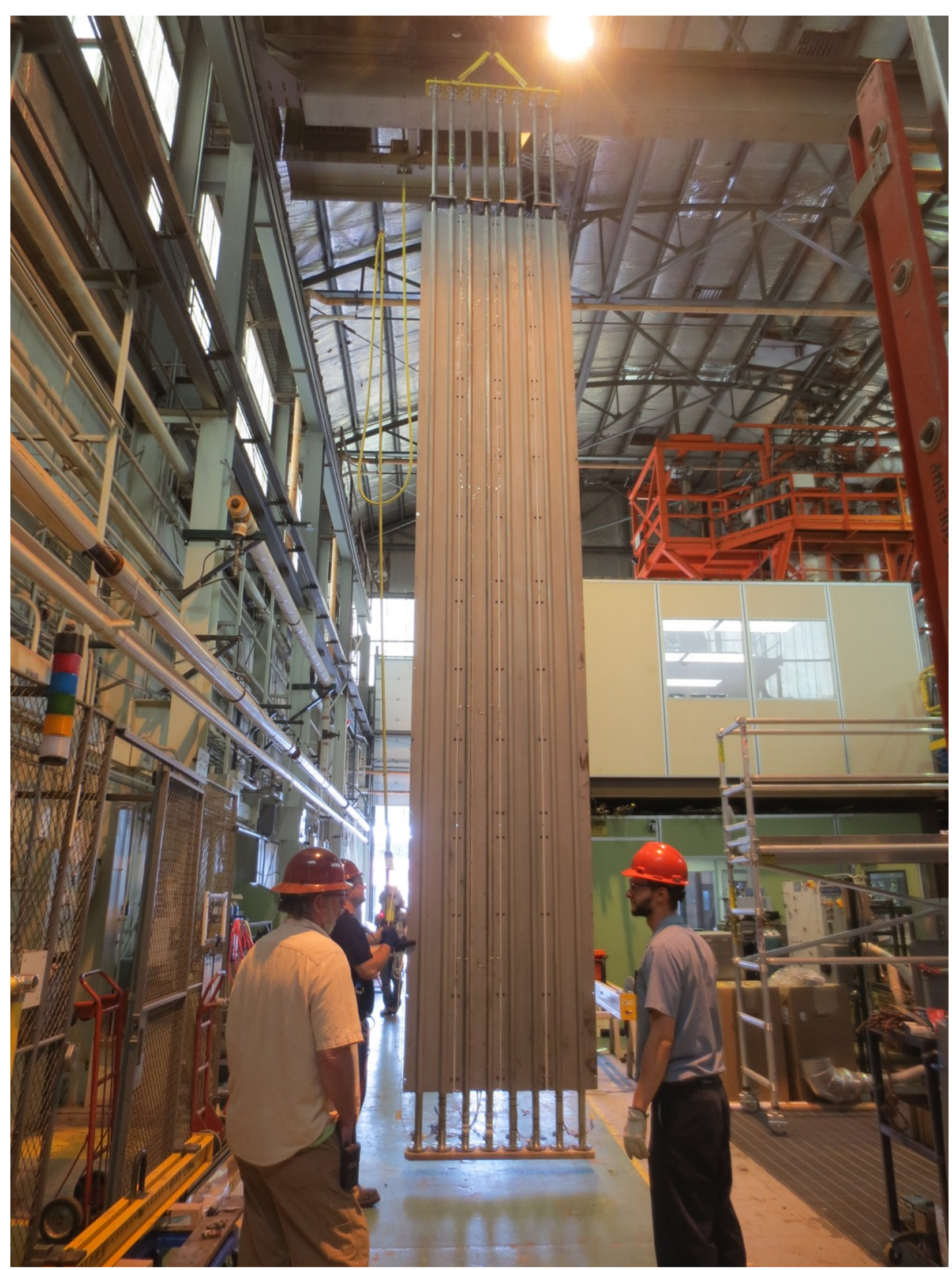

Figure 11: Vertical cooling panel prior to installation 
空

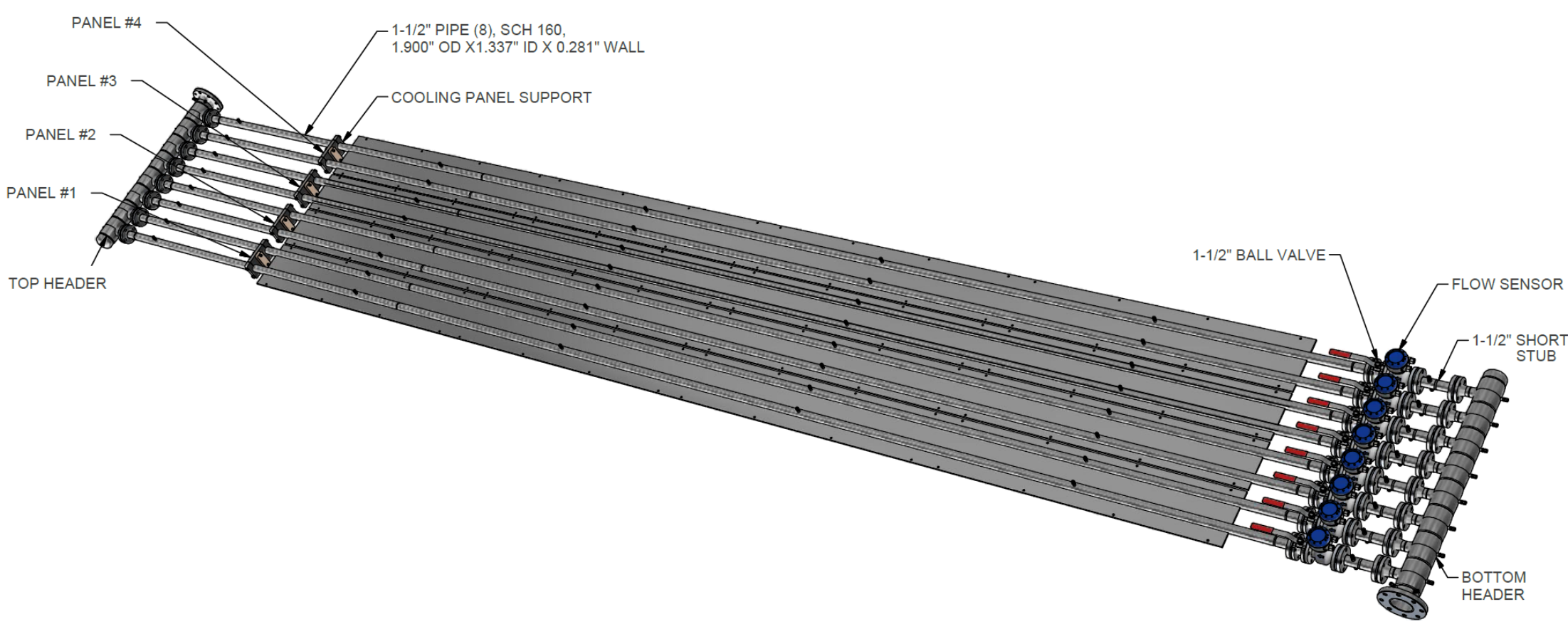

Figure 12: Isometric model of assembled cooling panel test section 


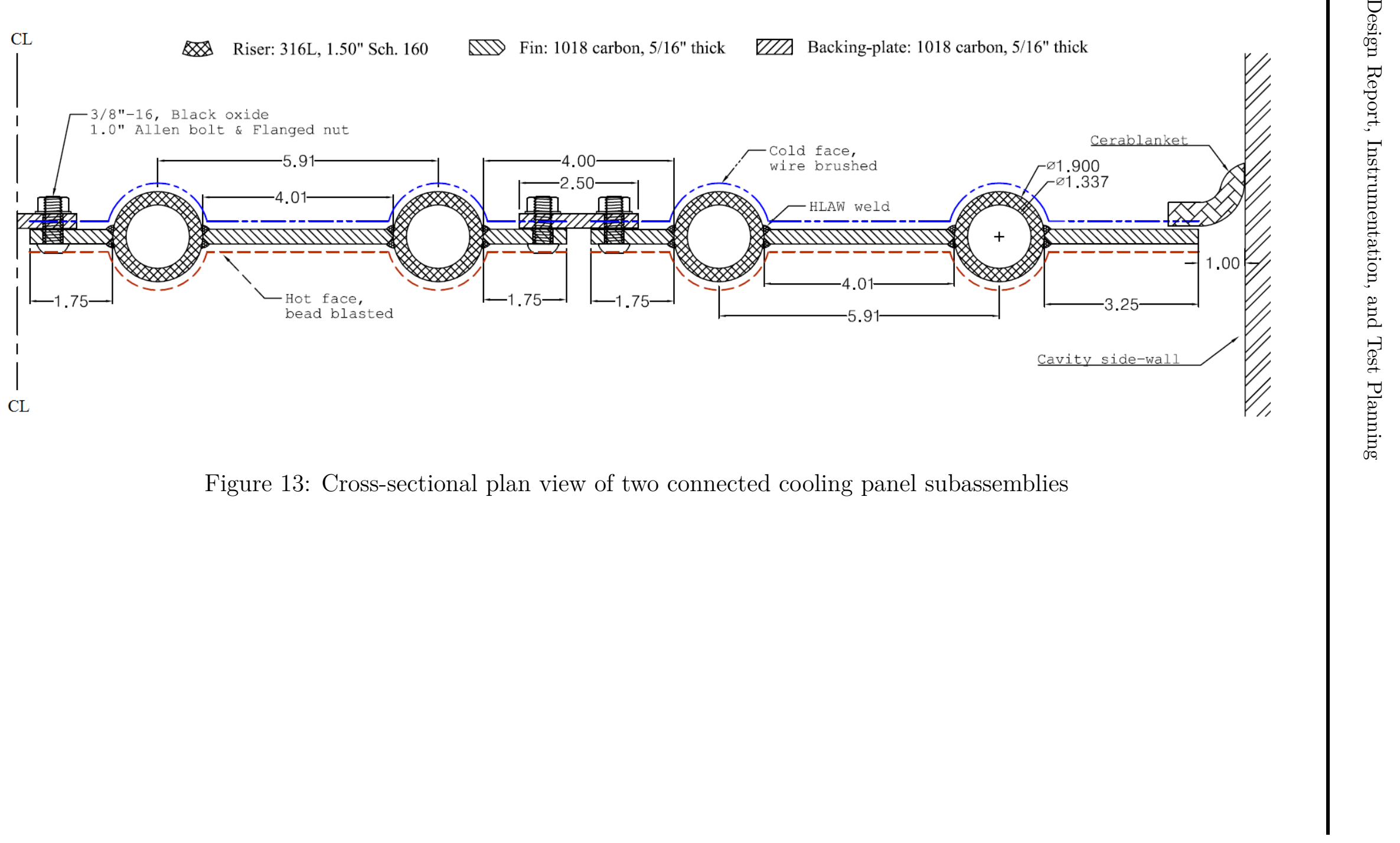




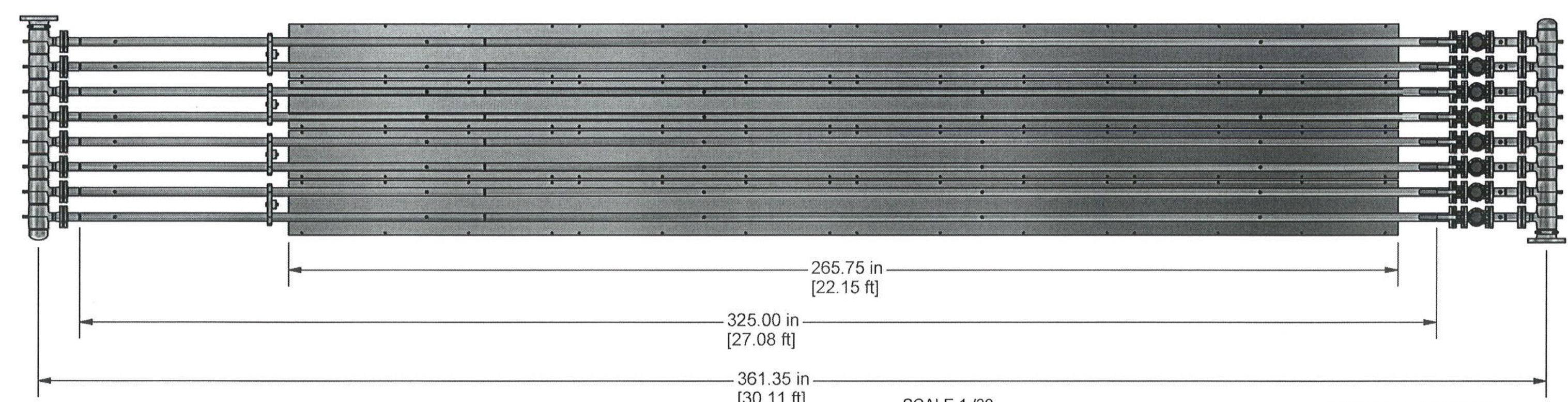

$361.35 \mathrm{in}$
$[30.11 \mathrm{ft}]$

SCALE $1 / 30$

-6 PORT LOCATIONS

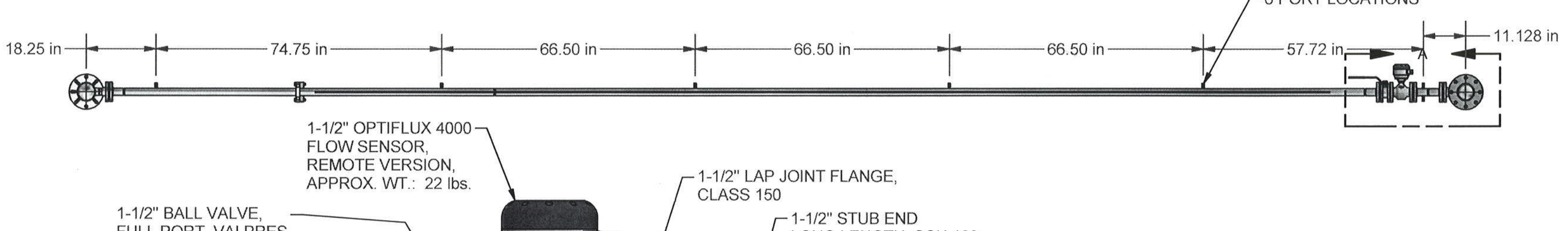

1-1/2" BALL VALVE,

FULL PORT, VALPRE

SERIES 720016

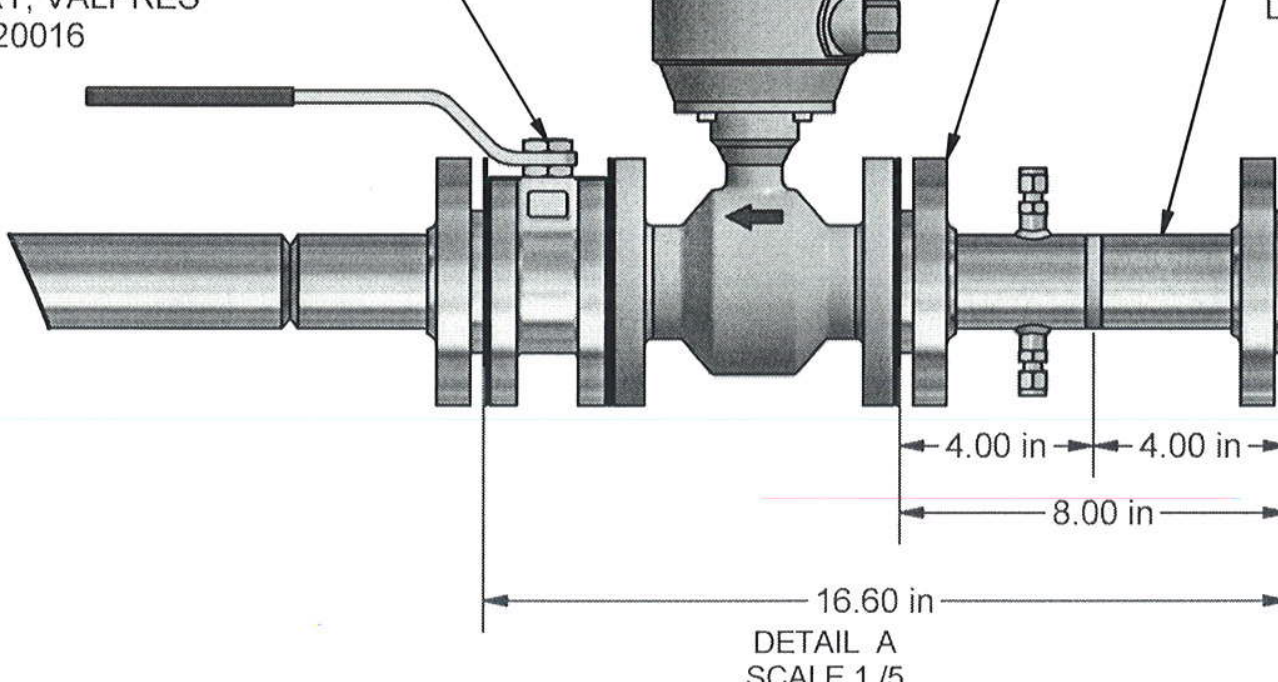

DETAIL A
SCALE $1 / 5$

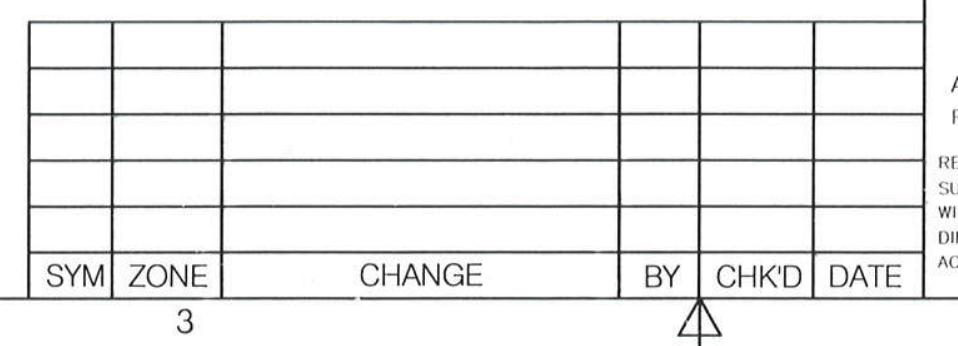

UNLESS OTHERWISE NOTED ALL DIMENSIONS ARE INCHES deCimal TOLERANCE

$\begin{array}{ll}x & \pm .1 \\ x x & \pm .02 \\ x \times x & \pm .005\end{array}$ $\begin{array}{lll}x & \\ \text { CULAR TOL } & \pm 1 / 2 \\ & \pm 1 / 64\end{array}$ RACTIONAL TOL $\quad \pm 1 / 64$

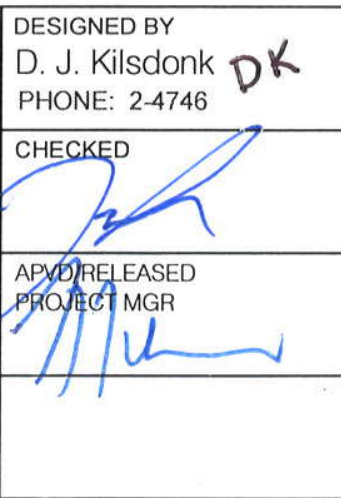

\begin{tabular}{l|l|}
\hline DATE \\
$7 / 26 / 2017$ \\
\hline $7 / 26 / 17$ \\
\hline DATE \\
\hline $7 / 26 / 10$ \\
\hline
\end{tabular}

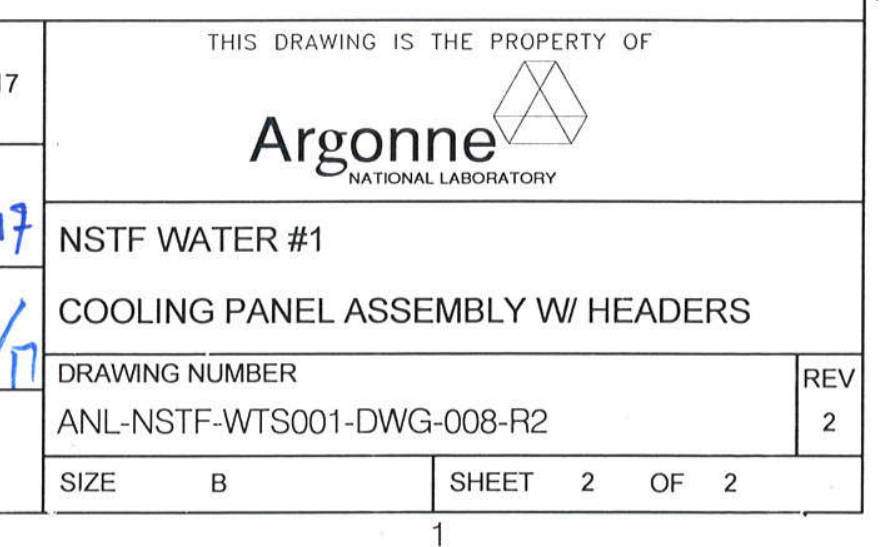




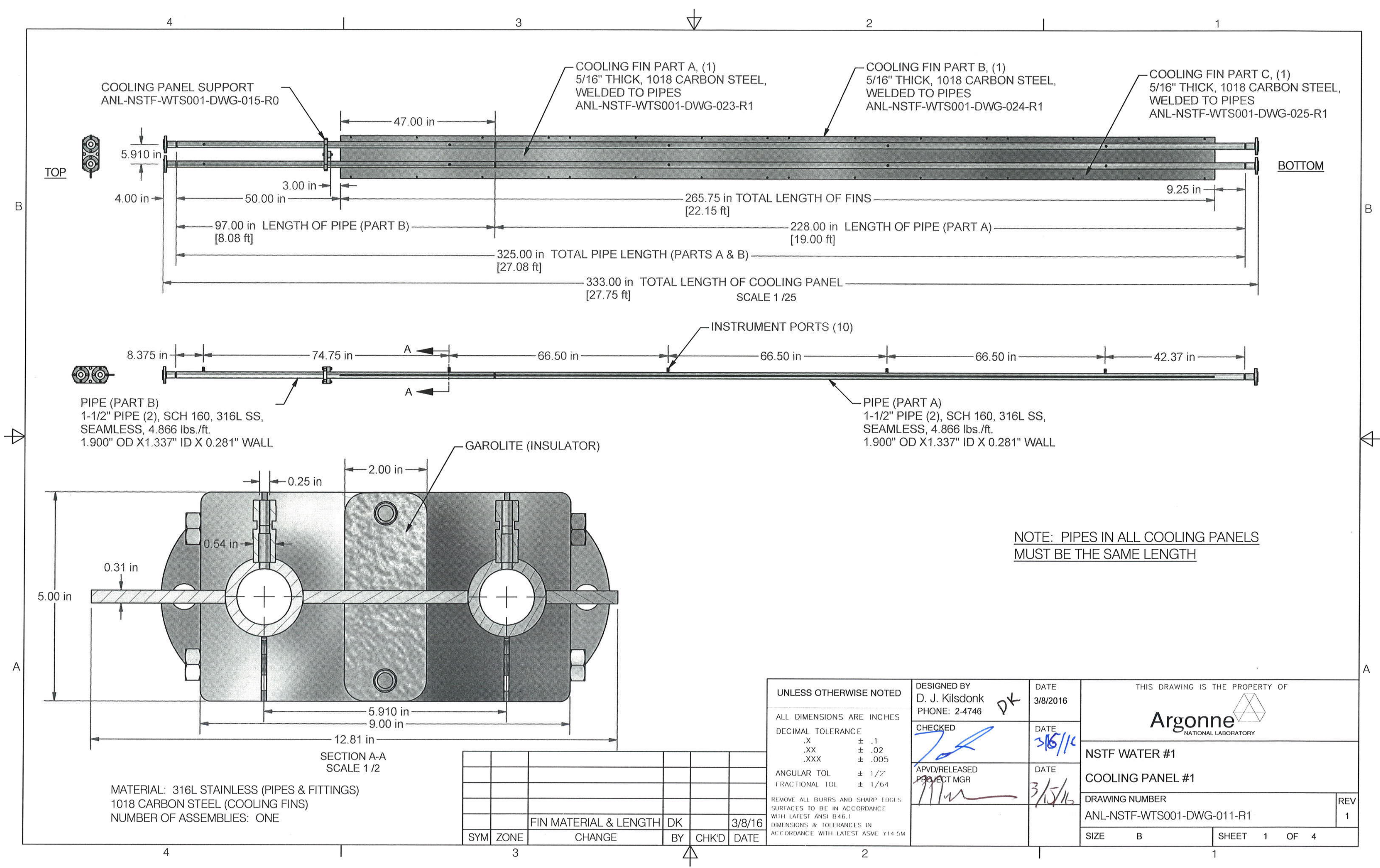




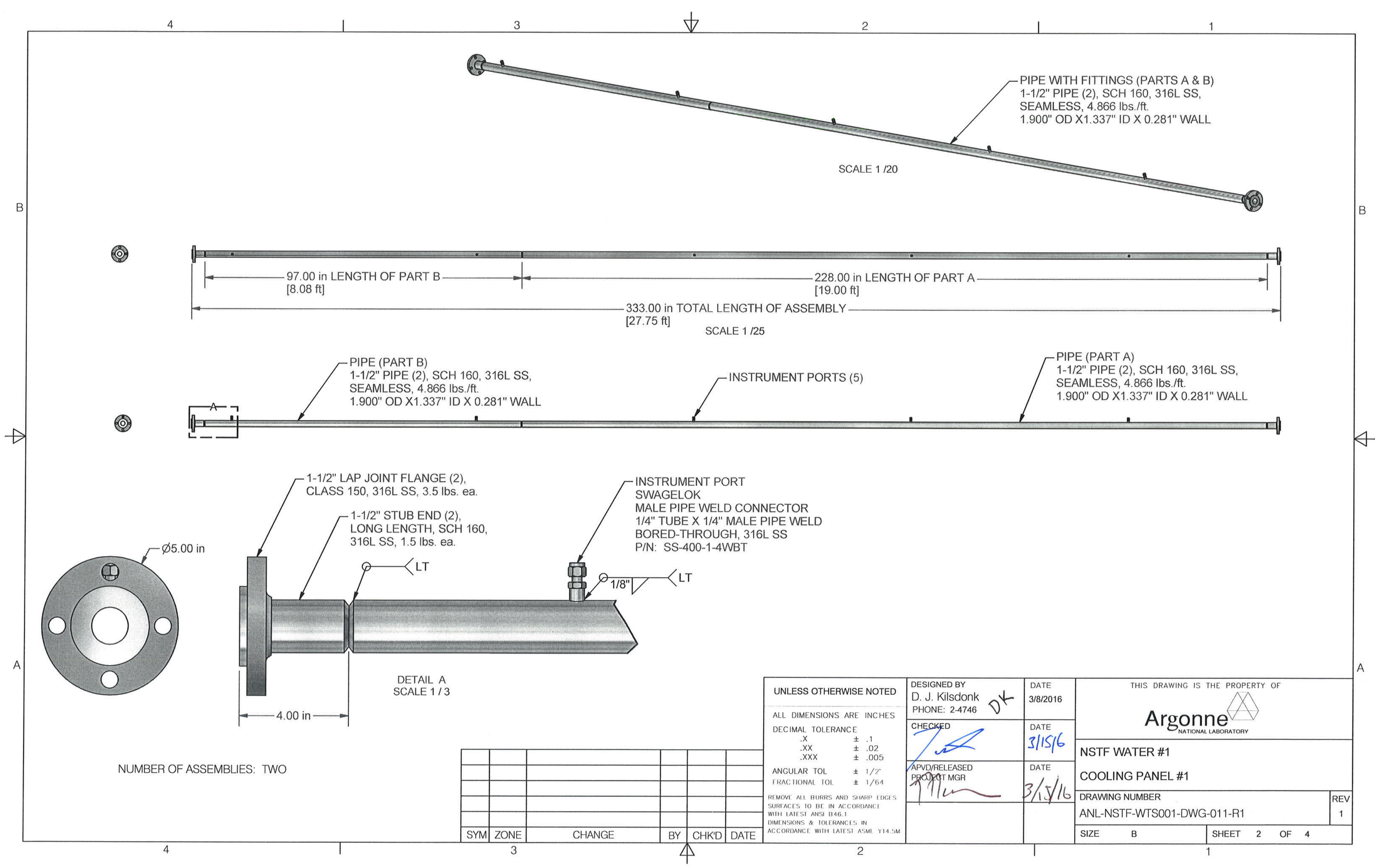




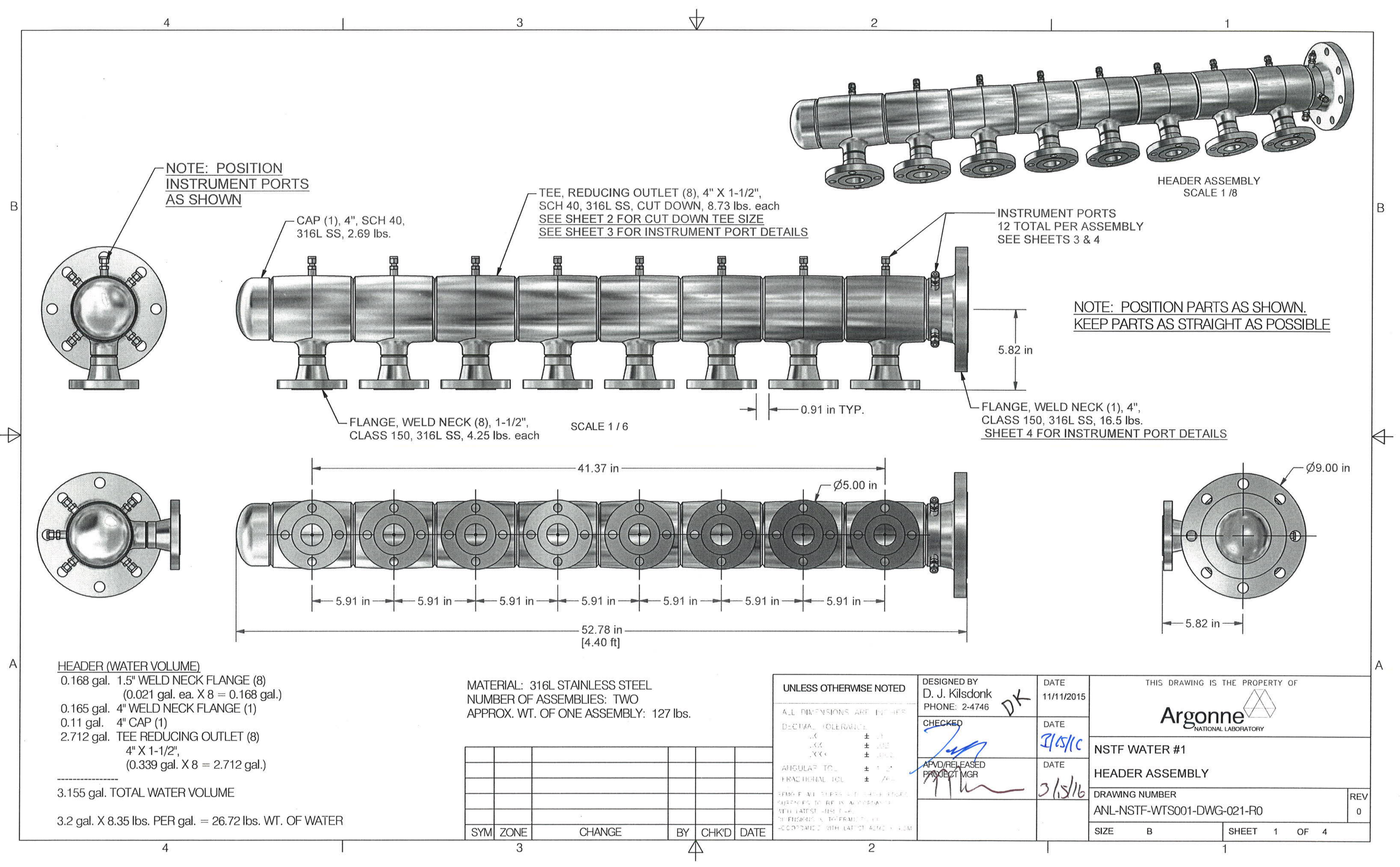




\subsubsection{Network Piping}

The primary piping is a single path network that joins the heat source and heat sink of the test facility, creating a single closed loop for natural circulation. Consisting of a chimney (hot line) and downcomer (cold line) segment, the chimney joins the outlet of the heated test section to the inlet of the water storage tank, while the downcomer joins the outlet of the water storage tank to the inlet of the heated test section cooling panel, Figure 14. Both sections are constructed entirely from 316L piping, sized 4.0" and Schedule 40. A total of 105-linear feet of piping, 9 long-radius elbows, and 34 flanges make up the network. Flange types are split between weld-neck and lap-joint style assemblies, with weld-neck favored for sections of high stress or cyclic loading.

An analysis of the piping system was contracted to verify code compliance and identify key areas for safety and design. The final deliverable comprised a PE-stamped report and CEASARII model passing all applicable requirements of ASME B31.3 piping code, 2014 edition. The CEASARII model was validated against seven different operating cases and included both stress and fatigue analysis.

Instrumentation access ports, 31 in total, are located at regular intervals along both lines of the network piping. These fittings are of the Swagelok type, allow installation of thermocouples, differential pressure taps, void fraction sensors, etc.. Additionally, two weld-neck fittings, of size 1.0-inch and 2.0-inch, are installed near the header inlet region to facilitate loop fill and drain operations, Figure 15. Included in this inlet region is also a large 4.0" EM flow meter and high precision throttle valve.

In the upper segment of the downcomer, immediately below the tank outlet, is a pneumatic shut-off valve and Y-diverter pipe. The combination of these two, along with port access off the dish of the tank, will allow the facility to operate in a forced flow mode of circulation, a critical function to determine form loss coefficients. 


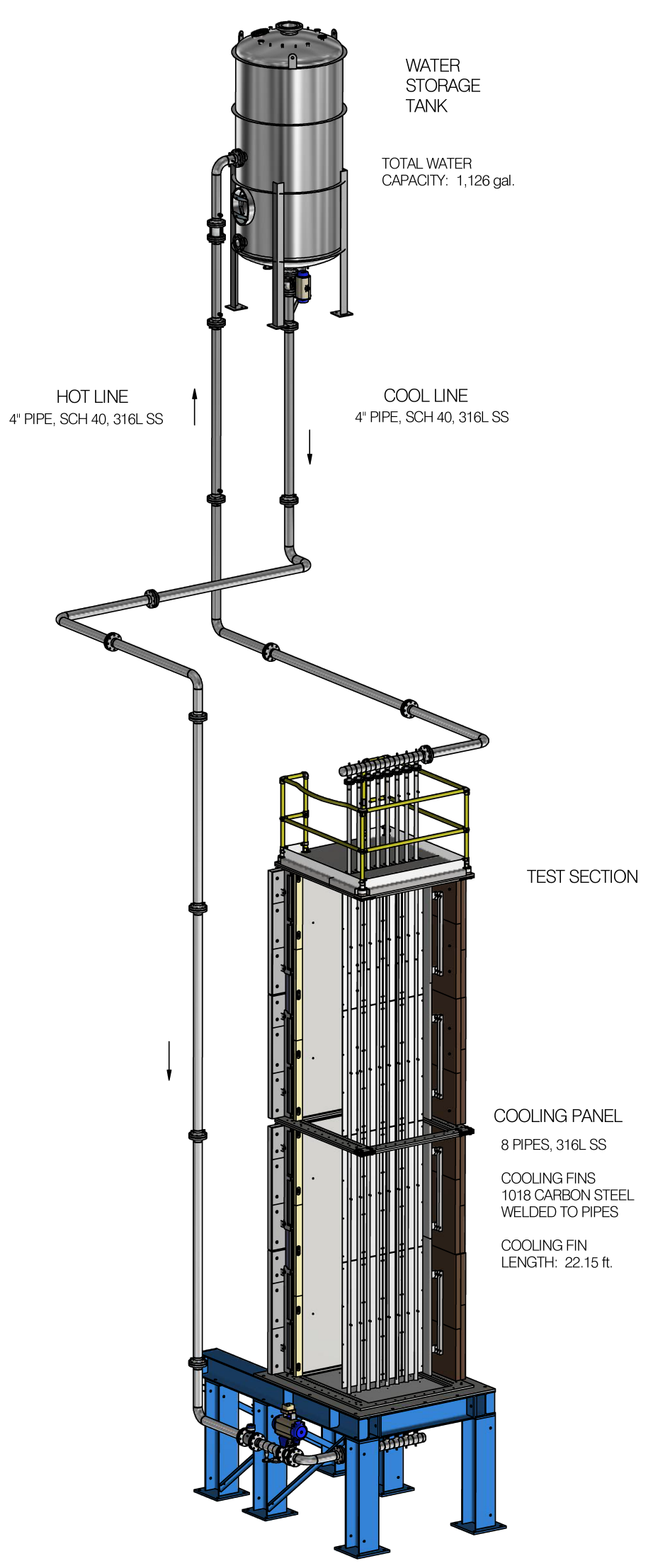

Figure 14: Hot and cold lines of primary network piping 

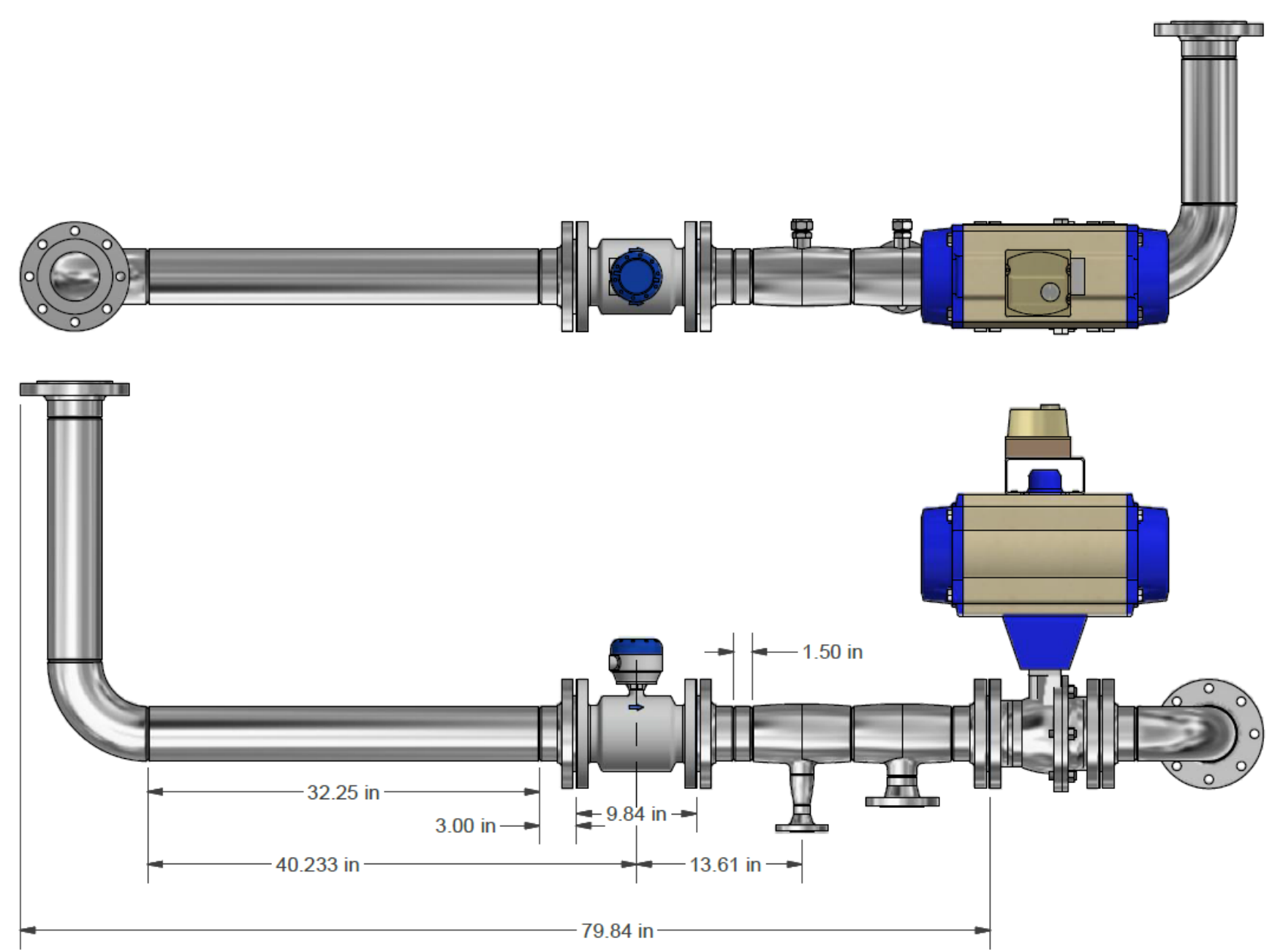

Figure 15: Solid model rendering of inlet piping segment, dimensions in inches. From left of page: i) elbow connection from downcomer, ii) straight length for flow development, iii) EM flow meter, iv) fill port, v) drain port, vi) throttle valve, vii) elbow connection to test section inlet header 


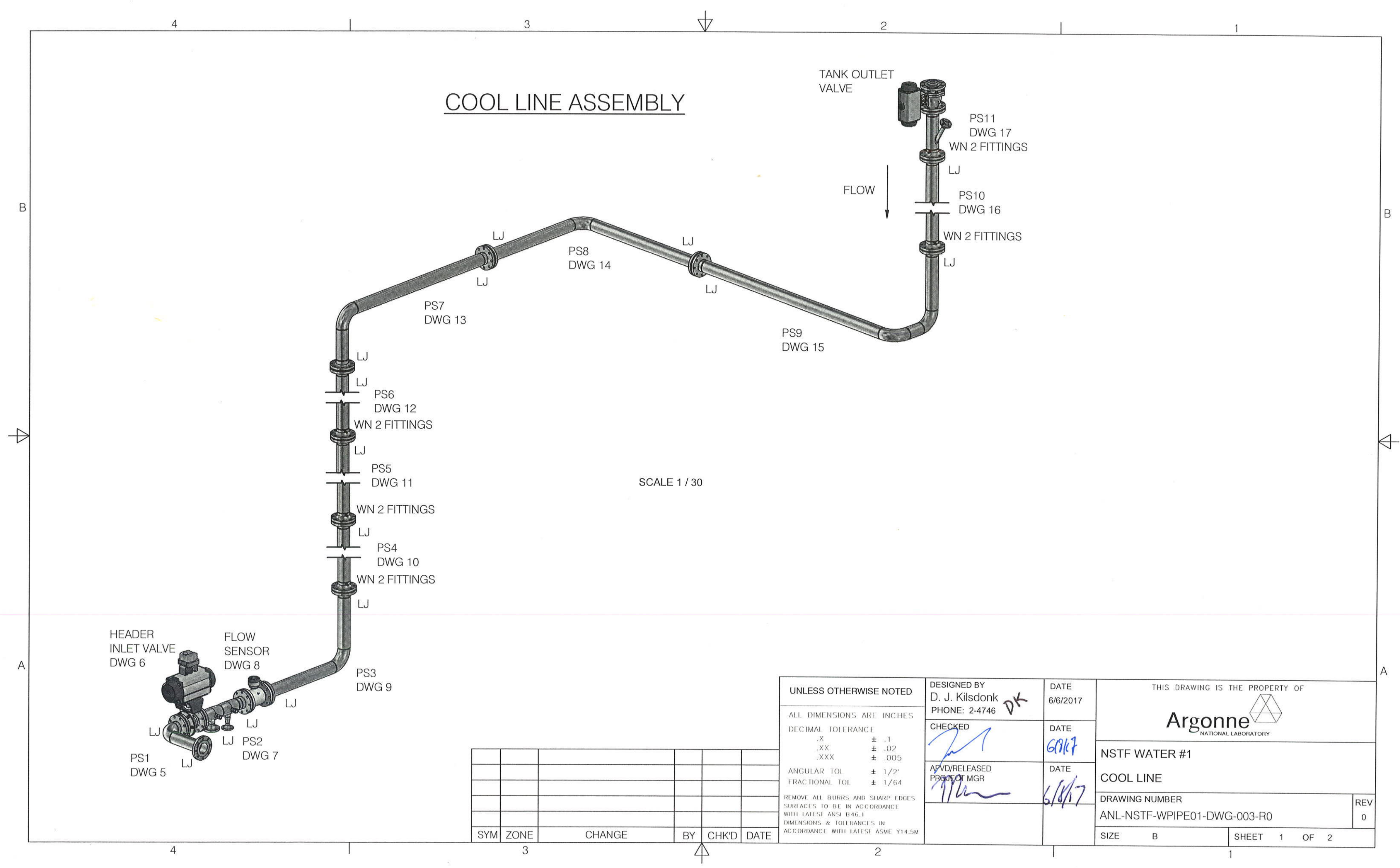




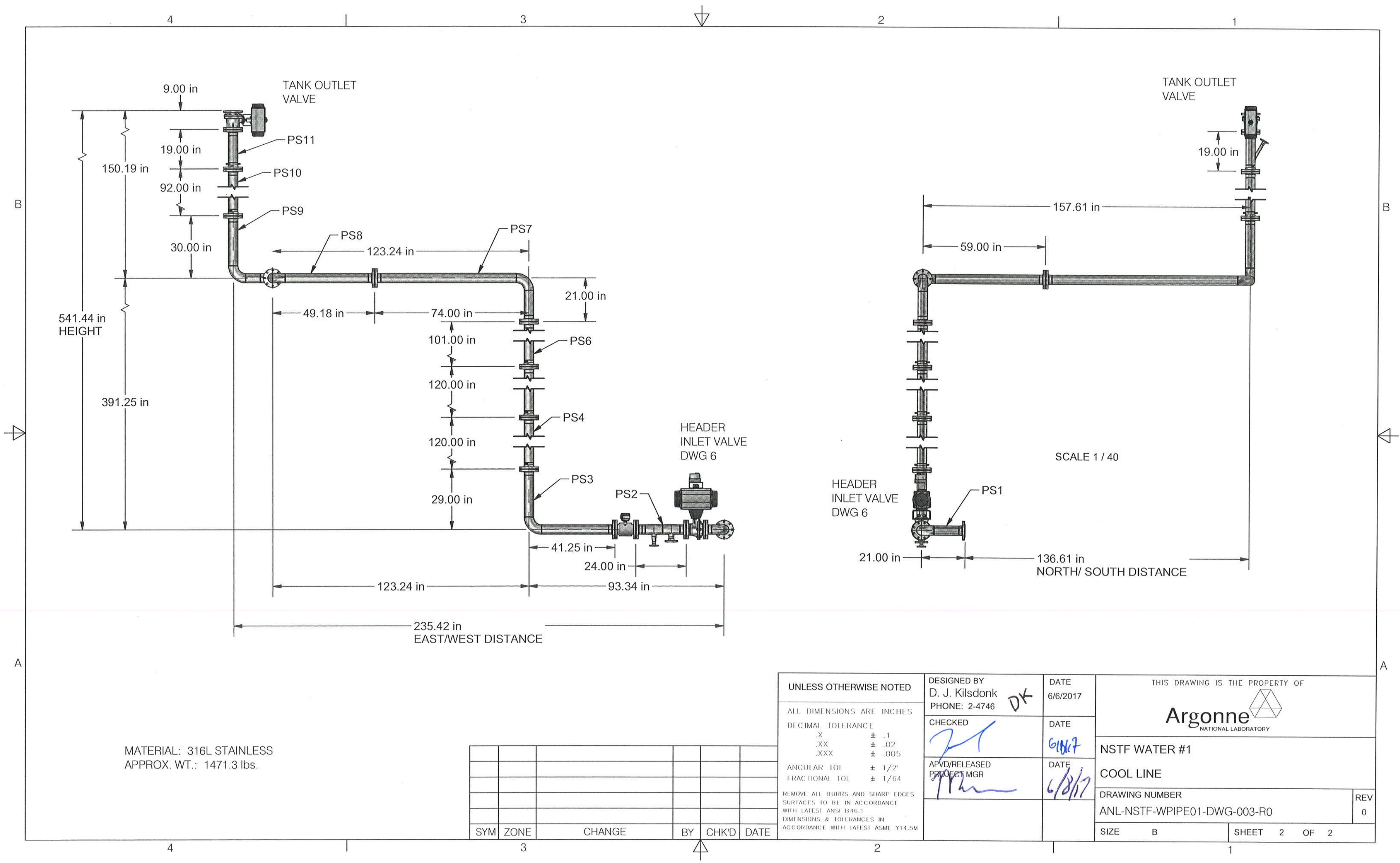




\section{$\underline{\text { HOT LINE ASSEMBLY }}$}

4" FLANGED CYLINDER GLASS DWG 26

DW" 1" SWAGELOK

PS 18

DWG 25

1" SWAGELOK

WN

FLow

4 FITTINGS

PS 17

DWG 24

PS 16

PS 16
DWG 23

SCALE $1 / 40$
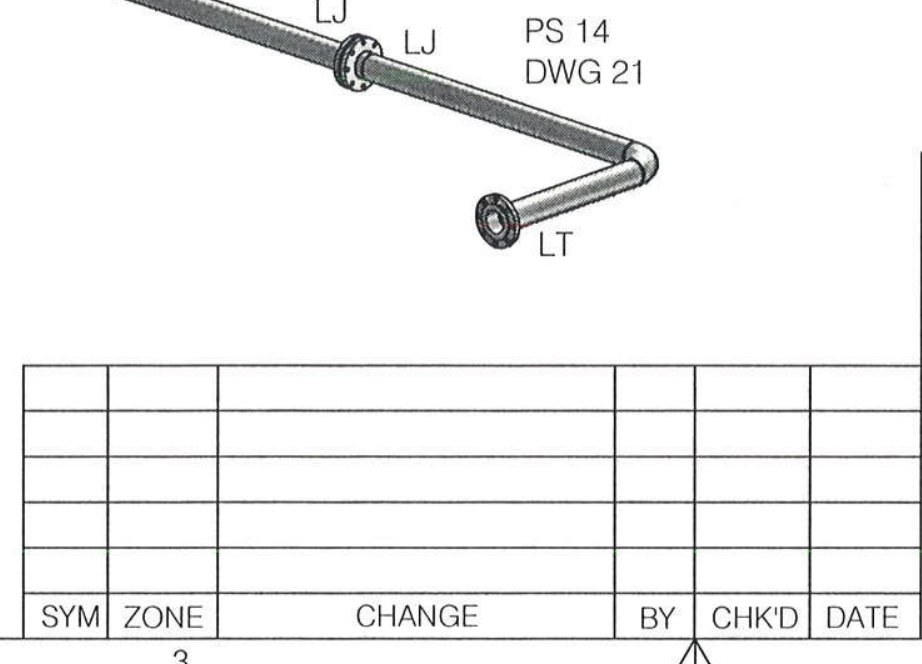


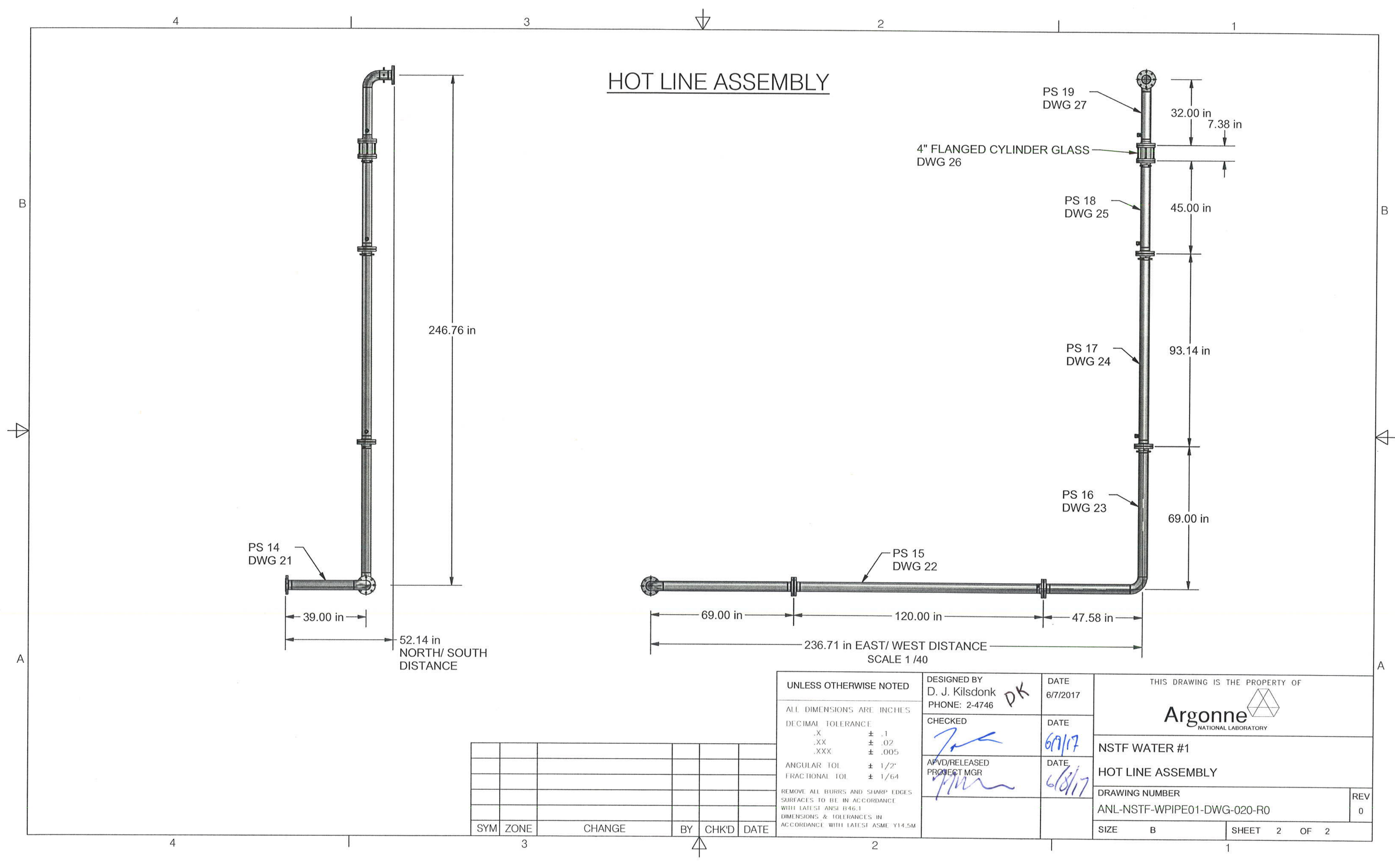




\subsubsection{Water Storage Tank}

The water storage tank was designed in-house and fabricated by an outside vendor to meet a number of project requirements. Primarily, the tank features a height-to-diameter ratio of 2, is able to hold a minimum 1,000 gallon capacity, includes dual side inlet port locations, and can be pressurized to 2 atmospheres. Additionally, several instrumentation access ports were included along the top dome, bottom dish, and side walls of the tank, ranging from 0.25 " Swagelok fittings for thermocouple and pressure taps, to a 8.0 " weld neck flange for future instrumentation and access needs, Figure 16. Finally, a 6.0" clear sight glass was added to the top dome, along with an 18" manaway access port to the side wall, facilitating inspection.

Prior to build, a seismic analysis on the loading of the support legs and mounting pads was performed by a license PE and approved by Argonne engineers, able to withstand a seismic event of Risk Category of I in a C class Site. The as-delivered tank is constructed from 316L stainless steel, has a capacity of 4,262 liters (1,126 gallons), and is stamped to Section VIII, Div. 1. of the ASME BPVC. Since delivery, the tank has been installed on the third floor mezzanine of the laboratory space and bolted to the W10x19 support I-beams. 


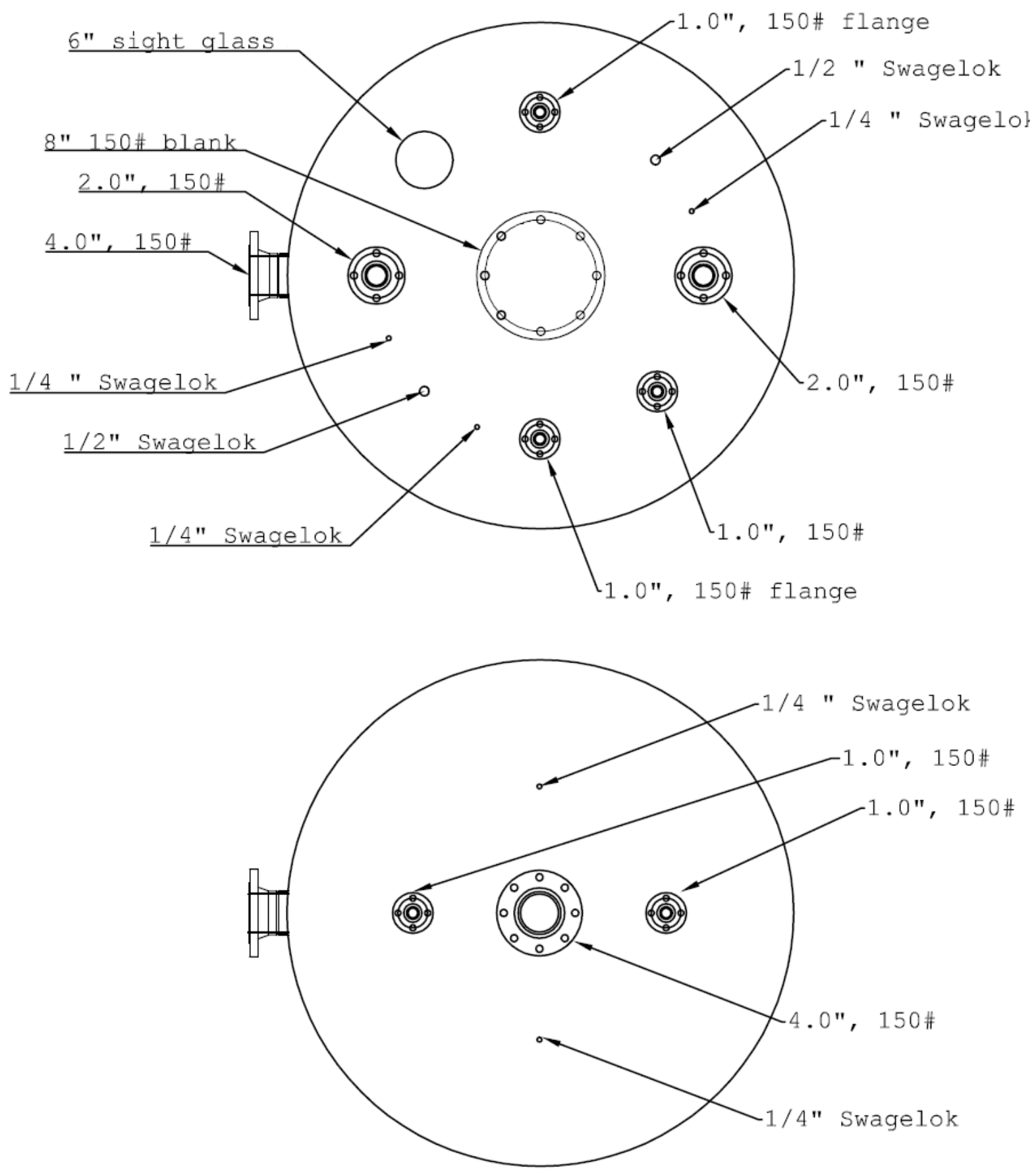

Figure 16: Access ports on dome head (top) and dish pan (bottom) 

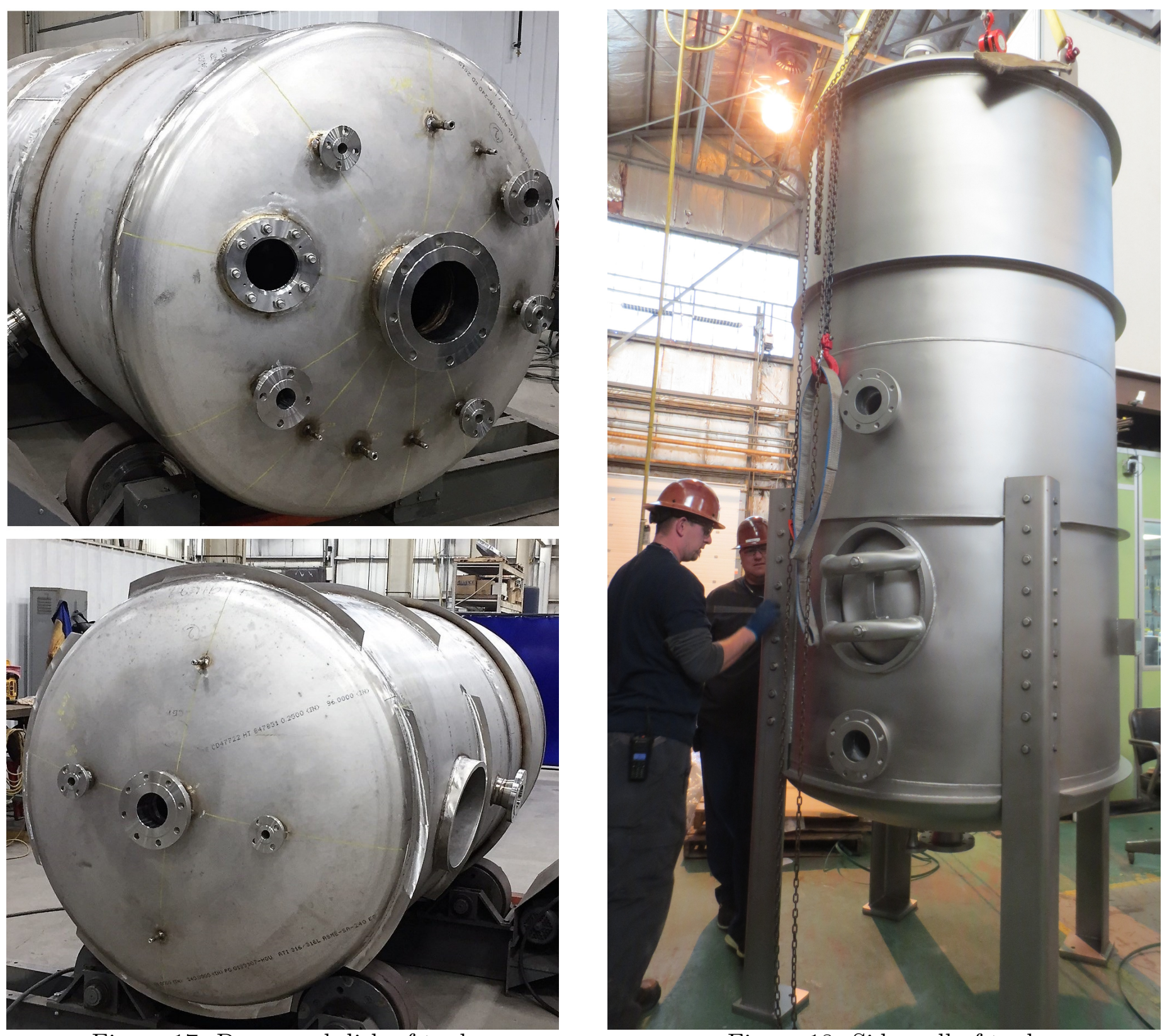

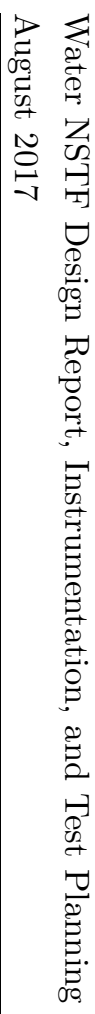

党

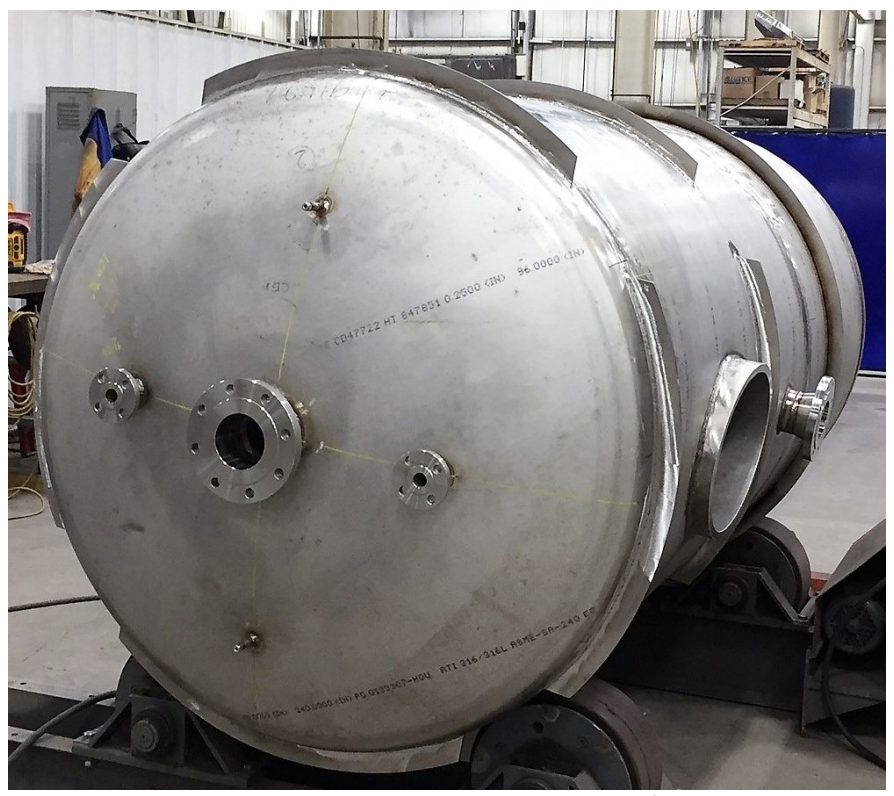

Figure 17: Dome and dish of tank

Figure 18: Side wall of tank 


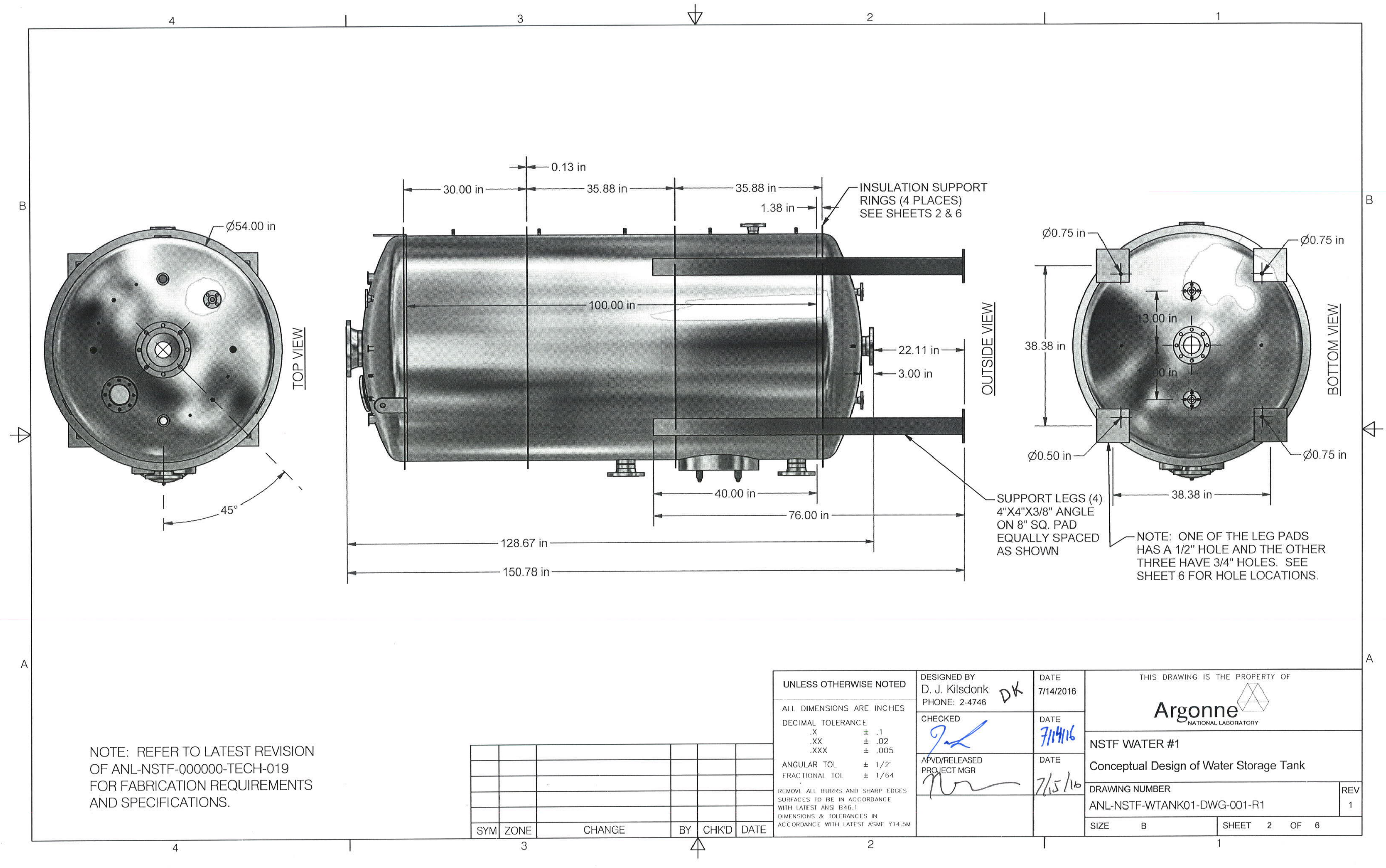




\subsection{Instrumentation}

A suite of sensors within the water NSTF will allow measurement of pertinent thermal hydraulic behavior during both single- and two-phase mode of operations. Instruments have been selected to minimize disturbance of the natural circulation flow. The instrumentation suite is diverse enough to quantify both integral and local behavior across the full extent of the systems components. To address the high priority system measurements, e.g. thermal and mass balance, both temperature and flow measurements utilize sensors that are minimally intrusive and exhibit very low uncertainty. Details of each sensor is provided in the following sections, with a high level summary provided in Table 3, and a facility diagram of installed locations in Figure 19.

Table 3: Overview of Water NSTF Instrumentation Suite

\begin{tabular}{ccccccc}
\hline Measurement & Sensor Type & Location & Qty. & Mfg. & Model & Range \\
\hline Flow rate & Magnetic & Inlet header & x1 & Krohne & Optiflux 4000 & $\pm 5 \mathrm{~kg} / \mathrm{s}$ \\
Flow rate & Magnetic & Inlet riser & x8 & Krohne & Optiflux 4000 & $\pm 1 \mathrm{~kg} / \mathrm{s}$ \\
Static head & Strain & Inlet header & x1 & Rosemount & $3051 \mathrm{~S}$ & $0-10 \mathrm{bar}$ \\
Steam pressure & Strain & Gas space & x1 & Rosemount & $3051 \mathrm{~S}$ & $0-2 \mathrm{bar}_{a b s}$ \\
$\Delta \mathrm{P}$ & Strain & Chimney & x2 & Rosemount & $3051 \mathrm{~S}$ & $\pm 6 \mathrm{kPa}$ \\
$\Delta \mathrm{P}$ & Strain & Risers & x3 & Rosemount & $3051 \mathrm{~S}$ & $\pm 62 \mathrm{kPa}$ \\
Liquid level & Strain & Tank & x1 & Rosemount & $3051 \mathrm{~S}$ & $0-3 \mathrm{~m}$ \\
Void fraction & Optical & Chimney & x2 & RBI & Twin-tip & $0-100 \%$ \\
Void fraction & $\gamma$-Density & Chimney & x1 & ThermoFisher & DensityPRO & $0-100 \%$ \\
Temperature & RTD & Fluid & x4 & Omega & UP, $1 / 10 \mathrm{DIN}$ & $0-250^{\circ} \mathrm{C}$ \\
Temperature & T-type TC & Fluid & x128 & ARi & T-31N & $0-400^{\circ} \mathrm{C}$ \\
Temperature & K-type TC & Test section & x24 & ARi & T-31N & $0-600^{\circ} \mathrm{C}$ \\
Temperature & K-type TC & Structures & x286 & ARi & Silica $20 \mathrm{AWG}$ & $0-600^{\circ} \mathrm{C}$ \\
Temperature & DTS & Test section & x20 & LUNA & ODiSI-A & $0-300^{\circ} \mathrm{C}$ \\
Water pH & pH Meter & Inlet header & x1 & Emerson & RBI 547 & $0-14 \mathrm{pH}$ \\
TrDO O $\mathrm{O}_{2}$ & Amperometric & Inlet header & x1 & Emerson & $499 \mathrm{~A}$ & $0.1 \mathrm{ppb}-20 \mathrm{ppm}$ \\
Conductivity & Magnetic & Inlet header & x1 & Krohne & Optiflux 4000 & $1-6,000 \mu \mathrm{S} / \mathrm{cm}$ \\
\hline
\end{tabular}




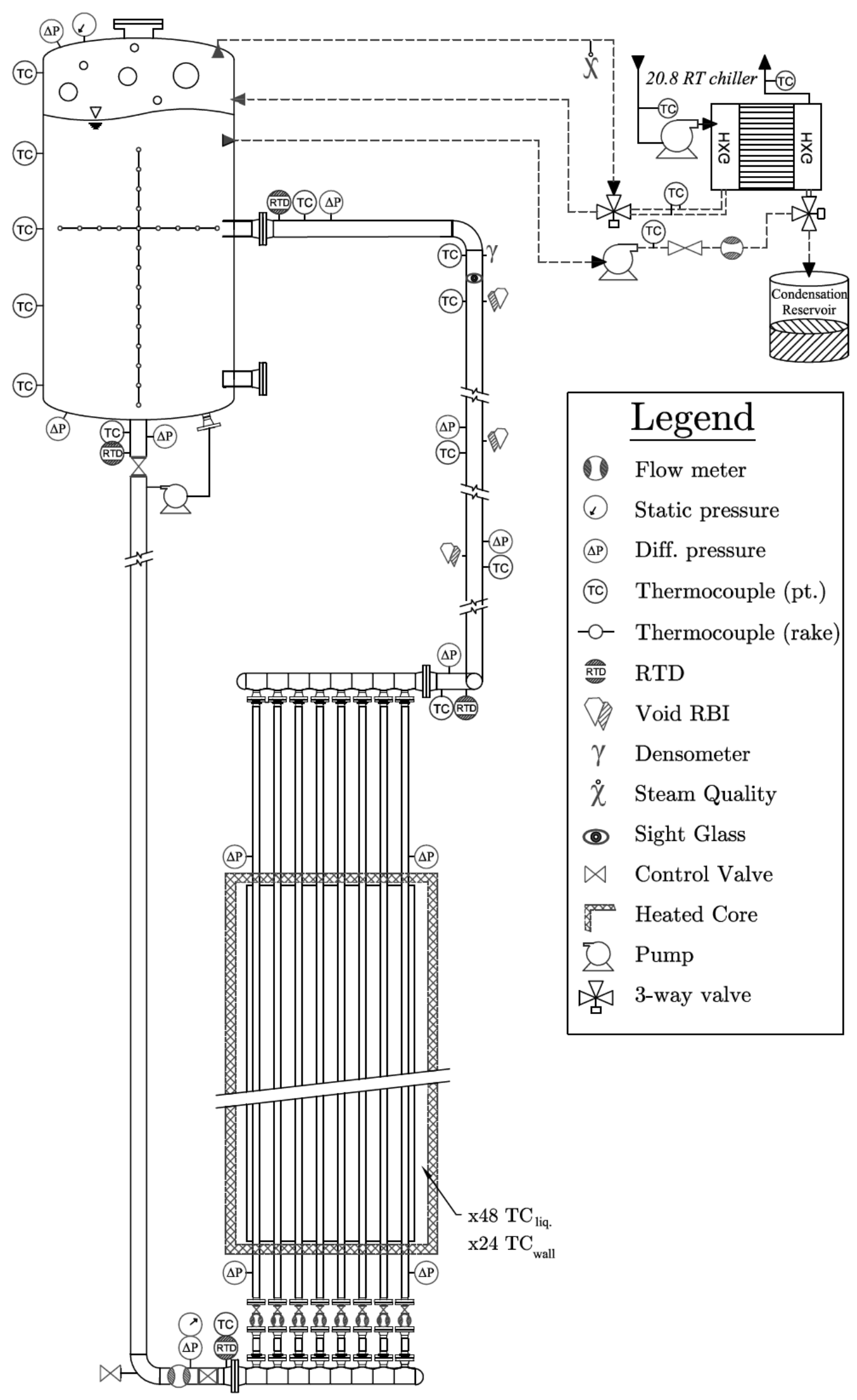

Figure 19: Overview of instrumentation locations on water NSTF 


\subsubsection{Flow Meters}

Flow rate measurements will be made using full-bore magnetic flow meters which maintain the inner diameter of the piping with zero added pressure losses. Ten Krohne Optiflux 4000 units have been procured, and have been installed to measure the flow across the primary network piping, each of the eight riser tubes, and across the heat removal HXG loop. Specifications are listed in Table 4, and an image of installation at the inlet of the test section provided in Figure 20.

Table 4: EM Flow Meter Specifications

\begin{tabular}{|c|c|}
\hline Manufacturer & Krohne \\
\hline Transmitter & Optiflux 4000 \\
\hline Signal Converter & IFC 300 \\
\hline Measurement Range & $0 \ldots 12 \mathrm{~m} / \mathrm{s}$ \\
\hline Measurement Error & $\pm 0.2 \%$ of $\mathrm{MV}+1 \mathrm{~mm} / \mathrm{s}$ \\
\hline Repeatability & $\pm 0.1 \%$ of $\mathrm{MV}$ \\
\hline Pressure Loss & neglible \\
\hline Size, DN & $100 \mathrm{~mm} 40 \mathrm{~mm}$ \\
\hline NSTF Count & $\mathrm{x} 8$ \\
\hline
\end{tabular}

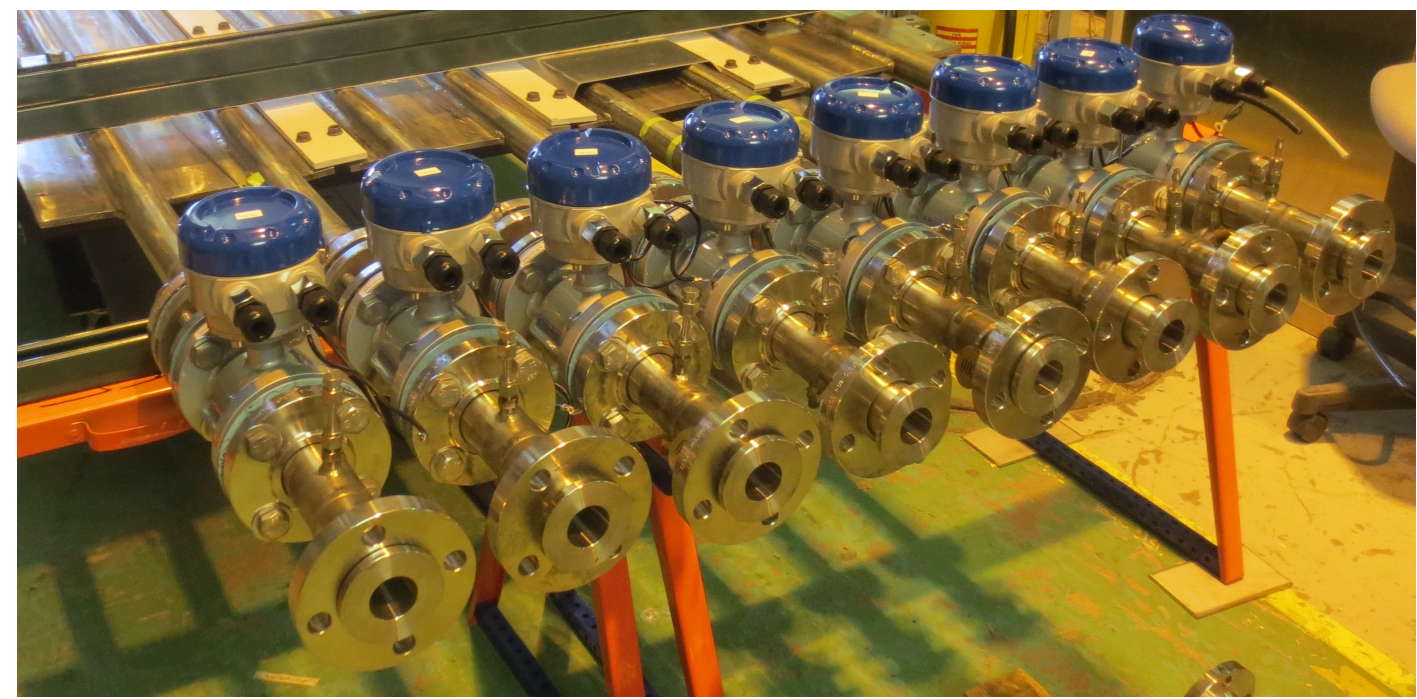

Figure 20: Riser inlet flow meters; stub entrance length sections visible 


\subsubsection{Pressure Transducers}

Pressure transducers, eight in total, are used throughout the facility to measure both differential and static pressure levels, Table 5. The total hydraulic head, or static pressure, of the full test loop will be measured at the inlet header, and the gas space pressure will be measured along the top dome of the water tank, above the liquid level. The inlet device has a range up to $150 \mathrm{psig}$, while the tank gas space ranges from 0 - 50 psia, allowing the device to detect any levels of negative pressure or vacuum within the gas space. Finally, a differential transducer will be placed across the vertical extents of the water tank and serve as a means to determine liquid level. Fluid properties will be referenced at known temperatures and pressures, allowing relatively high accuracy in measuring the liquid level.

Differential pressure measurements will be initially placed along five segments of the primary test loop - three across the risers and two across the chimney. However, several additional pressure taps have been pre-installed during fabrication and will allow configuration changes with relative ease. Three transducers span a range of $\pm 250 \mathrm{inWC}$, while the remaining two span \pm 25 inWC

Table 5: Rosemount Static and Differential Pressure Transducer Specifications

\begin{tabular}{rccccc}
\hline Purpose & $\Delta \mathrm{P}_{\text {chimney }}$ & $\Delta \mathrm{P}_{\text {risers }}$ & Liquid Level & Static head & Gas space \\
Transmitter & $3051 \mathrm{~S}$ & $3051 \mathrm{~S}$ & $3051 \mathrm{~S}$ & $3051 \mathrm{~S}$ & $3051 \mathrm{~S}$ \\
Manifold & $305 \mathrm{I}$ & $305 \mathrm{I}$ & $305 \mathrm{I}$ & $304 \mathrm{C}$ & $304 \mathrm{C}$ \\
Accuracy & $0.035 \%$ span & $0.035 \%$ span & $0.035 \%$ span & $0.035 \%$ span & $0.035 \%$ span \\
Rangedown & $150: 1$ & $150: 1$ & $150: 1$ & $150: 1$ & $150: 1$ \\
Stability & $15-$ year & $15-$ year & $15-$ year & $15-$ year & $15-$ year \\
Span & \pm 25 inH20 & \pm 250 inH20 & $0-3 \mathrm{~m}$ & $0-150$ psig & $0-50$ psia \\
NSTF Count & $\mathrm{x} 2$ & $\mathrm{x} 3$ & $\mathrm{x} 1$ & $\mathrm{x} 1$ & $\mathrm{x} 1$ \\
\hline
\end{tabular}




\subsubsection{Temperature Measurements}

Temperature measurements across the test assembly will be represented by four different types of sensors, each with varying levels of accuracy. The highest priority (and thus necessary to exhibit the lowest level of measurement uncertainty) lies with the energy balance measurements at the inlet and outlet locations across the riser tubes and water storage tank. For this application, the water NSTF will use match-calibrated 1/10 DIN, 4-wire platinum RTDs installed at the centerline of the 4-inch primary piping. All other fluid temperatures, e.g. multi-point rakes within the water storage tank, liquid temperature within the riser tubes, will be of Type-T thermocouples, while all surface temperatures will be measured with Type-K thermocouples. These two different thermocouple types have been selected based on their performance window and anticipated facility temperature ranges, and both are calibrated to Special Limits of Error (SLE). Lastly, DTS fibers have been installed within the fluid space and along the walls of risers $5 \& 6$.

A table summary of each sensor specification is provided in Table 6, comparison of accuracy ranges in Figure 21, typical network piping sensor arrangement in Figure 22, typical riser fluid sensor arrangement in Figure 23, typical riser and fin wall thermocouple arrangement in Figure 24, and typical riser and fin wall DTS arrangement in Figures 25 - 26.

Table 6: Temperature Sensor Specifications

\begin{tabular}{|c|c|c|c|c|c|}
\hline & \multicolumn{3}{|c|}{ Thermcouple } & RTD & DTS \\
\hline Type & K-Type & & ype & 4-wire platinum & Polyamide fiber \\
\hline Class & SLE & & $\mathrm{E}$ & $1 / 10 \mathrm{DN}$ & $\mathrm{n} / \mathrm{a}$ \\
\hline Accuracy & $\pm 1.1^{\circ} \mathrm{C}$ or $0.4 \%$ & $\pm 0.5^{\circ} \mathrm{C}$ & or $0.4 \%$ & \pm 0 & $\pm 1.1^{\circ} \mathrm{C}$ \\
\hline Range & $0-1250^{\circ} \mathrm{C}$ & $0-3$ & $70^{\circ} \mathrm{C}$ & $0-200^{\circ} \mathrm{C}$ & $0-300^{\circ} \mathrm{C}$ \\
\hline $\begin{array}{r}\text { Probe Dia. } \\
\text { Response Time }\end{array}$ & $\begin{array}{c}20 \mathrm{AWG} \\
\approx 2 \mathrm{~s}\end{array}$ & $\begin{array}{l}0.125 \text { inch } \\
\quad \approx 0.5 \mathrm{~s}\end{array}$ & $\begin{array}{l}0.0625 \text { inch } \\
\quad \approx 0.2 \mathrm{~s}\end{array}$ & $\begin{array}{l}0.125 \text { inch } \\
\quad \approx 1.1 \mathrm{~s}\end{array}$ & $\begin{array}{l}155 \mu m \\
\mathrm{TBD}\end{array}$ \\
\hline NSTF Count & $\widetilde{x} 276$ & x16 & $\mathrm{x} 80$ & $\mathrm{x} 4$ & $\mathrm{x} 10$ \\
\hline
\end{tabular}




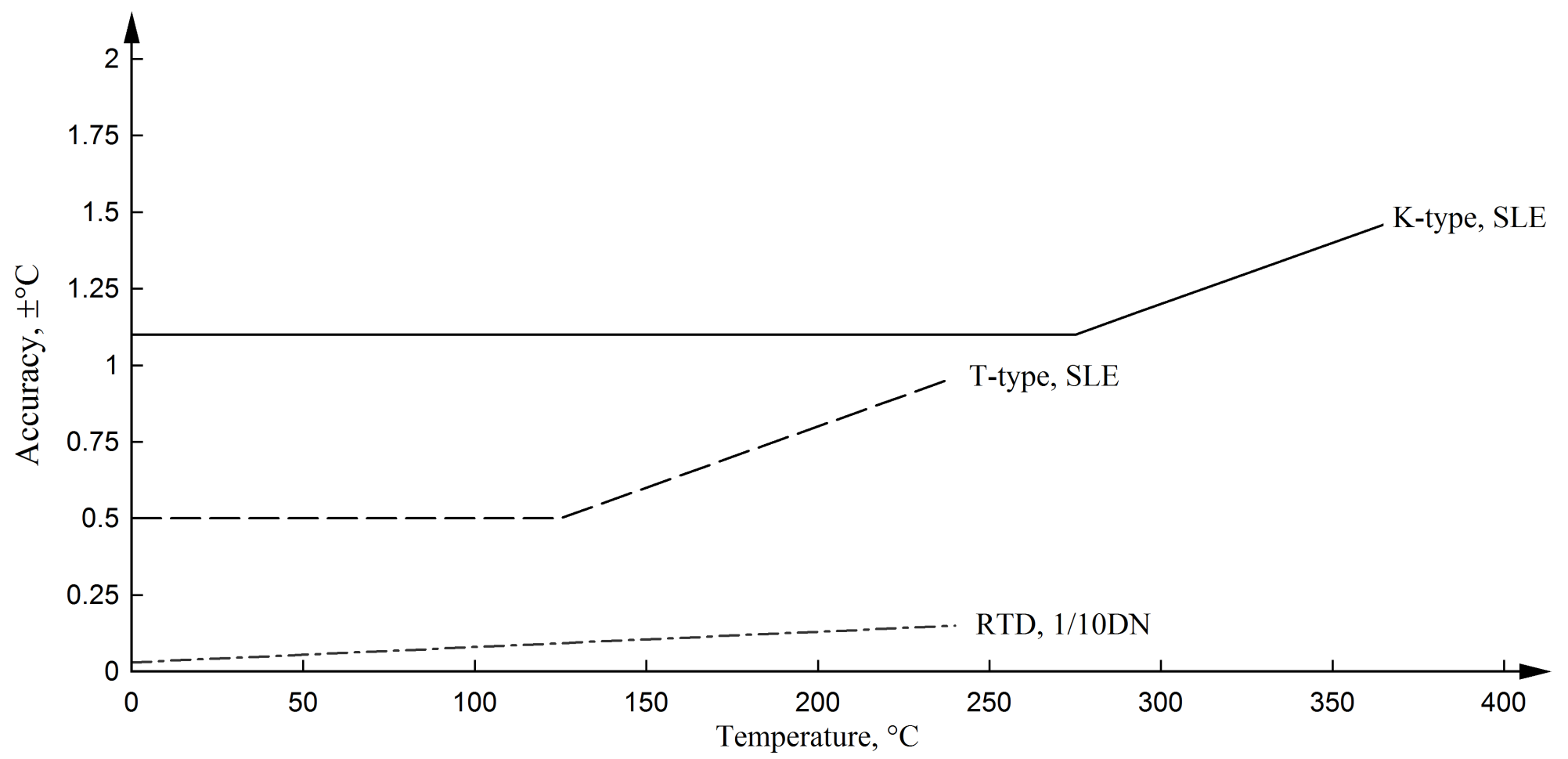

Figure 21: Accuracy of TC and RTD sensors over expected process range 


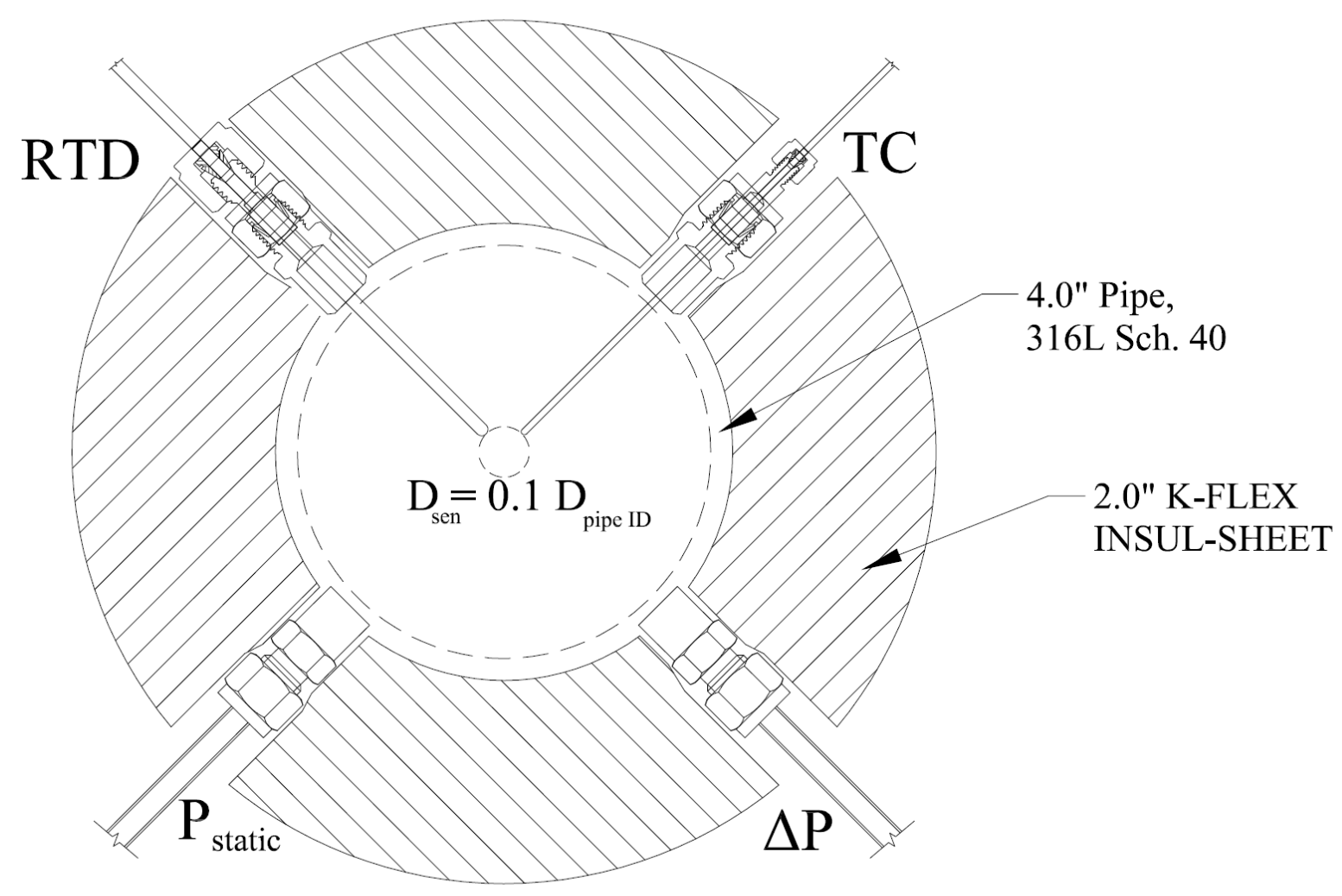


3
5
0
0
0
0
0

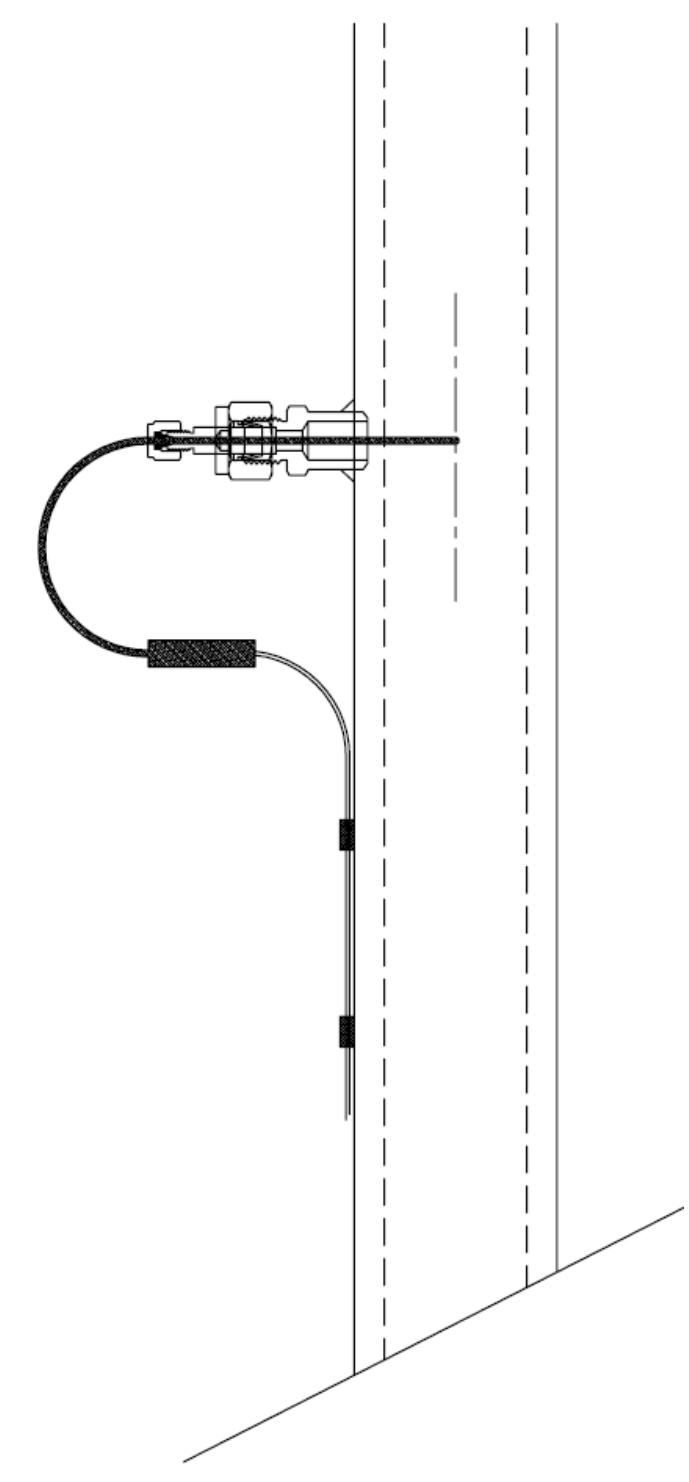

Figure 23: Riser liquid TC

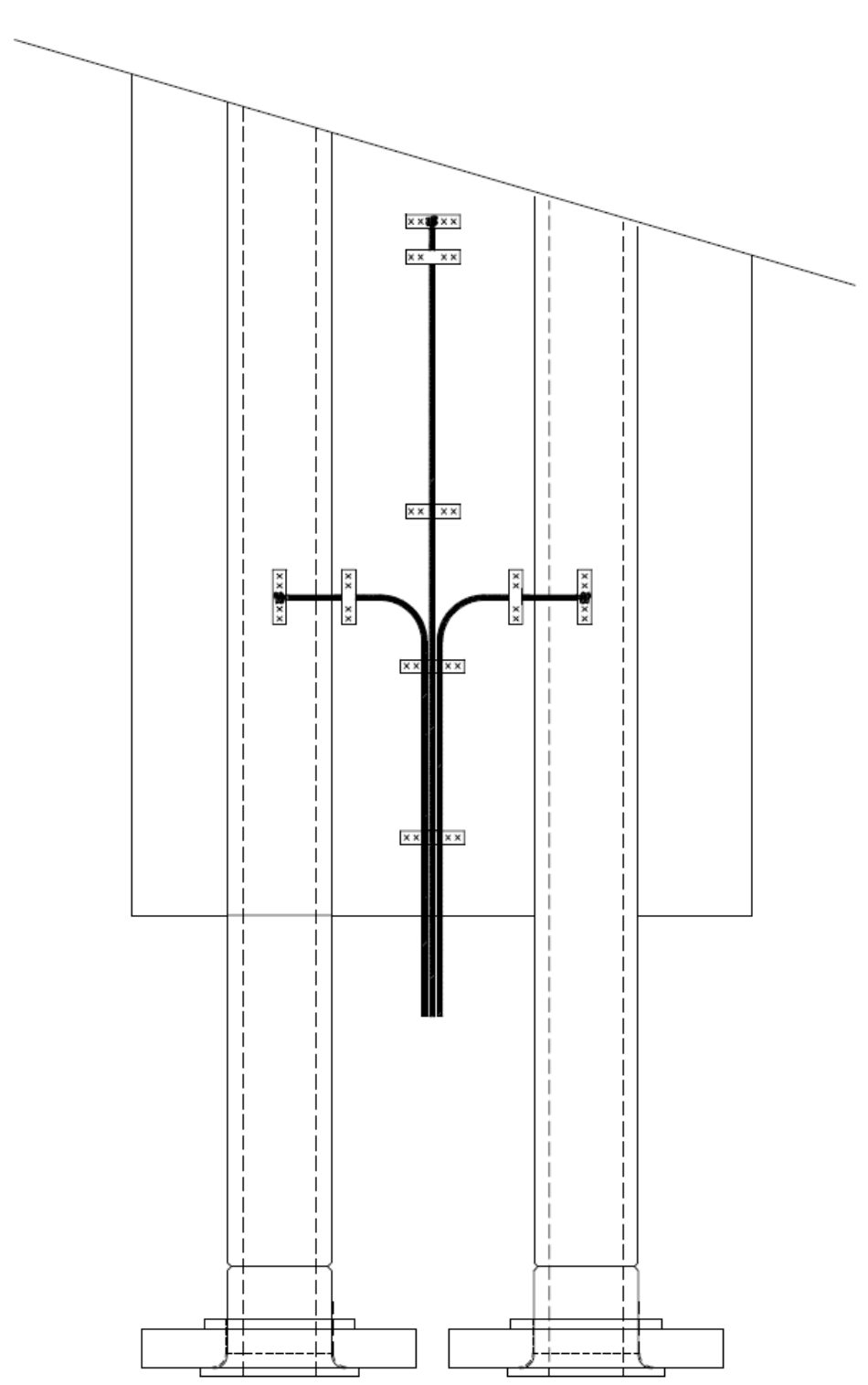

Figure 24: Riser and fin wall TC 


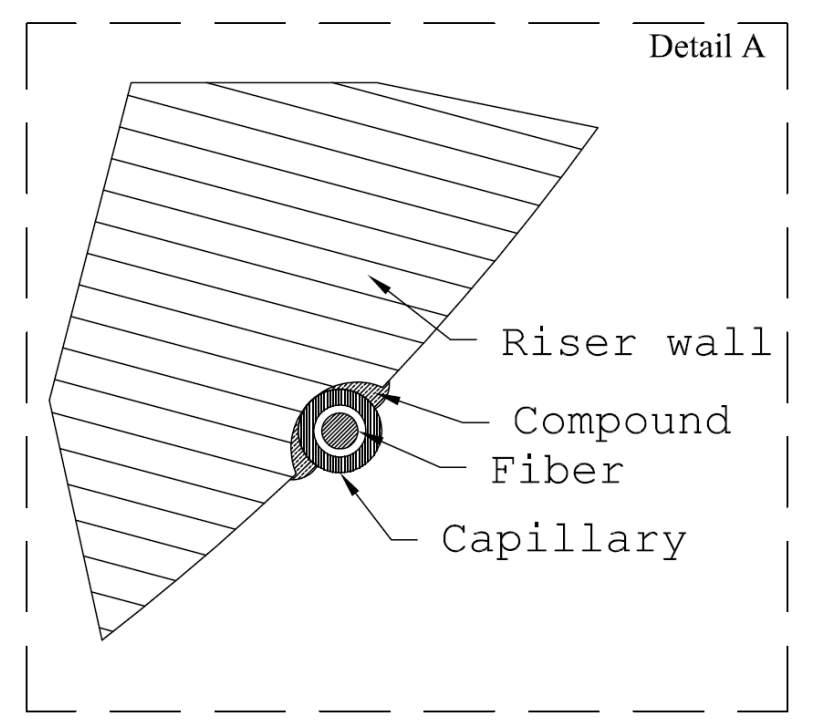

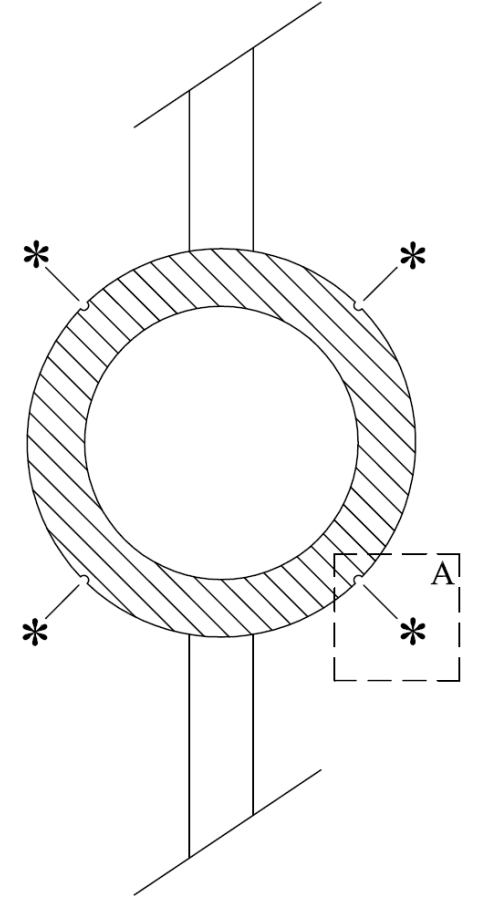

Figure 25: Riser fluid DTS

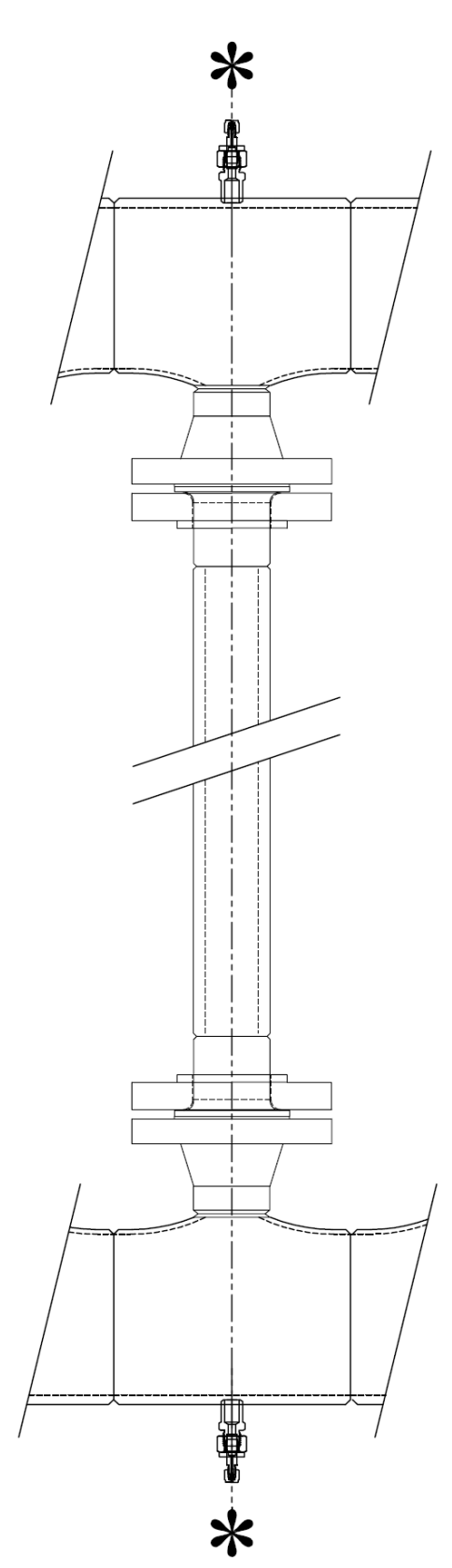

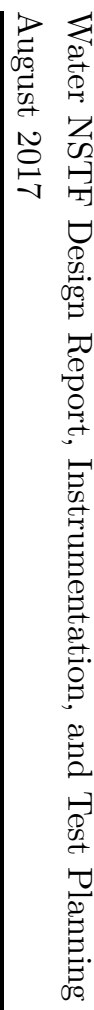

Figure 26: Riser wall DTS 


\subsubsection{Void Fraction}

Three devices are used for measurement and examination of the void fraction aspect of the anticipated two-phase flow, Table 7. Two of the sensors allow a quantitative measurement of point and bulk void fraction, while the third is purely qualitative and allows a visual examination of the flow patters within the network piping. All are installed on the vertical chimney section, immediately prior to the inlet of the water storage tank as shown in Figure 27, in a best attempt to capture the full network two-phase flow patterns.

Table 7: Void Fraction Sensor Specifications

\begin{tabular}{rccc}
\hline & Gamma Densitometer & Twin-tip sapphire & Sight Glass \\
\hline Operation & Cs-137 attenuation & Snell refraction & visual \\
Manufacturer & ThermoFischer & RBI & Ernst Co. \\
Model & DensityPRO & Standard & Model $255-4.0 \mathrm{in}$ \\
Max. Temp & $\mathrm{n} / \mathrm{a}$ & $120^{\circ} \mathrm{C}$ & $300^{\circ} \mathrm{F}$ \\
Max. Pressure & $\mathrm{n} / \mathrm{a}$ & $3 \mathrm{bar}$ & $70 \mathrm{psig}$ \\
Accuracy & $\pm 0.0015 \mathrm{~g} / \mathrm{cc}$ & $\mathrm{n} / \mathrm{a}$ & $\mathrm{n} / \mathrm{a}$ \\
Stability & $\pm 0.05 \% / 6 \mathrm{mo}$ & $\mathrm{n} / \mathrm{a}$ & $\mathrm{n} / \mathrm{a}$ \\
Response Time & $2 \mathrm{~s}$ & $\leq 0.5 \mathrm{~ms}$ & $\mathrm{n} / \mathrm{a}$ \\
NSTF Count & $\mathrm{x} 1$ & $\mathrm{x} 2$ & $\mathrm{x} 1$ \\
\hline
\end{tabular}

The first device, a gamma densitometer, model DensityPRO from ThermoScientific, Figure 28, is commonly used in industry applications as a simple density gauge [23]. Consisting of a source head, detector, and transmitter, the radioisotope (Cs-137) emits gamma radiation, passes through the piping wall and medium, and measured at the detector. The amount of transmitted radiation varies inversely with the medium density, or in the case of steam-liquid two-phase flow in the NSTF, the void fraction within the fluid. While this devices requires an initial online calibration of 0 and $100 \%$ voids, the built-in temperature compensation and proportional 4 - $20 \mathrm{~mA}$ signal output allows it to be seamlessly integrated into the overall data suite. The devices measure of volume averaged void fraction, is continuously operated, and fully non-intrusive to the flow field. 
The second device allows higher granularity in the measurement of two-phase flow and calculation of various statistics. Fabricated by the French company RBI, Figure 30, this device consists of twin sapphire tips (i.e. Descartes prisms) extending from a 3-mm stainless sheath. Using optical light and Snell's law of refraction, an electronic control system is able to detect the time spent in liquid vs gas phases [24]. With known spacing between the two tips, on average $1-2 \mathrm{~mm}$, the signal data can be used to determine not only local void fraction, but bubble diameter and superficial gas velocities. While only a point measurement, the system is able to sample at $2 \mathrm{kHz}$ and thus can accurately capture the behavior of even small diameter bubbly flow. Two probes will be installed along the chimney region of the NSTF, however additional access ports are pre-installed and will ease movement to other locations along the loop. Finally, a linear traversing device has been constructed and will allow spatial resolution in measurements using the RBI sensors, yielding void fraction as a function of pipe radius for the full diameter of the chimney network.

The third and final device is solely for visual or qualitative measurement of the two-phase flow regimes. A transparent sight glass, Model 255 from Ernst Co., Figure 29, will replace a 7.5-inch section of stainless pipe along the chimney region. Rated to the anticipated pressure and temperatures, the glass will be included in the nominal configuration and available for observation during heated test operations. While not yet procured, a dedicated camera and staged lighting is planned to record the flow behavior. 


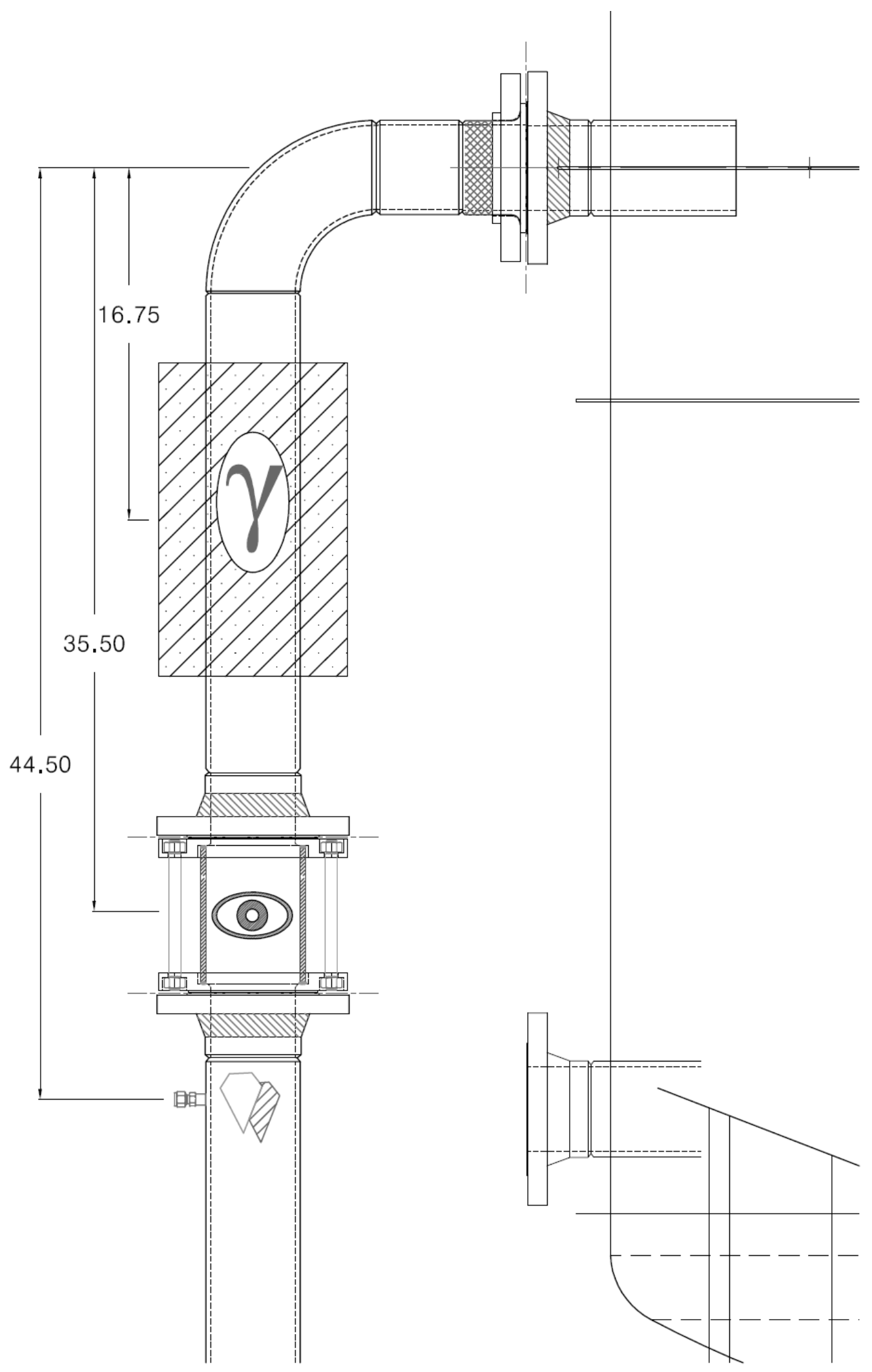

Figure 27: Void fraction sensor installation locations, dimensions in inches 

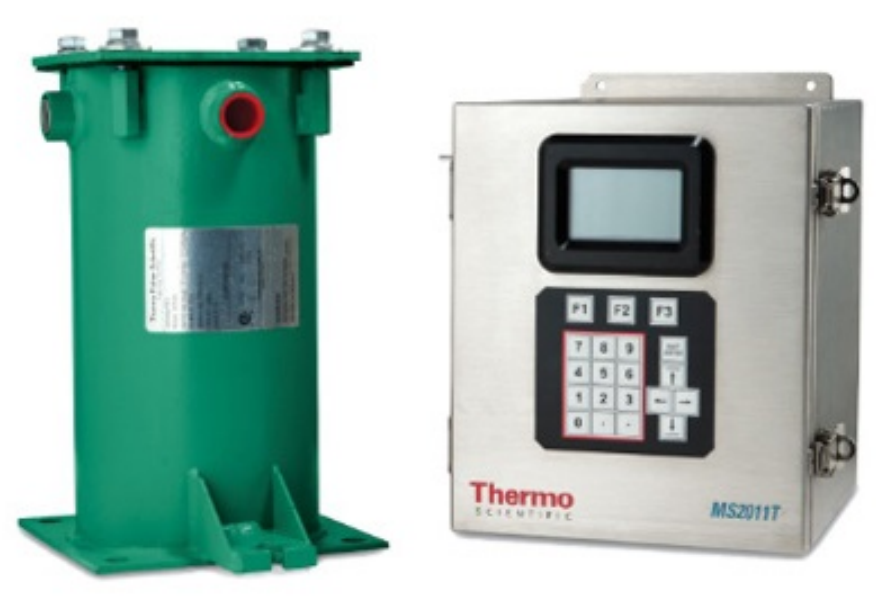

Figure 28: DensityPRO

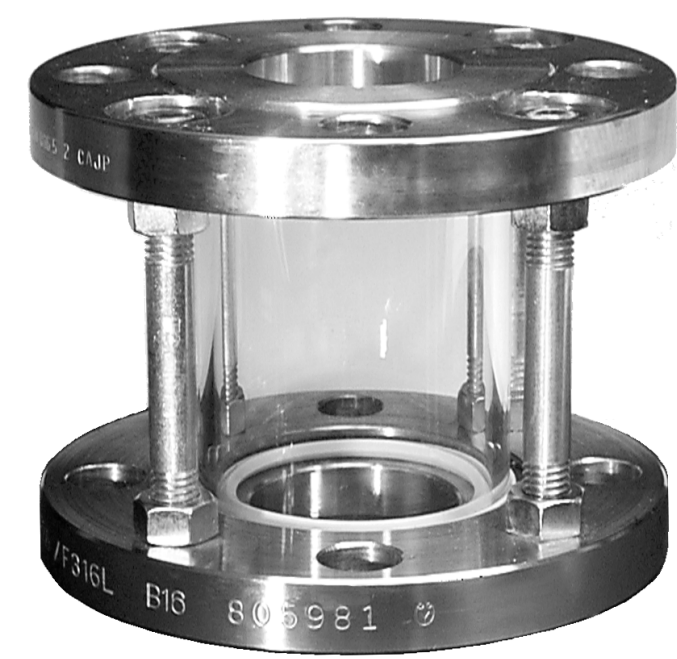

Figure 29: 4.0" sightglass

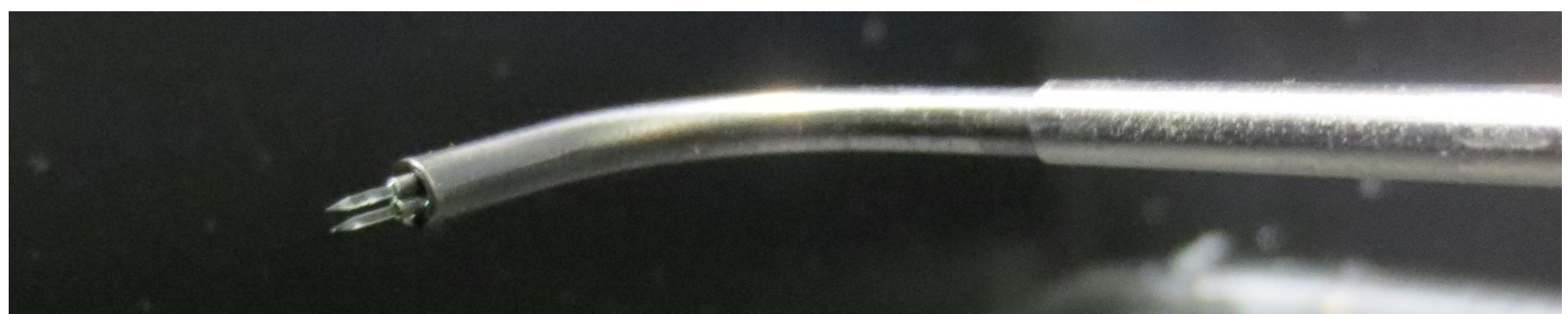

Figure 30: Twin-tip RBI probe, 3-mm OD sheath 


\subsubsection{Water Quality}

The source of inventory (water) to be used on the NSTF will be procured from on-site services and in the form of $18.2 \mathrm{M} \Omega(0.055 \mu \mathrm{S} / \mathrm{cm})$ distilled water. Storage of this water for use in the NSTF will only be within designated storage containers, installed within the 20-foot deep fit in Bldg. 308. Only clean water, either from the procurement source, or drained from the test loop (assuming no abnormal conditions occurred that may otherwise have contaminated the water), will be stored in the containers. Water chemistry will be maintained at specified values to ensure acceptable quality, with target metrics of:

- Conductivity: greater than $5 \mathrm{M} \Omega(0.20 \mu \mathrm{S} / \mathrm{cm})$

- $\mathrm{pH}$ : in the range of $7.0-7.5$

- Dissolved oxygen: less than $20 \mathrm{ppb}$

Quality metrics of conductivity, $\mathrm{pH}$, and trace dissolved oxygen will be maintained by proper cleanliness practices. Dissolved oxygen levels will be reduced by bubbling argon through the filled piping system at regular intervals. Finally, exposure of free surfaces will be limited to minimum required duration to prevent exposure to ambient air. These metrics will be assessed by continuous online monitoring via two water quality meters, Emerson RBI 547 and 499A TrDo, Table 8. Both will be installed along the network piping prior to the inlet header, and fed directly into the data acquisition for online monitoring.

Table 8: Water Quality Sensor Specifications

\begin{tabular}{rcc}
\hline Manufacturer & Emerson & Emerson \\
Model & RBI 547 & $499 \mathrm{~A}$ TrDO \\
Measurement & $\mathrm{pH}$ & Trace dissolved oxygen \\
Range & $0-14 \mathrm{pH}$ & $0.1 \mathrm{ppb}-20 \mathrm{ppm}$ \\
Max. Temp & $130^{\circ} \mathrm{C}$ & $50^{\circ} \mathrm{C}$ \\
Max. Pressure & $276 \mathrm{kPa}$ & $65 \mathrm{psig}$ \\
Accurancy & $\pm 0.01 \mathrm{pH}$ & $<20 \mathrm{ppb}: \pm 1 \mathrm{ppb} ;>20 \mathrm{ppb}: \pm 5 \% \mathrm{MV}$ \\
Stability & $\mathrm{n} / \mathrm{a}$ & $<4 \% / 60 \mathrm{~d}$ \\
Response Time & $5 \mathrm{sec}$ & $<20 \mathrm{sec}$ \\
\hline
\end{tabular}




\subsection{Control Systems}

\subsubsection{Throttle and Shutoff Valves}

Eleven control valves of varying types are placed throughout the test loop and serve to adjust

the flow resistance or create alternative flow configurations, Table 9. For valves located along the path of natural circulation, only full-bore valve are used, ensuring that when fully open they minimally affect the loop's form loss coefficient.

Two valves are located along the primary network piping, one at the outlet of the tank, and a second prior to the inlet header. The tank outlet valve allows on or off service, and will be used to isolate the tank from the remaining loop during maintenance activities. Additionally, it can be used to create a by-pass loop for forced circulation during characterization activities. The header inlet valve is of the proportional type and allows for precise control of the loss coefficient along the primary flow path. Both valves are of the full-bore type, driven by pneumatic pressure, controlled with a 4-20mA signal, and equipped with positioning indicators to confirm intended position.

At the inlet of the riser tubes, eight valves, also of the full-bore ball valve type, provide the ability to close off individual riser tubes. These valves are of the manual type and must be adjusted by experiment personnel. Finally, within the heat removal network, a globe-style valve with bolted bonnet and interchangeable Cv valve is used. Since this loop will be driven by a pump, a full-bore requirement was not necessary and instead a globe-style valve could be used. The valve was selected for maximum precision in adjusting the flow rate across the heat exchanger, allowing for a high level of granularity in adjustment, Figure 31. 
Table 9: Control and Throttle Valve Specifications

\begin{tabular}{rcccc}
\hline & Inlet Throttle & Tank Shutoff & Riser Shutoff & HXG Throttle \\
\hline Manufacturer & Jamesbury & Flow-Tite & Valpres & Badger Meter \\
Model & Series 9150 & Model F150 & Series 720016 & Series 9000 \\
Size & 4.0 in & 4.0 in & 1.5 in & $1.0 \mathrm{in}$ \\
Type & Full Port Ball & Full Port Ball & Full Port Ball & Globe \\
Range & $0-100 \%$ & On / off & On / off & $0-100 \%$ \\
Controller & Neles ND9103 & Asco WT8551 & manual & Neles ND9103 \\
NTSF Count & x1 & x1 & x8 & x1 \\
\hline
\end{tabular}

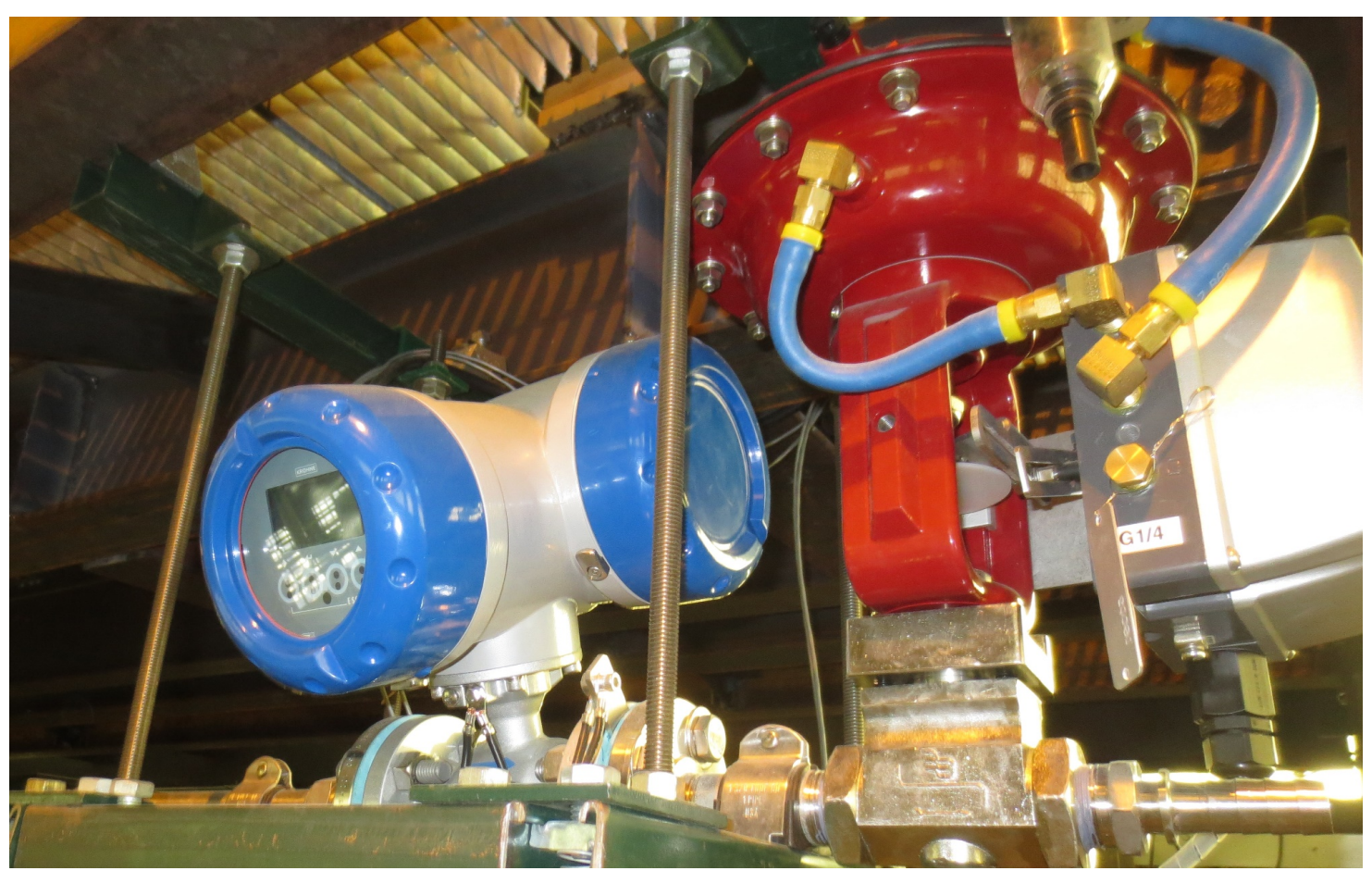

Figure 31: HXG throttle valve (Badger Globe) mated to Krohne EM flow meter 


\subsubsection{Heat Rejection Network}

To maintain a constant temperature of system inventory during steady-state test conditions, as well as serve as the heat sink for steam condensation during two-phase transients, a heat removal network will be installed as part of the overall test assembly.

Components will include heat exchangers, multiple water pumps, shut-off and diverter valves, etc. The proposed layout of this separate network will support reconfiguration by adjustment of only valves, allowing seamless transition from single-phase to two-phase modes of facility operation. The piping layouts for both configurations is shown in Figures $32-33$.

Dual tube-in-tube heat exchangers, model Sentry DTC-8, Figure 34, will be mounted in parallel and serve as both single-phase heat transfer for liquid to liquid, and as steam condensations for liquid to steam. The ultimate means for heat rejection from the test assembly will be from a chiller, model NQR20 from ThermalCare. The unit has a cooling capacity of 20.8 refrigeration ton $(\mathrm{RT})$, approximately $70.3 \mathrm{~kW}_{t}$, and features a remote aircooled condenser united mounted outside the laboratory space, Figure 36. In single-phase modes, cold water will be returned to the water tank through a sparger, Figure 35, while in two-phase modes, condensate liquid will be removed and stored within a condensation reservoir. 

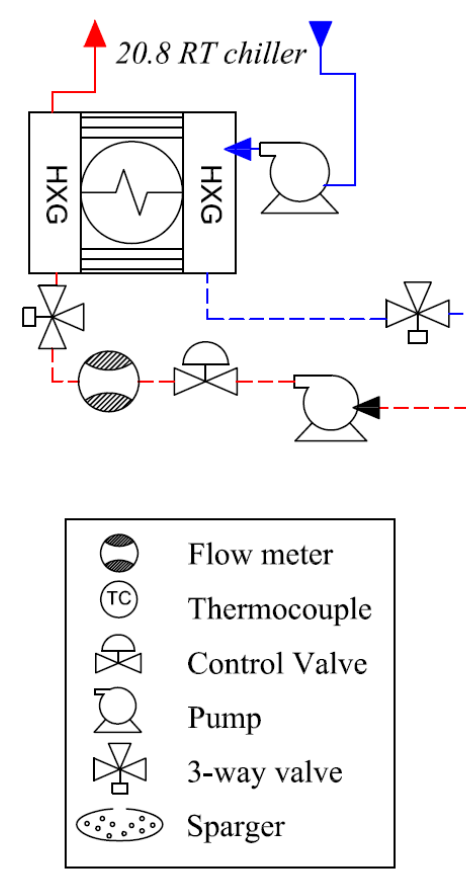

Figure 32: Single-phase heat removal network

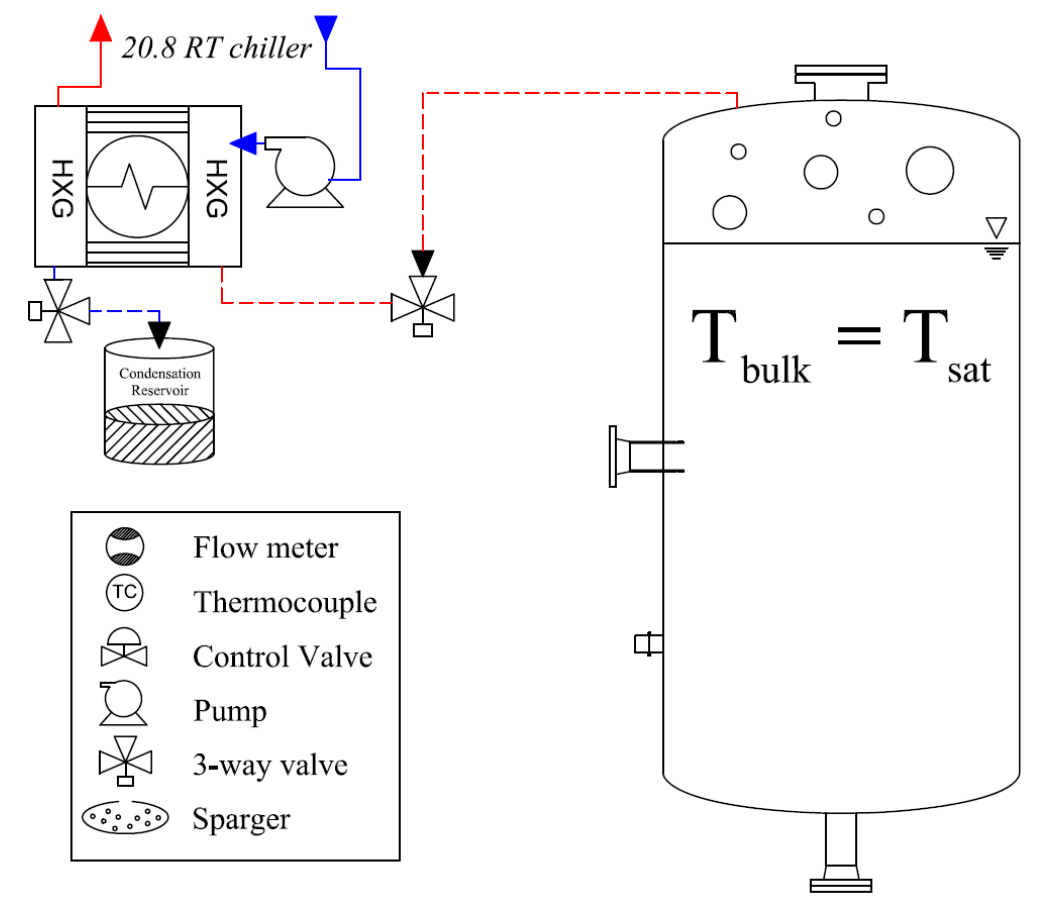

Figure 33: Two-phase and steam condensation network 
Model DTC-8

Surface Area $2.52 \mathrm{Ft}^{2}\left[0.23 \mathrm{~m}^{2}\right]$

[37.9 L/min] Cooling Water $95^{\circ} \mathrm{F}\left[35^{\circ} \mathrm{C}\right]$

18 PSI [1.2 Bar] Pressure Drop
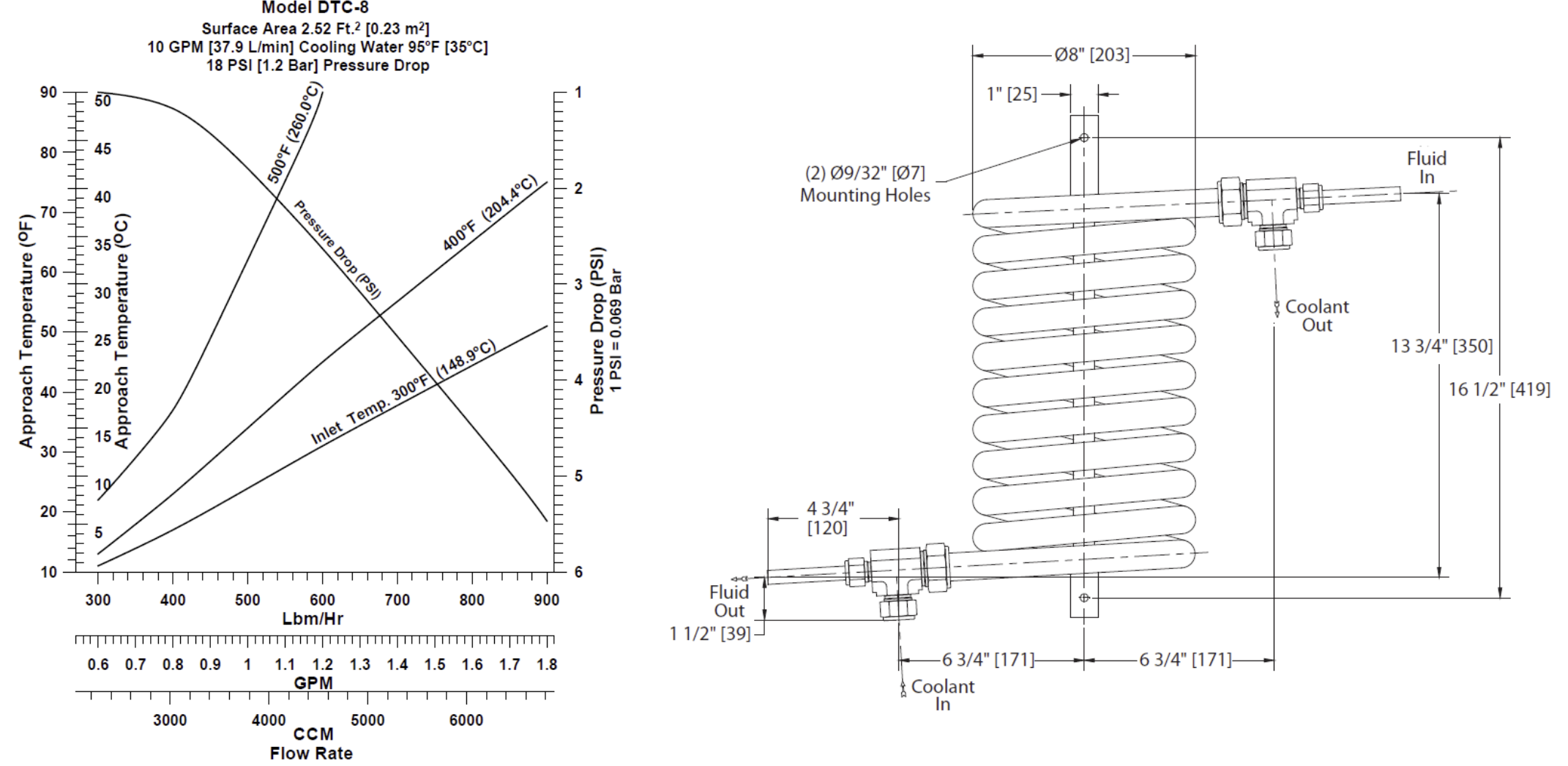

Figure 34: Sentry DTC-8 tube-in-tube exchanger, two will be used for heat removal 


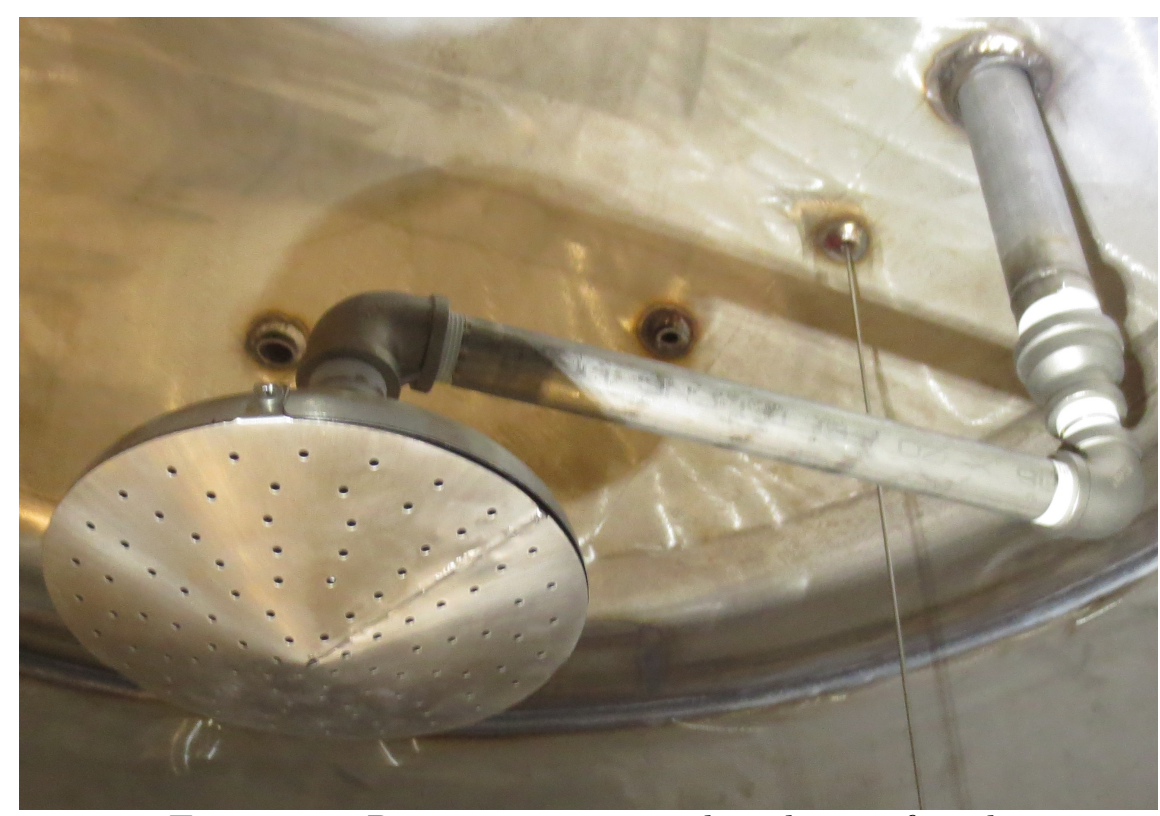

Figure 35: Return sparger within dome of tank

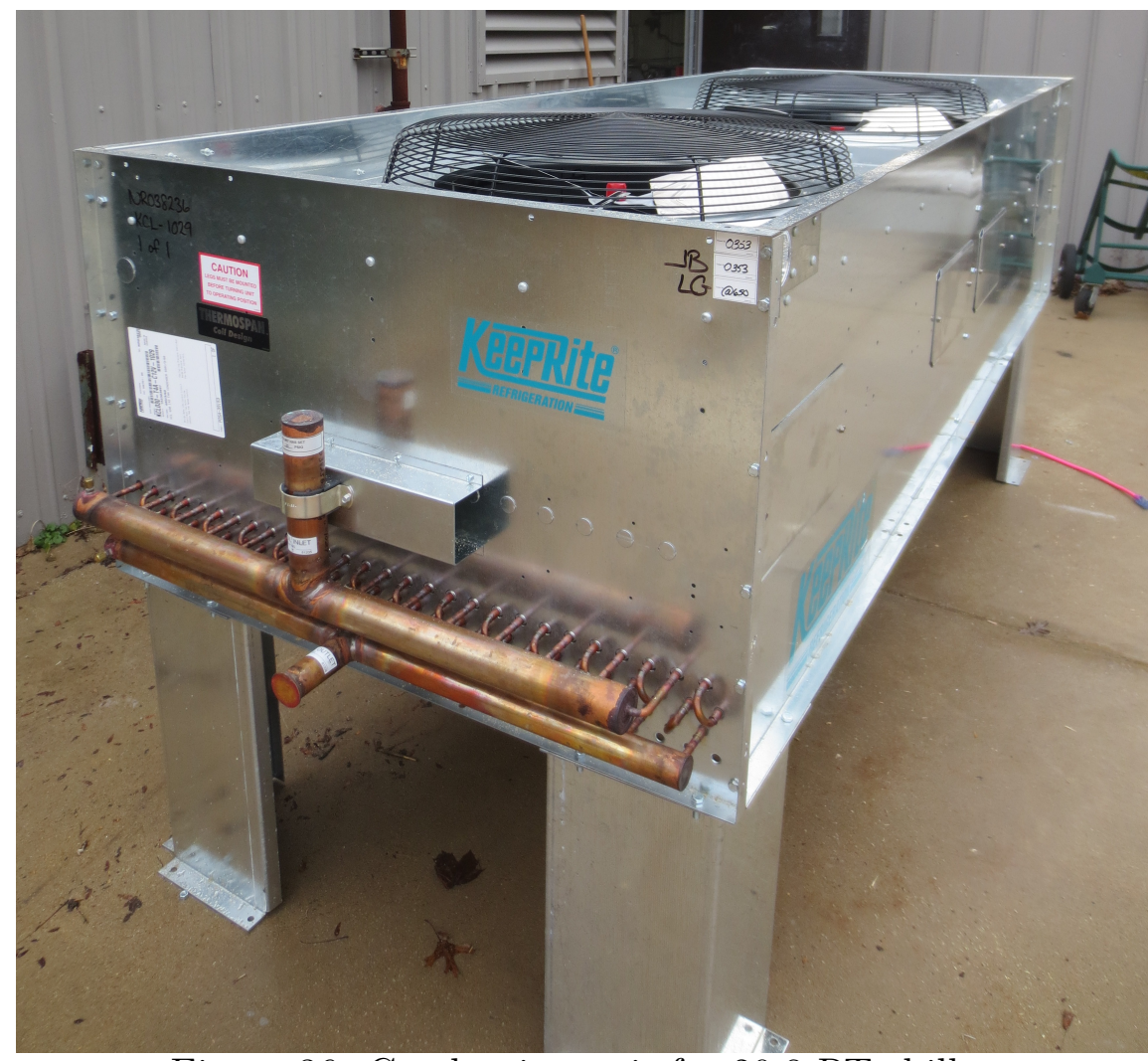

Figure 36: Condensing unit for 20.8 RT chiller 


\subsection{For-build}

At the time of this report, all design work and for-build drawings have been completed, reviewed, and approved by program personnel. In summary, the final assembly of the water NSTF will reflect a $1 / 2$ axial scale and $12.5^{\circ}$ sector slice of the primary design features of a full scale RCCS concept. High level design specifications are itemized below, general operating parameters listed in Table 10, front-facing facility view in Figure 37, and side-facing facility view in Figure 38.

- Riser tubes: 1.5" Sch. 160, 5.91" (150-mm) pitch, 316L stainless

- Heat transfer panels: 5/16" plates, 4.01" (102-mm) width, full penetration HLAW weld to risers, 1018 carbon steel stainless

- Cooling panel: Eight (x8) riser tubes and ten (x10) heat transfer panels, fabricated into banks of two (x2) riser tubes and three (x3) fins, joined by 5/16" carbon steel plates to form single section

- Network piping: 4.0" Sch. 40, 316L stainless

- Water tank: 4,260 liter capacity, H/D ratio of 2.0, rated to 2 bar over pressure

Table 10: Water NSTF Primary Operating Parameters

\begin{aligned} & \hline Parameter Value \\ & General Natural circulation, boiling water, thermal hydraulic test facility \\ & Overall facility height $18 \mathrm{~m}(59 \mathrm{ft} \\ &$. Operating modes i) Natural or forced circulation, ii) Single-phase with active cooling, \\ & iii) Two-phase with steam boil-off \\ & Working Fluid $18.2 \mathrm{M} \Omega$ water \\ & Liquid Inventory 4,260 liter storage tank, 389 liter piping and test section \\ & Heated section area Rectangular, $132 \mathrm{~cm}$ wide cavity with adjustable cavity depth rang- \\ & ing from 45 to $150 \mathrm{~cm}$ in $2.5 \mathrm{~cm}$ increments \\ & Heated section length $6.7 \mathrm{~m}(22 \mathrm{ft} \\ &$. Heating distribution One long side heated; other 3 sides adiabatic \\ & Heated operating modes i) Constant heat flux (heater maximum: $\left.23 \mathrm{~kW} / \mathrm{m}^{2}\right)$, ii) Constant \\ & temperature (maximum: $\left.500^{\circ} \mathrm{C}\right) \\ &$ Total input power $220 \mathrm{~kW} \\ &$ Heated zone resolution x10 axial segments, x4 azimuthal control zones \\ & \hline\end{aligned}




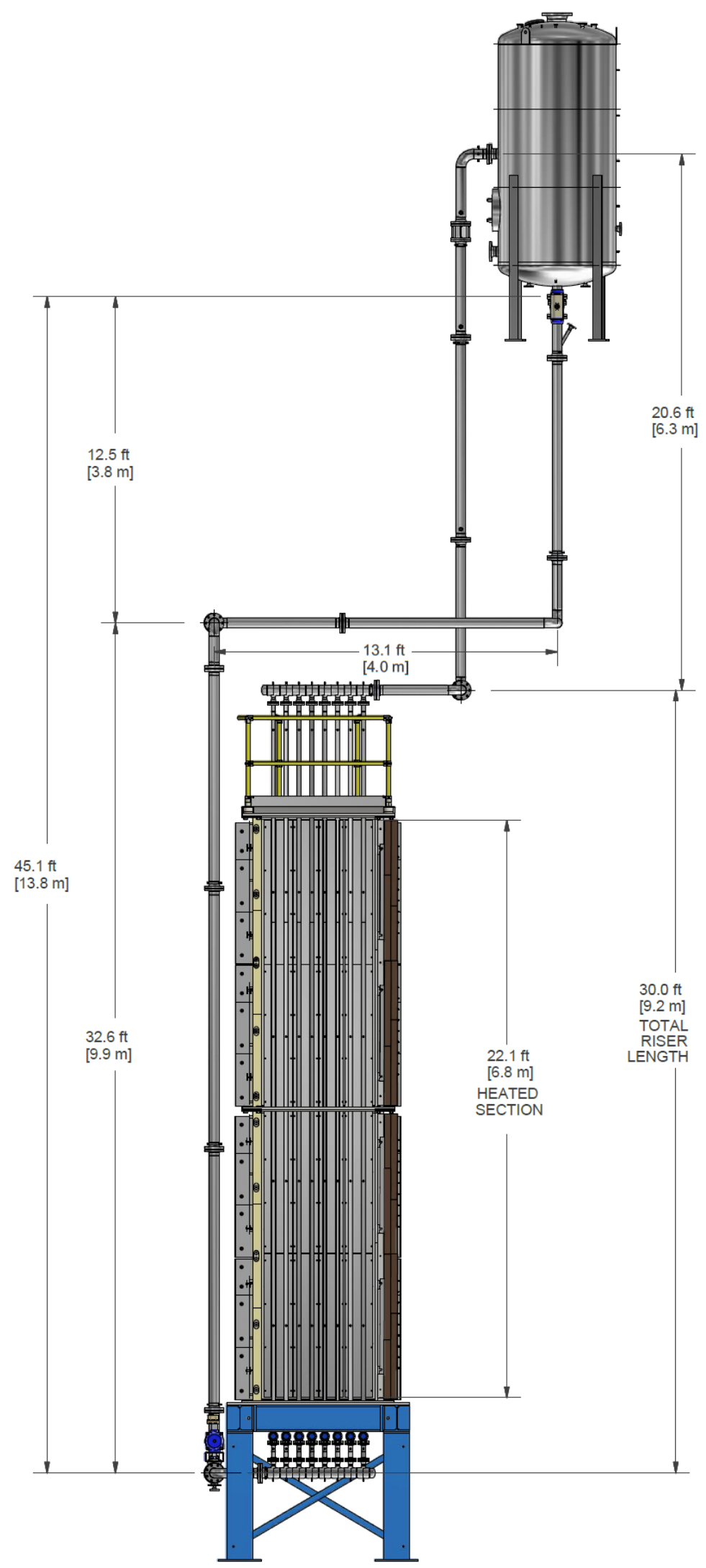

Figure 37: As-built dimensions of water NSTF, front (East facing) view 


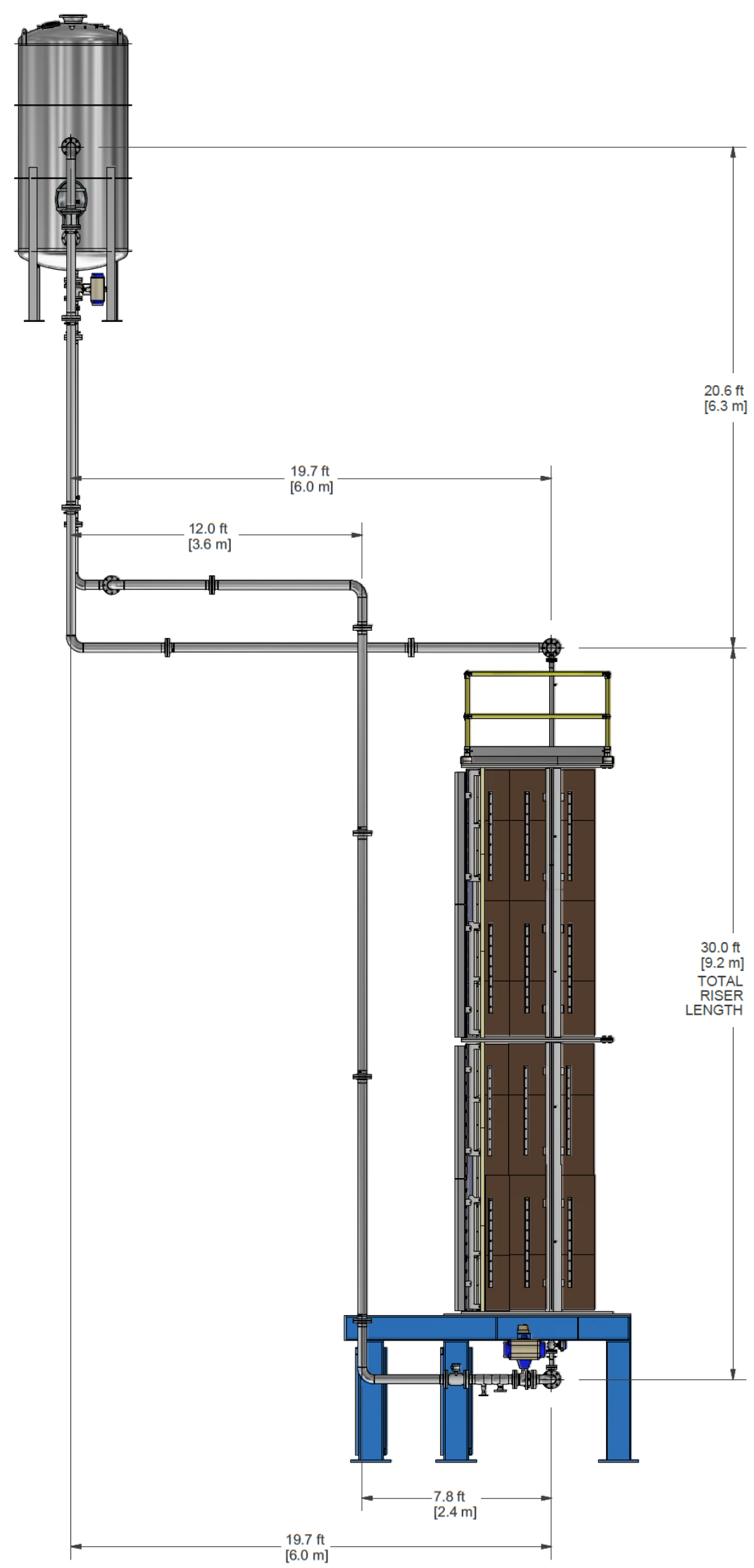

Figure 38: As-built dimensions of water NSTF, side (South facing) view 
This page was intentionally left blank. 


\section{Acknowledgments}

This work was supported by the U.S. Department of Energy Office of Nuclear Energy's Advanced Reactor Technology (ART) program under contract number DE-AC02-06CH11357. The program team wishes to extend our gratitude for the funding, support, and guidance from our program sponsors and associated laboratories, including Diana Li, Steve Reeves, Diane Croson, and Hans Gougar. The authors also sincerely thank our colleagues at Argonne National Laboratory for their previous work on the design and analysis of NSTF, including Drs. Constantine Tzanos, Tom Wei, Dave Pointer, Taeseung Lee, and past summer students James Schneider and David Holler. Lastly, we extend our appreciate for the time and efforts of the Argonne quality assurance staff, John Woodford and Roberta Riel. 
This page was intentionally left blank. 


\section{References}

[1] Tzanos, C. P. and Farmer, M. T., "Feasibility Study for Use of the Natural Convection Shutdown Heat Removal Test Facility NSTF for Initial VHTR Water-Cooled RCCS Shutdown," ANL-GenIV-079, Nuclear Engineering Division, Argonne National Laboratory, 2006

[2] Tzanos, C. P. and Farmer, M. T., "NSTF Facilities Plan for Water-Cooled VHTR RCCS: Normal Operational Tests," ANL-GenIV-080, Nuclear Engineering Division, Argonne National Laboratory, 2006

[3] Steward, R. R., Argonne National Laboratory, unpublished information, 1987

[4] Lomperski, S., et al., Argonne National Laboratory, unpublished information, 2010

[5] Lomperski, S., Pointer, W. D., Tzanos, C. P., et al., "Generation IV Nuclear Energy System Initiative: Air-Cooled Option RCCS Studies and NSTF Preparation", ANLGenIV-179, Argonne National Laboratory, 2011

[6] Hu, R., Kraus, A., Bucknor, M., et al., "Final Project Report on Computational Modeling and Analysis of Air-Based NSTF," ANL-ART-46, Argonne National Laboratory, 2016

[7] Lisowski, D., Lee, T., et al., "Final Project Report on RCCS Testing with the Air-based Natural convection Shutdown heat removal Test Facility", ANL-ART-47, Argonne National Laboratory, 2016

[8] Lisowski, D., et al., Argonne National Laboratory, unpublished information, 2015

[9] NSTF Program Control Records, Argonne National Laboratory, unpublished information, 2015

[10] Lv, Q., Kraus, A., Hu, R., et al., "Progress Report on Computational Analyses of Water-Based NSTF", ANL-ART-103, Argonne National Laboratory, 2017 
[11] Lisowski, D. D., "Thermal Hydraulic Analysis of an Experimental Reactor Cavity Cooling System with Water: Performance and Stability", Ph.D. Thesis. University of Wisconsin - Madison, USA. 2013

[12] Lisowski, D., et al.,"Infuences of boil-off on the behavior of a two-phase natural circulation loop", Int. J. of Multiphase Flow, 60, 135-148. 2014

[13] NSTF Program Control Records, Argonne National Laboratory, unpublished information, 2016

[14] AREVA, No.: 12-9237246-000, "Water-Cooled RCCS RD Designer Observation Report", Technical Data Record, 2014

[15] AREVA, No.:12-9239789-000, "RCCS Designer Input Report", Technical Data Record, 2014

[16] ASME NQA-1-2008 (with 1a 2009 addenda) "Quality Assurance Requirements for Nuclear Facility Applications", 2008

[17] ANL Quality Assurance Plan, current revision

[18] ANL Nuclear Engineering Division Local Work Planning and Control NE-WPC-01, 2012

[19] INL Document PLN-2690, Rev. 10, "Quality Assurance Program Plan VHTR Technology Development Office," effective 2013

[20] Code of Federal Regulations, Title 10, Part 50 (10CFR50), Appendix B, "Quality Assurance Criteria for Nuclear Power Plants and Fuel Processing Plants," 2006

[21] Argonne National Laboratory, ANL-NSTF-000000-CALC-002, "Thermal stress calculation for water-based NSTF test section", Calculation, 2015

[22] Lisowski, D., Farmer, M. T., et al., "Design Report for the 1/2 Scale Air-Cooled RCCS Tests in the Natural convection Shutdown heat removal Test Facility (NSTF)", ANLSMR-8 Argonne National Laboratory, 2014 
[23] Shaikh, A., Al-Dahhan, M., "A new method for online flow regime monitoring in bubble column reactors via nuclear gauge densitometry", Chemical Engineering Science 89, 120-132. 2013

[24] Murzyn, F., Mouaze, D., Chaplin, J.R., "Optical fibre probe measurements of bubbly flow in hydraulic jumps", Int. J. of Multiphase Flow, 31, 141-154. 2005 
This page was intentionally left blank. 
Argonne

Nuclear Engineering Division

Argonne National Laboratory

9700 South Cass Avenue, Bldg. 206

Argonne, IL 60439-4854

www.anl.gov 